\title{
Henosis Experience in Gaming: A Metric for Adjustments to Global Schema and Appraised Meaning
}

\author{
Evan Robert Watts \\ West Virginia University, erw0008@mix.wvu.edu
}

Follow this and additional works at: https://researchrepository.wvu.edu/etd

Part of the Communication Technology and New Media Commons, Mass Communication Commons, and the Other Communication Commons

\section{Recommended Citation}

Watts, Evan Robert, "Henosis Experience in Gaming: A Metric for Adjustments to Global Schema and Appraised Meaning" (2019). Graduate Theses, Dissertations, and Problem Reports. 4087.

https://researchrepository.wvu.edu/etd/4087

This Dissertation is protected by copyright and/or related rights. It has been brought to you by the The Research Repository @ WVU with permission from the rights-holder(s). You are free to use this Dissertation in any way that is permitted by the copyright and related rights legislation that applies to your use. For other uses you must obtain permission from the rights-holder(s) directly, unless additional rights are indicated by a Creative Commons license in the record and/ or on the work itself. This Dissertation has been accepted for inclusion in WVU Graduate Theses, Dissertations, and Problem Reports collection by an authorized administrator of The Research Repository @ WVU.

For more information, please contact researchrepository@mail.wvu.edu. 
Henosis Experience in Gaming:

A Metric for Adjustments to Global Schema and Appraised Meaning

\author{
Evan R. Watts
}

Dissertation submitted

to the Eberly College of Arts and Sciences

at West Virginia University

in partial fulfillment of the requirements for the degree of

Doctor of Philosophy in

Communication Studies

Jaime Banks, Ph.D., Chair

Nicholas D. Bowman, Ph. D.

Elizabeth L. Cohen, Ph. D.

Liesel L. Sharabi, Ph.D.

Natalie Shook, Ph.D.

Department of Communication Studies

Morgantown, West Virginia

2019

Keywords: henosis, gaming, meaningfulness, entertainment

Copyright 2019 Evan R. Watts 


\begin{abstract}
Henosis Experience in Gaming:

A Metric for Adjustments to Global Schema and Appraised Meaning
\end{abstract}

Evan Watts

Meaningfulness is a media gratification distinct from enjoyment characterized by feelings of insight, contemplation, and poignancy. Video games, too, can elicit experiences of meaningfulness, but the mechanisms underlying meaningfulness are unclear and in need of further exploration. Adapting work from existential psychology, this research proposes the construct of henosis as one mechanism that might contribute to meaningful video game experiences. Henosis is a response to experiences in which a person's fundamental schema about the world (global schema) is challenged by an event which contradicts this schema. Henosis describes the process by which this discrepancy is resolved via either reappraising the meaning of the event, or altering one's global schema. In order to test the existence of this new construct, this research conducted a series of focus groups asking participants to describe meaningful video game experiences in which they experienced something unexpected. A thematic analysis revealed that video game players do indeed experience henosis while playing video games, and that players will engage in both reappraisal and schema adjustment when encountering schema-violating video game events. Next, a metric to measure experiences of henosis was constructed, using themes from the focus groups as a framework for item development. After administering the item pool via an online survey and conducting an exploratory factor analysis, two henotic factors emerged: schema adjustment and experience adjustment. Validation measures confirmed that both of these factors were related to experiencing meaningfulness in video games. One implication of this factor's illumination is that players do not need to alter their mental structures for normality or for their ideals in order to have a meaningful experience, and the act of fitting a surprising experience into an existing mental structure is (or can be) meaningful. 
Running head: HENOSIS EXPERIENCE IN GAMING

\section{TABLE OF CONTENTS}

ABSTRACT

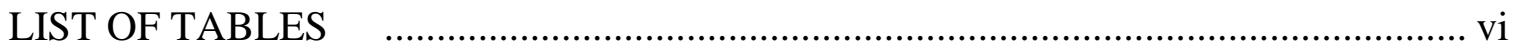

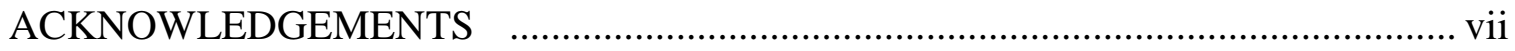

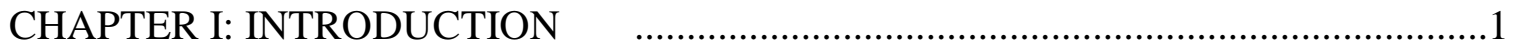

CHAPTER 2: REVIEW OF LITERATURE ............................................................6

The Meaning-Making Model and Henosis: A Mechanism of Meaning .......................11

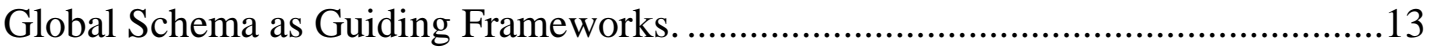

Appraised Meaning as Local Perception...................................................................15

Schema Disequilibrium as Cognitive Dissonance.................................................17

Henosis as Disequilibrium Resolution toward Media Meaningfulness. ........................18

Henosis in Gaming Experiences.....................................................................20

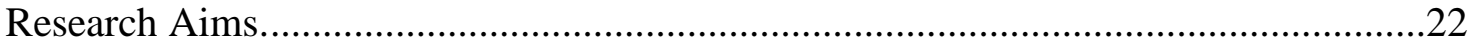

CHAPTER 2: PHASE 1: EXPLORATION OF HENOSIS AMONG GAMERS'

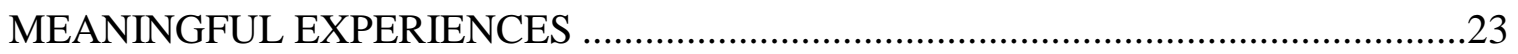

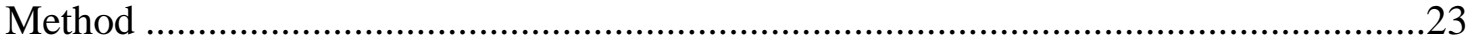

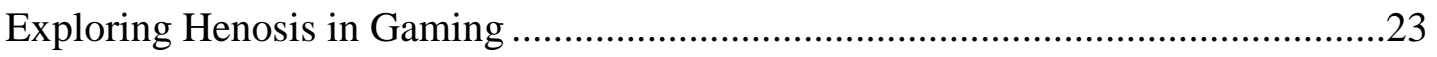

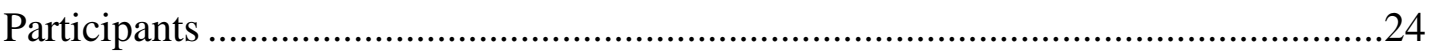

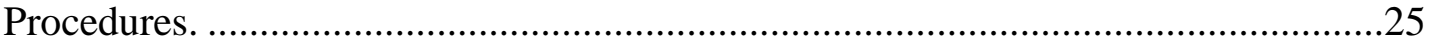

Question guide. .....................................................................................26

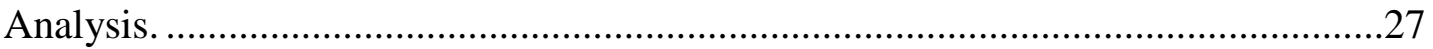

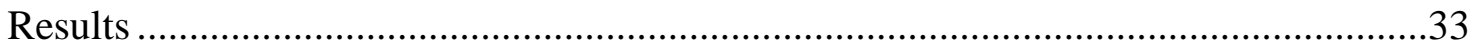

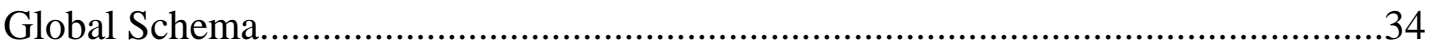

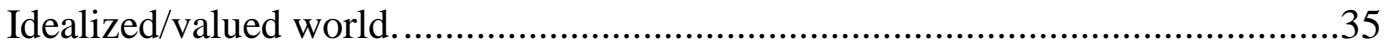

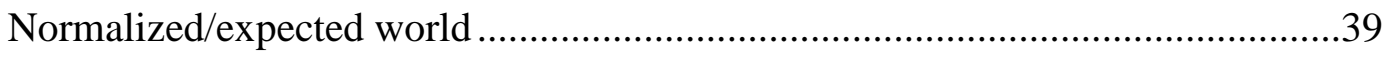

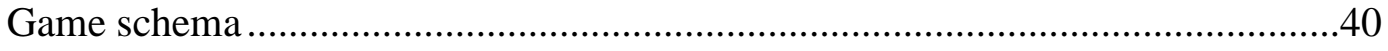

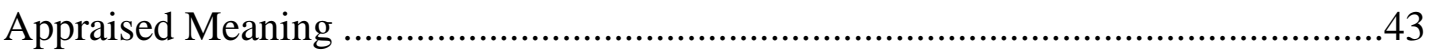

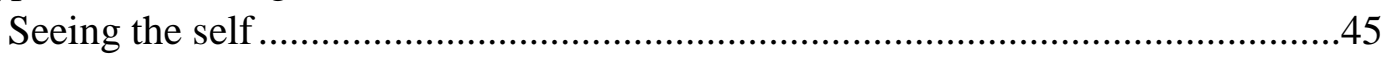

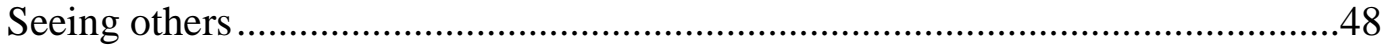

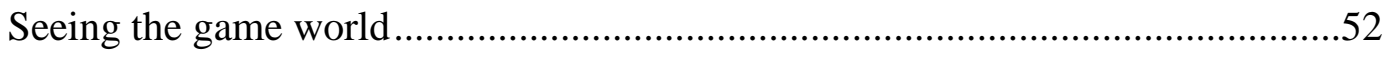

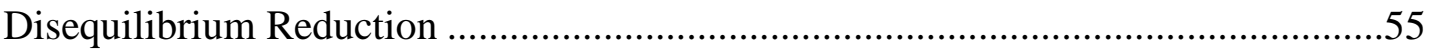

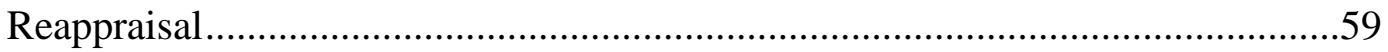

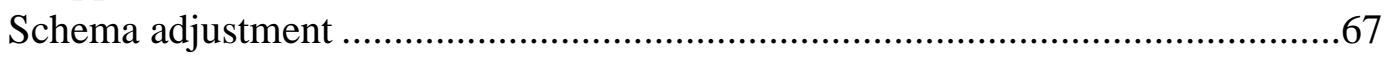

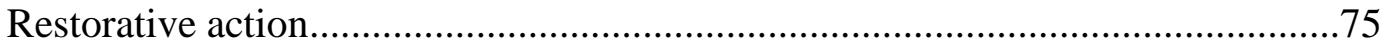

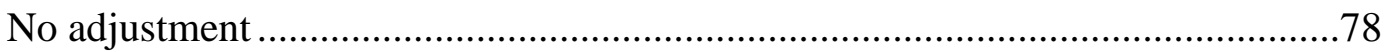




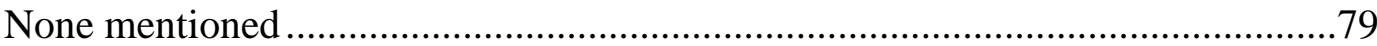

CHAPTER 3: PHASE 2: DEVELOPING THE HENOSIS SCALE …………………........80

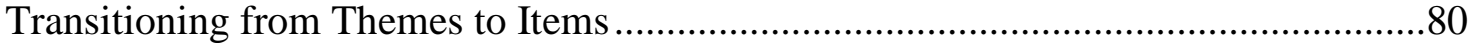

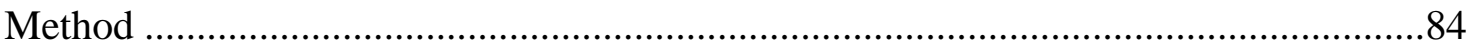

Item Pool Development: Overview ……………………........................................84

Item development: Schema adjustment ...............................................................88

Item development: Appraised meaning adjustment..............................................90

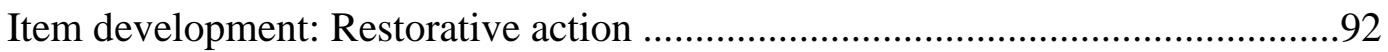

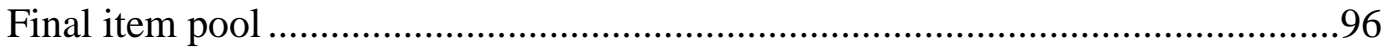

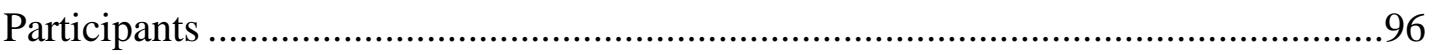

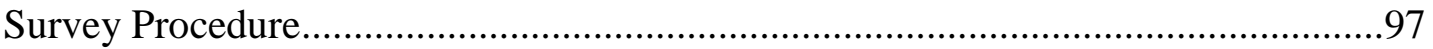

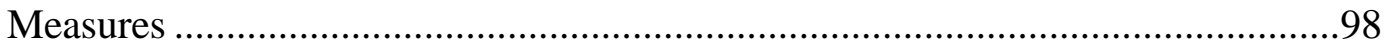

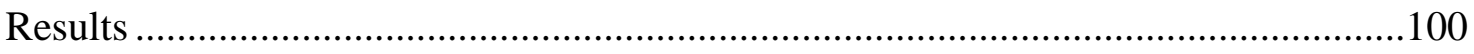

Data Preparation ………………………………………....................................100

Scale Development: Exploratory Factor Analysis ....................................................101

Interpreting the Factor Structure of the Henosis Experience (HEX) Scale ...............104

Experience adjustment .....................................................................................104

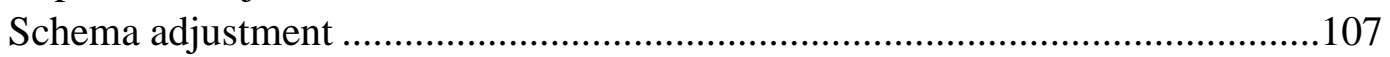

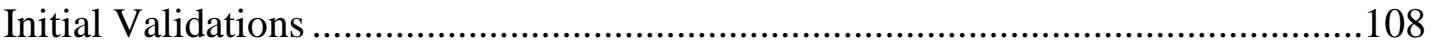

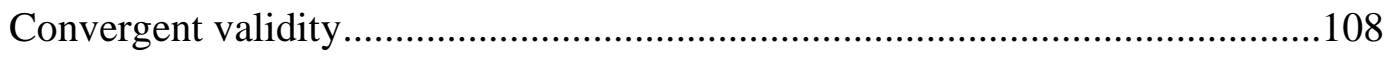

Discriminant validity ..................................................................................111

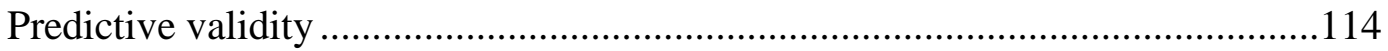

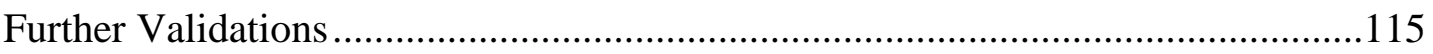

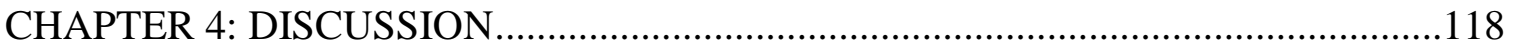

Phase 1: Exploration of Henosis Among Gamers' Meaningful Experiences ..............118

Implications for Development of a Henosis Scale .................................................126

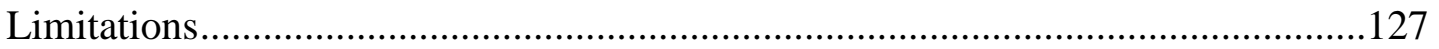

Phase 2: Measuring Henosis as Adjustments to Experience and Schema ...................129

Theoretical Implications for Meaningfulness in Gaming........................................133

Henosis in Relation to Self-Determination............................................................135

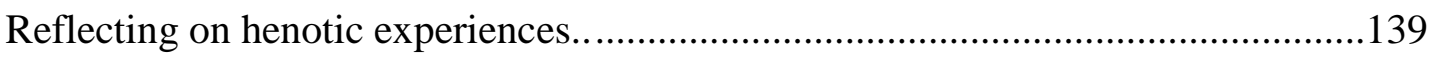

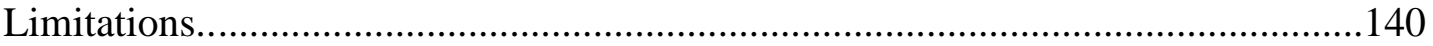

Overall Theoretical Implications and Future Directions .............................................141

Conclusion .........................................................................................................148 


\section{HENOSIS EXPERIENCE IN GAMING}

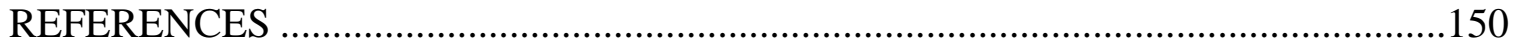

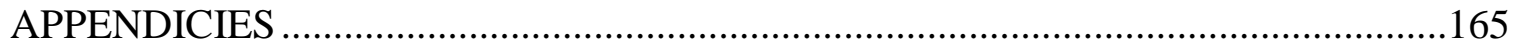

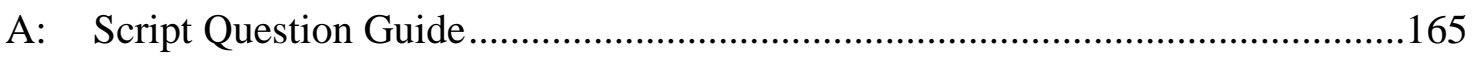

B: Henosis Survey Instrument ........................................................................169 
HENOSIS EXPERIENCE IN GAMING

\section{LIST OF TABLES}

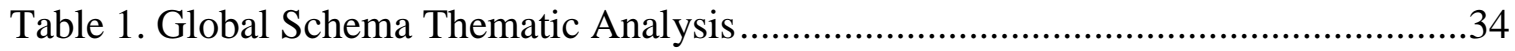

Table 2. Appraised Meaning Thematic Analysis ....................................................44

Table 3. Disequilibrium Reduction Thematic Analysis.................................................56

Table 4. Schema Adjustment Item Construction ........................................................89

Table 5. Reappraisal Item Construction.................................................................91

Table 6. Restorative Action Item Construction ...........................................................83

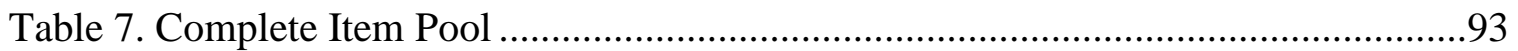

Table 8. Factor Loadings of Henosis Dimensions ....................................................103

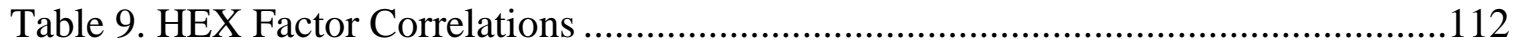

Table 10. Experience Adjustment Validations .........................................................116

Table 11. Schema Adjustment Validations.............................................................116 
HENOSIS EXPERIENCE IN GAMING

\section{ACKNOWLEDGEMENTS}

This manuscript could not have been constructed without the unrelenting support of a great many people. It is those people that I would like to acknowledge and thank for helping me in ways big and small through this arduous, but ultimately rewarding journey.

First, obviously, Janet Weeks. You've endured with me every single up and down since we moved here. I would be lost without you. There is no chance I could have done this without having you supporting me all this time. Every day that I keep at it, every day that I wake up happy - that is because of you, and I cannot wait to start the next adventure.

Next up, I of course have to thank my advisor Dr. Jaime Banks! There’s never been a time that I've gone into a meeting with you in your office that I haven't left more encouraged by several orders of magnitude. Often I went in there thinking the end of days has come, my academic career over due to this or that roadblock stalling whatever I am working on. You always find a way forward, because that's what you do...not just for yourself, but for so many people around you as well. Your enthusiasm is contagious, your wisdom deep, and your guidance through the PhD program has been irreplaceable.

I’d also like to thank my committee, starting with Dr. Nicholas Bowman. We have worked together quite a lot during this brief graduate school experience. We've been to Tokyo together and bought Super Famicoms. I have learned a lot from you, and I do not show you enough gratitude for that. Your influence and mentorship has helped me grow in ways I would not have thought possible, and I have made it this far because you helped make it so. To Dr. Liesel Sharabi: we have not had as much interaction over the years, but I truly appreciate all of the help you have provided on and off my committee. I 


\section{HENOSIS EXPERIENCE IN GAMING}

am honored that you have taken the time to be a part of my academic journey. To Dr. Natalie Shook: I was humbled you were so open and accommodating in allowing me into your class in social cognition. I genuinely looked forward to every day of that class, and it has left a lasting impact on my perspective. I will always be grateful for that. Finally, to Dr. Elizabeth L. Cohen: sometime between now and when I defend this dissertation, the battle of Winterfell against the Night King is going to take place, and we are going to have to sit there talking about henosis, instead of that. On a more positive note though, I wanted to say that I have really enjoyed the time I have gotten to spend collaborating with you on projects together, and that you have made a tremendously positive impact on my experience at WVU, as a scholar and a human.

One of the best parts of being at WVU is who we get to share the experience with, and I was very lucky to find myself in my particular cohort. Each person in our doctoral program is uniquely and irreplaceably valuable to this school, this field, and this world, and deserves more recognition than I can offer. First, there’s Catie Clark-Gordon. I chose her first because our student ID numbers are one digit away from one another, which makes us the most alike. That, and the fact that we both entered the program at the same time, study similar topics, and have been through this whole program together. I can't remember how many times Catie’s been there to support myself and everyone else, in whether that takes the form of enlivening the office with impromptu holidays, reminding me when it's time for class, or just being there to commiserate with. I can't imagine having gone through this program without her. She is also good at being shot with Nerf ${ }^{\mathrm{TM}}$ darts. Next up is Sara Pitts, also known as the reason everyone in the program is still sane. Knowing she’s there to listen to any of us vent at any time has been a constant 


\section{HENOSIS EXPERIENCE IN GAMING}

blessing, and the fact that she is still able to maintain so much positivity even as she sits there absorbing and dissipating all that vented negativity from her fellow cohort members (me), is something of a bewildering miracle-one that keeps that office afloat, and has helped me more than I can say. Next, there's James Baker, the best and only office mate I have ever had. James' nigh-unflappable attitude is an example to us all, and I'm lucky to have been able to work alongside him. Rounding out the cohort is Joe Wasserman: master board game researcher, hater of temperate weather, and good friend. My heartfelt thanks are extended to Joe for helping develop ideas, brainstorming methodologies, and inspiring new ideas...but above all for being a good friend, throughout this graduate school experience.

I also want to acknowledge and thank McKay West, TRU-TV aficionado and master at losing the game; Stephen Kromka, former teaching-assistant and current instructional superstar; Kylie Wilson, assistant to the regional manager; as well as Dana Borzea, Mary Donato, Molly Eikholt, Julia Weiss, Christine Anzur, Jennifer Knight, Kevin Knoster, Heath Howard, Stephen Jackson, Margo Thorwart, Hamlet Autumn, Heather Barone, Katelyn Whyte, and Andrew Nicholson. This program is what it is because of the people in it, and what growth I have undergone as a scholar that allowed me to produce this manuscript, could not have happened without the input of each person mentioned here.

Lastly, I want to thank Dr. Alan Goodboy, Dr. Matthew Martin, and the faculty for their support through this project and program; my mom and the rest of the family for their support; and finally, my friends not in graduate school - I look forward to seeing you all again soon. 


\section{CHAPTER I}

\section{INTRODUCTION}

Video games have undergone substantial maturing in recent years, and with this maturation, theorizing regarding entertainment gratifications (and by extension, video game gratifications) has increased in sophistication as well. In particular, an academic interest on entertainment gratifications that go beyond simple enjoyment to focus on experiences of meaningfulness has arisen at roughly the same time that video games have begun to focus on player experiences beyond (but not mutually exclusive with) fun. Indeed, the days in which video games were largely homogenous and consisted of mostly fast button presses, quick reflexes, simplistic narratives, and unambiguously fun-oriented experiences have given way to a diversification of narrative depth, gameplay complexity, and sociality. Emblematic of this are games which seem geared as much toward poignancy, thematic complexity, and meaningfulness as they are toward fun (Oliver et al., 2016). A telltale example is hit adventure game The Walking Dead (Telltale Games, 2012), which eschews the heavily action-oriented gameplay mechanics (e.g., Left 4 Dead 2; Valve Corporation, 2008) or resource-management mechanics (e.g., State of Decay; Undead Labs, 2013) found in other zombie-focused fare. Instead, the game focuses on choices made that impact the narrative of the game moving forward, akin to choose-yourown-adventure books. Often no "good” options exist that would satisfy our inherent desire to see liked characters win, or at least avoid harm (see Zillmann, 2000), instead forcing the player to choose between two negative outcomes. At the climax of the game, the player is bit by a zombie and forced to decide whether to ask 9-year-old Clementine, who the player has been protecting throughout the whole game, to leave the player- 
character to die, or instead to mercy-kill the player-character. Little about such a situation is suggestive of a "fun” experience; rather, it seems to fall more aptly into what entertainment scholars call a meaningful experience (Oliver \& Raney, 2011), characterized by feelings of insight, poignancy, and contemplation.

Of course, while this shifting focus does represent a marked change in trajectory for the industry, its mention here is not meant to imply that the idea of a meaningful experience has previously been foreign to video games or those that play them. Meaningfulness — at least, as the term is used colloquially_ can conceivably refer to numerous types of experiences that are subjectively described as such. It is worth noting that meaningful experiences in games often seem to involve playing and experiencing games with other people (De Schutter \& Vanden Abeele, 2010; Oliver et al., 2016), and that games have been socially oriented (Bowman, 2018), and thus potentially meaningful, long before developers began focusing on engendering insight, poignancy and contemplation. Unsurprisingly, many scholars have rightly pointed out that the notion of meaningfulness as a media experience is quite multifaceted (Wirth, Hofer, \& Schramm, 2012), and that further research and theorizing is needed to account for its manifestations and underlying psychological components. There have been promising advances on this front in terms of different emotional underpinnings of meaningful media experiences (e.g., Oliver et al., 2018). However, the bulk of this research focuses on experiences which can be gleaned from both interactive and noninteractive media, and it has only been recently that the meaningful side of video games, a medium whose interactivity poses potentially novel ways to experience meaningfulness, has begun to receive scholarly attention (Oliver et al., 2016; Schafer \& Yu, 2011; Seaborn, Pennefather, \& 
Fels, 2019). Furthermore, the specific psychological processes by which meaningfulness is experienced remain similarly underexplored.

Poignancy, felt connection to other players, and other experiences described above and elsewhere have in common that they differ from the hedonic gratifications (experiencing enjoyment/positive arousal; Oliver \& Raney, 2011) traditionally associated with video games and other entertainment media. As such, these experiences are sometimes referred to as nonhedonic gratifications, though this belies the reality that they often correlate with hedonic gratifications (Oliver \& Bartsch, 2010). They do however remain conceptually distinct. These experiences of meaningfulness are also sometimes called eudaimonic gratifications or appreciation (Oliver \& Raney, 2011), or simply meaningful media experiences (Oliver et al., 2018). The phenomenon of meaningful media experiences in traditional media and the potential psychological outcomes and effects of such experiences continue to receive substantial attention (Bailey \& Ivory, 2018; Odağ, Uluğ, Arslan, \& Schiefer, 2018; Oliver \& Raney, 2011; Oliver et al., 2018; Wirth et al., 2012) , and as research on meaningful video games is catching up (Oliver et al., 2016; Schafer \& Yu, 2011; Seaborn et al., 2019), it is becoming increasingly important to identify and clarify what mechanics comprise these experiences. There seems no better starting place than asking the players themselves about these experiences.

Research does show that players recognize that these experiences exist, as they seemingly have no trouble recalling meaningful game experiences when prompted (Oliver et al., 2016; Rogers, Woolley, Sherrick, Bowman, \& Oliver, 2017). The present research seeks to shed some light on experiences of meaningfulness though video games and entertainment media by drawing on the meaning making model (Park, 2010), which 
describes a process by which humans experience meaning by reducing perceived discrepancies between (a) schema-derived expectations about the world and (b) the appraised meaning given to a specific situation. While this overall process is referred to simply as “meaning-making” (Park, 2010) by the model, that term is wrought with ambiguity and is treated differently across disciplines. I argue here for specific attention to that discrepancy-reduction process - a process that I will specifically call henosis. The term henosis is used by classic Greek philosopher Plotinus to describe the process of achieving unity with what he terms the One-essentially, that which is the true reality and from which all causes are generated (Stamatellos, 2007). Global schemas are in a sense a psychological analogue to the One, in that they represent a person's idea about fundamental reality. Henosis is defined here as an adjustment of global schema or local meaning that produces experiences self-described as meaningful.

The meaning-making model's mechanism here being adapted to media experiences under the name henosis was initially devised to describe meaning-making in response to trauma or threat (Park, 2010), but as used here describes a response to any global schema violation, rather than only highly traumatic ones-including violations that occur while consuming media and playing video games. Henosis is useful in that it may be able to provide some insight into some of the underlying cognitive and affective processes which underlie some experiences of meaningfulness that people have during video game play. However, while some research has described similar dissonancereduction mechanisms in relation to meaningfulness, such as the moral dissonance resolution described in the MIME (e.g., Tamborini, 2011), there is scarce evidence thus far in terms of if and how this mechanism operates in gaming situations. Furthermore, 
given the increased interactivity of video games compared to other media, there may be unique ways that henosis engenders meaning in video games compared to other media (see Oliver et al., 2016). Thus, this research will attempt to provide some preliminary evidence that henosis is indeed at play in some experiences of meaningfulness in video games.

In the present study, I explore the potential for henosis to function as a meaningful process in the course of playing video games and (that potential confirmed) to develop a metric for capturing gamers’ experience of henosis in gameplay situations. Results support (a) that gamers experience henosis in some of their meaningful video game experiences, and (b) that henosis, via the metric created and factor-analyzed in this study, is revealed to consist of two dimensions: schema adjustment, and experience adjustment. 


\section{CHAPTER 2}

\section{REVIEW OF LITERATURE}

In recent years, there has been a movement in the games industry toward crafting video games that facilitating experiences of narrative or thematic depth. Roughly corresponding with this maturation of games as a medium, there has been a renaissance in entertainment theory emphasizing the broadening of entertainment to include gratifications that are not strictly pleasure. Traditional views of media entertainment centered around hedonic enjoyment as an explanation for why people seek out media content. For example, mood management theory (Zillmann, 2000), affective-disposition theory (Raney, 2011) and excitation transfer theory (Zillmann, 1996) explain, with robust empirical support, different psychological processes by which hedonic pleasure is derived from media content (maintenance of excitatory homeostasis, moral evaluations of characters and narrative outcomes, and transforming negative arousal to positive arousal through narrative resolution, respectively). However, other lines of research have highlighted the shortcomings of thinking about entertainment as a solely hedonic pursuit. Tearjerkers, for example, exist not to elicit pleasurable emotions, but rather elicit sad and negative mood states; however, this type of content remains popular and a sought-out mediated experience (Oliver, 1993). Anti-hero narratives and morally ambiguous characters are appealing as well, despite the fact that affective disposition theory would predict audiences should dislike characters who are morally unrighteous and the stories in which they succeed (Janicke \& Raney, 2015). Importantly, the fact that scenarios such as these challenged existing ideas about where media enjoyment comes from should not be taken to mean that these experiences are not enjoyed, and research in these areas has 
yielded some interesting explanations for how such fare can indeed be enjoyed through alternate mechanisms-i.e., metaemotional reappraisals for tearjerkers (Oliver, 1993), and identification and moral disengagement for antihero narratives (Janicke \& Raney, 2015). However, continuing challenges to entertainment theories also have led to a focus on gratifications that are not enjoyment at all; that is, there is more to the appeal of media than simple pleasure responses.

Ultimately, such exceptions to the assumption of entertainment-as-hedonic have led to an increased focus on experiences described as meaningful, insightful, and contemplative, which have been collectively labeled eudaimonic gratifications (Oliver \& Raney, 2011). These experiences are generally characterized by deeper reflection and a self-reported sense of meaningfulness during and after having consumed some sort of media content. Furthermore, meaningful media experiences are also found in many modern video games. For example, That Dragon, Cancer (Numinous Games, 2016), a game focusing on caring for a child dying of cancer, is a video game analogue to a tearjerker film. The game Night in the Woods (Secret Lab, 2017) is a heartfelt and bittersweet look at both mental illness and the slow decay of small-town life in America—similarly not a fun experience, but certainly a meaningful one, at least for some (Spencer, 2017). That current theorizing has arrived at a focus on meaningfulness gratifications just as video games are beginning to prioritize such gratifications by design makes the current state of theorizing well suited to now explore meaningful video game experiences, as indeed some research has already begun to do (Elson, Breuer, Ivory, \& Quandt, 2014; Oliver et al., 2016; Rogers et al., 2017) 
Meaningfulness is a broad and abstract concept which has been described in many ways by many researchers (see Hicks \& Routledge, 2013), such that a brief review of these sometimes-disparate scholarly characterizations is necessary to shed light on potential commonalities. As mentioned above, viewed in the context of media use, the term eudaimonia is generally used to denote an experience of meaningfulness in response to media, conceptually unique from hedonic pleasure responses to media content (e.g., Oliver \& Raney, 2011) and often labeled appreciation (rather than enjoyment). This is not to say that pleasure and meaningfulness cannot co-occur-certainly they can and often do (Oliver \& Bartsch, 2010; Roth, Weinmann, Schneider, Hopp, \& Vorderer, 2014). Rather, the experience of meaningfulness in entertainment is different than simply enjoying something. Meaningful media experiences might take the form of deeper elaboration (Tamborini, 2011), a sense of living one’s life in a holistic and fulfilling way (Rigby \& Ryan, 2017), a sense of appreciation for acts of extreme moral virtue (Algoe \& Haidt, 2009), or other manifestations. However, there is still much left unanswered about what sort of cognitive or affective processes occur for these meaningful experiences to transpire-put another way, it's not clear what the mechanisms of meaningfulness actually are, and it seems likely that the abstract nature of the term has led to many disparate experiences being summed under the label of eudaimonia or meaningfulness, as has happened with various other experiential phenomena studied by media researchers, such as presence (Lombard \& Ditton, 1997), or character identification (Downs, Bowman, \& Banks, 2017).

Synthesizing a range of research on eudaimonia, Oliver and colleagues (2018) described the construct as being characterized by three features: mixed affect, higher 
levels of effortful processing, and the satisfaction of intrinsic needs. These authors also suggested that eudaimonic experiences are only a subset of meaningful media experiences, which are primarily self-focused and inward driven. They argue that meaningful media experiences can also be self-transcendent, in the sense that they focus the viewer outward on other people and on humanity as a whole. Self-transcendent experiences are characterized by a sense of interconnectedness, a sense of human virtue and altruism, and/or spirituality. As Oliver and colleagues (2018) suggest, meaningful media gratifications may exist on a continuum of self- to other-focused, with eudaimonia on one end and self-transcendent experiences on the other. Further, the same media content could facilitate either self-transcendent or self-focused emotions for different media users. For example, an individual could play the game That Dragon, Cancer (Numinous Games, 2016), which depicts a family’s tragic experience of having a terminally-ill child, and through this feel a sense of connectedness to that specific family or even more generally an appreciation of the strength of the human spirit. This would be a self-transcendent emotion. Conversely, a person could play the same game but through doing so feel empowered to take on similar situations. This would be a more self-focused response. The notion of a broadened conceptualization of meaningful media experiences is useful theoretically in highlighting the range of experiences people might subjectively refer to as meaningful. This distinction is also useful practically, particularly in research such as this which is ultimately focused on designing a measurement tool to capture a specific type of meaningful media experience. Specifically, if researchers can more concretely and specifically identify the meaningful media experiences they wish to measure, they can also have a better idea of what they are not trying to measure. To the 
degree that self-transcendent and self-focused emotions are unlikely to co-occur (which one would expect of experiences that fall along a single spectrum - the same experience should not be able to occupy more than one position on a single spectrum), they might be able to serve as discriminant validity measures for one another. That is, an experience that is self-focused should not be able to also be self-transcendent for the same person at the same time. Of course, this is not to say that each type of meaningful experience that could possibly happen is mutually exclusive from one another. However, identifying unique characteristics of each that exist only for certain types of meaningful experiences and not others can help ensure more precise and discriminant measurement, and one way to go about identifying such characteristics is examining the mechanisms that uniquely underlie different types of meaningful experiences.

One reason it is particularly important to identify discrete, specific mechanisms that allow a more precise understanding of what meaningful media experiences are is that video games may offer unique ways to experience meaningfulness. For example, Oliver et al. (2016) found that people prompted to recall meaningful video game experiences cited the sharing of the experience with valued others to be a primary reason for the meaningfulness of their game experiences. While of course, people can watch movies with friends and loved ones as well, the connection to others may be a more salient component of the experience of video games; that is, game designers build these experiences into the game purposively, so they may take on a more important role in comprising meaningfulness in video games. Alternatively, games may immerse people into narratives and facilitate meaning in the same way that traditional media can. Narrative and gameplay are generally understood to comprise different types of game 
experiences (Calleja, 2007; Lindley, 2003), and they hence may involve different types of meaningfulness. By identifying henosis as a unique mechanism by which meaning can be derived, this work seeks to offer greater precision to the understanding of meaningful video game experiences.

In sum, one advantage of research such as the present research, which seeks to identify some mechanisms underlying meaningful experiences, is that highlighting different mechanisms can potentially help with differentiating out different versions of meaningfulness based on the processes by which they manifest. Such processes could help identify more specific types of experiences and help clarify definitions and terminology used to describe meaningful experiences. Clearly, there are quite a few media experiences that have received attention in the literature that are in some way “meaningful," which is perhaps not surprising given the abstract nature of the concept. It is not the goal of this research to describe all of them, but to propose and explore a specific mental mechanism that can be used to help explain some of these experiences. This process is termed henosis, but before discussing how henosis can lead to meaningful media experiences, a discussion of the model on which it is based, the meaning-making model (Park, 2010), is warranted.

\section{The Meaning-Making Model and Henosis: A Mechanism of Meaning}

It is often been argued by philosophers that human beings are driven to find meaning in life (Heidegger, Macquarrie, \& Robinson, 1962; Kierkegaard, 2009) and this idea has been borne out in psychological research (see Hicks \& Routledge, 2013). That said, perhaps the most basic question in this area of inquiry is what is it that humans are driven to find exactly? What exactly is meaning? Meaning can be understood as simply 
the expected relationship between two ideas (Proulx, 2013), the sense that one's actions fit into a larger life narrative (Crescioni \& Baumeister, 2013), or an awareness of the causal nature of the world (Heintzelman \& King, 2013). With so many different ideas about such a foundational concept in this area of study, it becomes critical to clarify what it is that is actually meant by meaning and what the implied psychological mechanisms are by which meaning is experienced. The meaning-making model (Park, 2010) succeeds in this regard by defining meaning as an outcome of dissonance reduction between global schemas and appraised meaning.

The meaning-making model relies on the concept of a cognitive schema. Schemas are cognitive structures that "represent knowledge about a concept or type of stimulus, including its attributes and the relations among those attributes” (Fiske \& Taylor, 1991, p. 98). For example, a person might have a schema about a football game that involves expectations of cheering, popcorn, players, a stadium, fans, intense heat, etc. To use a video game example, a person might have a schema about video games in a certain series' built up over many repeating iterations of said series. For example, games in the Zelda series (e.g., Nintendo, 1986) often feature similar structures in the sense that the player wanders around a large open world before entering dungeons filled with puzzles and enemies. To the extent a player has played these games before, they will likely have developed some kind of schema for the game consisting of enemy types, puzzle structures, combat mechanics, items that can be obtained, etc., which then guide players' expectations and engagement with any subsequent Zelda game experience.

We are biased to perceive things in line with our existing schema. People will remember schema-consistent information more than inconsistent information, and are 
likely to misremember things to be schema-consistent (Cantor \& Mischel, 1977). To use the Zelda (Nintendo, 1986) example further, people might best remember the aspects of a given Zelda game that conform to the patterns already mentally established for that player-that is, that conform to the player's Zelda schema. A player might particularly remember obtaining the master sword, bombing walls to find treasure, and memorizing enemy patterns to search for weak points, because these are all common tropes across entries in the series. Further, we tend to interpret information as being in support of existing schema, and prefer to incorporate information into these schema rather than alter our schema to be consistent with the new information (Piaget, 2001). For example, perhaps a new mechanic introduced in a modern Zelda game (e.g., The Legend of Zelda: Breath of the Wild; Nintendo, 2017) might be interpreted as an evolution of an established mechanic from older games; or, a player might interpret the new Zelda game as not being a "real” Zelda game, rather than adjusting their schemas for what a Zelda game is supposed to be.

\section{Global Schema as Guiding Frameworks}

Schemas can exist at various levels of abstraction. While the schemas thus far mentioned are somewhat specific in their referents (e.g., Zelda; Nintendo, 1986), JanoffBulman (1989) argued that schemas can exist at a more abstract level such that they comprise our basic assumptions of the world. This work originated in terror-management research which was interested in understanding how people adjust to extremely traumatic events by referring back to their basic assumptions about the world (Figley \& JanoffBulman, 1985; Janoff-Bulman \& Frieze, 1983). Janoff-Bulman (1989) proposes that one reason traumatic events can be so psychologically damaging is because they shatter a 
person's previously unchallenged understandings about their world which up until that point had provided a sense of safety and security. For example, a sudden tragic loss of a loved one violates an implicit expectation that one will not undeservingly experience a highly negative outcome without provocation, i.e. "I never thought it could happen to me.” These baseline expectations about the world can be understood as top-level schemas in that they exist at a very high level of abstraction compared to schemas as they are usually studied. These top-level schema can include things like assumptions about how good or bad human beings are, morally speaking, or whether justice typically prevails most of the time. Janoff-Bulman (1989) argued that people react to violations of these assumptions in the same way they react to any other type of schema violations—-by attempting to interpret the information in light of the schema and incorporate it if possible (a process known as assimilation) or, failing that, by adjusting their schema in light of the new data (a process known as accommodation).

These top-level schema are what the meaning-making model refers to as global schema (Park, 2010)—basic orientation systems through which people interpret the world which include beliefs, values, and goals (Janoff-Bulman \& Frantz, 1997). Janoff-Bulman (1989), in creating a scale to assess the content of global schemas in the context of understanding trauma, identified three categories of assumptions relevant to dealing with trauma — that is, they found three global schema categories consistent across people. These three categories are (a) the perceived benevolence of the world, (b) the meaningfulness of the world, and (c) the worthiness of the self. The perceived benevolence of the world refers to a person's beliefs about the extent to which, in general, good events are more likely to happen than bad events. The perceived 
meaningfulness of the world global schema consists of "people's beliefs about the distribution of outcomes; that is, once individuals have a sense of the extent to which good versus bad outcomes occur, the question of how these outcomes are distributed arises” (Janoff-Bulman, 1989, p. 118). The author suggests that some people will believe that people get what they deserve based on their actions and justice is ultimately served. Others believe that the outcomes experienced by people are a product of the person's intentional action; that is, people can control what happens to them through careful planning and deliberate action. Others believe there is no justice or controllability —all outcomes experienced by people will be random regardless of deservingness or attempts to control one's destiny. Finally, the third category is the worthiness of the self. These are a person’s schema regarding their own value, self-controllability, and luck.

Importantly, the idea that all humans hold these global schemas is not to suggest that everyone holds the same assumptions about these aspects of existence; rather, these are categories in which all humans have assumptions, the nature of which can vary. For example, different people can have different assumptions about how benevolent or meaningful the world is, but each person will hold assumptions in that category, and for each person these assumptions will be integral to their understanding of the world. Also, these three categories found by Janoff-Bulman (1989) are, as the author is quick to point out, by no means exhaustive of the global schema people may have, but they are a useful starting point for understanding what global schema are.

\section{Appraised Meaning as Local Perception}

In addition to global schemas that guide expectations about life and reality, the meaning-making model also describes how any given experienced event has an 
appraised meaning (Park, 2013). The appraised meaning is the immediate interpretation of events currently being perceived. It might also be understood as implicit meaning that does not require substantial effort to obtain—per Thompson and Janigian (1988), “any event has an implicit meaning to people undergoing it; there is no need to search for this type of meaning,” (p. 262). Lazarus and Folkman (1984) described how appraised meaning can arise in response to potentially stressful situations, manifesting as an immediate response to an event as threat, challenge, or benign.

Of course, while this model is particularly concerned with highly stressful events and how they are processed, the idea that people appraise everyday experiences in an implicit and immediate way is unlikely to be exclusively a response to traumatic events. Indeed, there is nothing inherent about appraised meaning that says that it only arises in response to trauma. Rather, in discussing appraised meaning (also called situational meaning), Park and Gutierrez (2013) state “people continually assign meanings to occurrences in their lives. These situational meanings refer to the specific appraisals that individuals assign to these occurences” (p. 10). Hence, appraised meaning should result from any event a person experiences, including those found in video games.

While appraised meaning should arise in response to any stimuli regardless of whether it is mediated or non-mediated, when talking about how people appraise meaning in a mediated context, one must also account for alterations in perception that might occur when consuming media. For example, in some instances media consumers become so linked with a character in a narrative that they start to experience events and other characters as though they themselves are that character-a psychological merging of self and character known as identification (Cohen, 2001). In other instances, media 
consumers become enrapt in the narrative itself, rather than a specific character, a phenomenon known as narrative transportation (Green \& Brock, 2000). In media generally and particularly with games, people can also achieve a flow state, in which they lose awareness of surroundings, of time passing, and of themselves, due to a balance of challenges offered by the media/game content and skills held by the viewer or player to meet those challenges (Sherry, 2004). All of these experiences involve an alteration in how media consumers (including game players) perceive media content, thereby impacting what the appraised meaning of this content is. Depending on the manner in which players are involved with games (identified, transported, etc.), players might engage with games as a system of challenges and appraise the killing of enemies as overcoming obstacles, or they might alternatively engage with games on a more narrative level and appraise killing enemies as a moral act (see Calleja, 2007).

\section{Schema Disequilibrium as Cognitive Dissonance}

Sometimes appraised situational meanings do not line up with global schemas: events or conditions or actors that one experiences in the world do not actually line up with one’s guiding worldview. This may result in a particular type of psychological distress which philosophers have sometimes labeled existential angst (Kierkegaard, 2009) and which cognitive psychologists have labeled disequilibrium or dissonance (Festinger, 2001; Piaget, 1985; Proulx, 2013). A schema violation can result from all kinds of experienced events, depending on what specific assumptions and worldviews are held by a particular individual. For example, a schema violation for someone who believes that the world is generally just would be an unjust outcome; conversely, a schema violation for someone who believes the world is not just would be justice being served. A person 
who believes that life is generally all made up of chance happenings is less likely to be surprised by a sudden fortune or misfortune than someone who does not hold this belief. Regardless, the process of reducing the discrepancy is thought to instill a renewed sense of faith in one's own life value and in the world at large (Park, 2013). Video games will often seek to subvert expectations in a way that might generate a similar discrepancy reduction response. For example, Spec Ops: The Line (Yager Development, 2012), a traditional action-oriented shooter game, features a moment where the player is forced to encounter the results of chemical warfare, a scene designed to subvert expectations of consequence-less violence and prompt players to reconsider their in-game actions (Westerman, Bowman, \& Lachlan, 2014). Hence, video games may indeed facilitate this same discrepancy reduction and similarly generate meaning in this way.

The meaning-making model holds that when faced with this distress, individuals tend to take some action to resolve the discrepancy between appraised and global meaning, and this process is referred to as meaning-making (Janoff-Bulman \& Frantz, 1997; Park, 2013; Proulx, 2013). Meaning-making might involve adjusting one’s global schema to accommodate the appraised meaning of a present situation (accommodation) or reappraising the meaning of the discrepant event so that it is consistent with existing global schema (assimilation). According to the model, meaning-making can be a willful exertion or an automatic reaction to the discrepancy.

\section{Henosis as Disequilibrium Resolution toward Media Meaningfulness}

As mentioned before, there are several ways that meaningful experiences can result from media engagement, possibly existing on a continuum from egoic to selftranscendent media experiences. The meaning-making process described by the meaning- 
making model is just one way people might experience meaning, which may overlap with some modes of meaningful media experiences already theorized (and may also overlap with hedonic media experiences). For clarity, this discrepancy-reducing process is dubbed henosis to distinguish it from these other forms of meaningfulness.

Global schemas are systems of meaning that represent humans’ fundamental understandings about the reality they inhabit and how the world works (Janoff-Bulman \& Frantz, 1997). Conversely, appraised meaning is the meaning that a person assigns to the current moment or situation. Appraised meaning and global schema can exist in equilibrium — that is, a person can appraise a situation or event as being consistent with what they would expect based on their global schema. In this case, a person would experience expected and unsurprising events. However, appraised meaning and global schema can also be in disequilibrium, such that the appraised meaning of a situation does not align with the expected reality derived from global schema. The pursuit of matching lived experience with these fundamental understandings echoes the notion of pursuing unity with the One as described by Plotinus (Stamatellos, 2007). Hence, the term henosis is borrowed from Plotinus and defined as the process of minimizing discrepancies between appraised meaning and global schema.

If the disruptions to schema are small enough such that the event can be reinterpreted and incorporated into a person's existing global schema, the person will tend to opt for this rather than altering their global schema. However, some events are so discrepant that they cannot be incorporated into global schema and the global schema itself must be altered. In either event, discrepancies between global schema and appraised meaning will result in attempts to reduce this discrepancy. This reaction has been shown 
in response to many different types of psychological threats, including threats to selfesteem and morality salience (Heine, Proulx, \& Vohs, 2006)—-threats that can and frequently do manifest in various ways in video game experiences via toxic gaming culture (Consalvo, 2012) or games which feature realistic depictions of death such as the aforementioned That Dragon, Cancer (Numinous Games, 2016). Similar psychological responses are also shown in work looking at how people react to cognitive dissonance by finding ways to restore their sense of order and meaning (Festinger, 2001; Piaget, 1985; Proulx, 2013).

\section{Henosis in Gaming Experiences}

Media will sometimes present a stimulus that disrupts a global schema, and given that media experiences are often experienced as real (Lombard \& Ditton, 1997; Reeves \& Nass, 1998), we should expect people to attempt to resolve those discrepancies the same as they attempt to do with any others. For example, media could provide portrayals of characters behaving in ways inconsistent with the viewer or player's global schemas, e.g. murdering innocent people or being unreasonably cruel in a way that disrupts a person's global schema about the general goodness of the world. Alternatively, a game could provide portrayals of characters behaving in unexpectedly altruistic ways, similarly disrupting a person's global schema about the general selfishness of humanity. To the extent these mediated experiences violate a person's global schema, they should result in either assimilation (e.g., rationalizing the actions, as sometimes happens with moral disengagement; Hartmann \& Vorderer, 2010) or accommodation (changing one’s ideas about the general goodness or morality of humans). For example, a person could experience a schema-disrupting event like those describe above and then reason through 
why this is not so unexpected when looked at differently (e.g., using a different schema)—-this would be assimilation. Alternatively, a person could experience that same event and then change their expectations for future events based on this event—-their worldview itself has changed, a process known as accommodation (Janoff-Bulman, 1989). In both cases, they will engage in henosis, and as a result experience meaningfulness.

Games add an additional complication in that the player controls the form and content of the media experience (Steuer, 1992) to some extent, unlike in other media where the audience can only psychologically respond to the encounter but cannot actively do anything to change what is happening. However, this may also aid in providing a greater sense of connection to the on-screen action as it is to some extent happening to the player, depending on how the player is relating to the avatar (Banks \& Bowman, 2016). It may even be the case that the increased interactivity of video games may allow people to actually alter the media content in such a way to make it align with existing schema in a way that is impossible with other media. Such an outcome would make sense, given that people are motivated to maintain their own enjoyment and will even reinterpret their game experiences in order to do so (Hartmann \& Vorderer, 2010). It is unknown to what extent the interactive nature of games might change or influence the way in which players experience henosis, if they experience it at all. However, if they do experience henosis, it may take on unique forms based on the interactive affordances of the medium. Furthermore, a greater understanding of how henosis takes place in interactive media such as video games can help shed greater light on how games as a medium can help communicate meaningful messages in unique ways-a potentially 
significant contribution to studies of mediated communication effects broadly. Hence, video games offer a uniquely useful lens through which to begin probing this new construct.

\section{Research Aims}

To reiterate, meaningfulness as a media experience is a well-established phenomenon, but there is a limited understanding of the mechanisms by which it unfolds. Henosis offers one such possible mechanism, and a potentially novel way to identify a particular type of meaningful experience that people can have while consuming media and playing video games. However, to this point the arguments for its existence as a mediated experience have remained largely theoretical. The goal of this research is to explore the potential the existence of henosis as a video game experience. Should the evidence be sufficient to demonstrate that henosis does emerge as a process leading to meaningfulness in gaming, the second phase of the research will attempt to devise a metric to capture the phenomenon. As such, the following research aims are put forth:

1.) Determine whether and how the henosis mechanism can lead to some of players' meaningful gaming experiences.

2.) Develop a metric to capture the extent to which players experience henosis in meaningful gaming experiences. 


\title{
CHAPTER 2
}

PHASE 1: EXPLORATION OF HENOSIS AMONG GAMERS’ MEANINGFUL EXPERIENCES

\begin{abstract}
Method
This project took a mixed-methods approach because doing so allowed for the use of in-depth qualitative data to inform the construction of quantitative measures. Through this, the aim was to gain insight into player's likely experiences of henosis as told in their own language and then develop a tool by which henosis can be measured. The work was undertaken in two phases. Phase I consisted of conducting focus groups to gain insight into whether players experience henosis in games, and if so, how players talk about the experience of henosis. Phase II consisted of the construction and factor analysis of a measurement tool for the experience of henosis.

\section{Exploring Henosis in Gaming}

Although research does suggest that people are able to readily identify meaningful video game experiences (Oliver et al., 2016), players talk about these experiences in a lot of different ways (Rogers et al., 2017). Furthermore, given that the henosis mechanism represents a novel approach to understanding meaningful game experiences, no existing research has directly queried whether and how this mechanism is experienced by game players. In order to verify that henosis is at least sometimes at play in meaningful game experiences and then develop a tool that measures the same construct across participants, it becomes critical to ensure that the measurement describes experiences that are consistent with how players perceive these experiences (see Morgan, 1997). Thus, the first step of this project was to explore the role that henosis plays, if any, in the
\end{abstract}


meaningful game experiences players have. This was done through the use in-depth focus groups.

Focus groups are "small groups of people with particular characteristics convened for a focused discussion of a particular topic” (Hollander, 2004, p. 606). They are particularly useful in gaining an understanding of participant experiences because they allow for the emergence of deep reflections and interpretations of topics by drawing on commonalities in group member experiences (Lindlof \& Taylor, 2011). Even if players do not often consider global schemas, appraised meanings, and/or disequilibrium between them in isolation, putting participants in a group can potentially yield a dynamic in which players realize commonalities in their own experiences (Lindlof \& Taylor, 2011), and it is these commonalities which can provide insights into specific types of gameplay events, narrative events, or interpersonal interactions through which people can experience henosis (such as what global schema, or aspects of global schema, are commonly drawn from and salient in video games; what are some common ways that appraised meaning of game experiences matches and conflicts with these schema; and whether players do indeed seek to reduce any disequilibrium between the two and the language they use to talk about these experiences.)

\section{Participants}

For participants in Phase 1, this research targeted people who were familiar enough with playing video games that they were able to talk at length about their experiences. This did not necessarily preclude casual gamers, however, who may experience henosis as well, albeit perhaps in different ways. To access participants with gaming experience, some participants were recruited from a local gaming club on 
campus: the WVU Collegiate Gaming Club. The club is an officially sanctioned student organization focused around both competitive and casual video gaming — a focus wide enough to encompass many different types of video games. The club regularly holds events and is active on social media (Facebook and Twitter) as well as hosting its own Discord server and group on Steam (a popular online gaming platform). The broad focus on gaming suggested that participants recruited from this community would likely be able to reflect on a wide variety of topics and build off of one another's interpretations. The researcher contacted the club using their posted email address and explained the purpose of the project, what it would entail and asked for volunteers to participate. A second group of participants was recruited from the WVU communication studies participant pool, via an online advertisement. This advertisement specified that participants must have some experience playing video games (while also making clear that mobile gamers and other casual gamers can still participate). For all participants, the purpose of the focus group was stated as trying to learn more about how people experience meaningfulness while playing video games. Participants were also told they would be entered into a drawing to potentially win a $\$ 100$ Amazon gift card. Snacks and refreshments were also advertised and provided.

\section{Procedures}

Participants met in a reserved classroom on WVU campus in Armstrong Hall, with the idea that, because the participants are already affiliated with WVU, hosting the focus group on campus should not prove to be difficult to get to. Time slots were reserved for 90 minutes. There were initially 12 available slots, as 6-12 participants is generally considered a good range of participants for focus groups-higher than this can 
mean not all participants are heard, and lower can mean less diversity of conversation (Lindlof \& Taylor, 2011). However, after running several groups, it became apparent that groups larger than six tended to result in less forthcoming participants, and the time slots were revised so that only six participants could be in a focus group. In total, twelve focus groups were run, with between 1 and 9 participants. The focus groups were held on multiple days during the week (to accommodate varying class schedules) and avoided times that intersected with any major athletic or other on-campus events.

Once participants arrived, introductions were made. Then, following the practices outlined by Lindlof and Taylor (2011), the researcher explained that the purpose of this study is to shed light on how people experience meaningfulness when playing video games. The researcher then proceeded to ask a series of questions aimed at soliciting player descriptions of their recollections of experiences of henosis. The questions were designed to be as open-ended as possible to allow for many possible interpretations (as participants were expected to potentially have quite different ways of thinking about and recalling henosis).

Question guide. The question guide can be found in Appendix A. While the categories identified by Janoff-Bulman (1989) offer some insight into some of the global schema that, when violated, can result in henosis, as these authors point out, this set is unlikely to be exhaustive of global schema categories, especially because it is geared only toward those that are violated by intensely traumatic experiences. Instead of using these categories as a guide, then, this question guide opted for a bottom-up approach which attempted to solicit global schema categories from participants (as well as the appraised 
meaning which violates them and insight into how this disequilibrium was resolved) through in-depth questioning and subsequent thematic analysis.

First, an icebreaker question was offered asking participants to tell the group about the last video game they played and whether they liked it. The researcher then asked participants to describe the last gaming experience that they thought was especially meaningful, offering a personal example to get the conversation moving. Following this, the researcher described how one way that video games might be meaningful, similar to how life events can be meaningful, is when things happen that challenge our expectations or understandings of the world, of people, or of ourselves, and asked participants whether they had had any such experiences, and if so, to describe examples of these experiences. For the general questions about meaningfulness, the researcher asked follow-up questions in order to probe why these experiences were meaningful. For the experiences which violate expectations about the world, the researcher asked probing questions to get at a) what global schema was challenged by the experience, if any, b) why the experience was challenging (appraised meaning), and c) how the participant reconciled this challenge (disequilibrium reduction/henosis). The entire session was audio-recorded. The structure of each session was loose enough to allow conversation to flow naturally, with participants being allowed to build on the comments made by other participants.

\section{Analysis}

Once all focus groups had been conducted, a thematic analysis (Braun \& Clarke, 2006) was conducted in order to determine if henosis did indeed manifest in the data and if so, what forms it took. To begin, the researcher transcribed the audio logs for the focus groups verbatim, including verbal non-word utterances (e.g., laughter) where appropriate. 
To expedite this process and reduce biomechanical strain on the researcher, and after experimentation with several transcription methods, ultimately each audio log was played back at half speed while the researcher listened with noise-cancelling headphones and spoke aloud the words spoken by all parties into a microphone to be automatically transcribed into Google Docs using free voice recognition software. The researcher read the words as they appeared, pausing to correct any errors that occurred and to denote when the speaker changed.

In the transcripts, names were removed and replaced with codes indicating the date, time, and participant number for the session (e.g., 0124_1430_1). If focus groups contained only one participant, that participant was labeled participant 1 . In focus groups in which multiple participants were present, they were given numerical number in the order in which they introduced themselves in the audio log. There were seven instances in which it was impossible to determine which participant a statement or utterance came from, and these were marked as such. Of these, six of them contained two or fewer words. All were marked as participant X in the transcript.

The transcription of the data served a second purpose, in that it allowed the researcher to become familiar with the data corpus. Once data was entirely transcribed, a thematic analysis (Braun \& Clark, 2006) was conducted in order to determine whether and how henosis processes manifested in participants' reported gaming experience. First, the data were broken down into individual data extracts to be coded. A data extract was defined as a complete story, sequence, or set of related ideas, and ranged in size from a single word to a paragraph in length. This was chosen as the preferred unit of analysis because through initial familiarization, it became apparent that many participants speak at 
length using many filler words while essentially describing a single basic idea or relating a single important gameplay event. Separating out individual sentences would be highly difficult and, in many cases, impossible, since participants do not often speak in complete sentences. More to the point, it often took participants many sentence (fragments) to achieve their point, and often it was only when looked at as broad, encompassing units that the full meaning of a participant's statement could be accurately and authentically understood. Given the somewhat roundabout way many participants used in describing their experiences, breaking down the data into smaller units than the ones used risked separating out components of a common process or experience into discrete units and potentially obscuring their relationships to one another. Given this project's interest in understanding how different meaning structures relate to one another (and impact player experience), when in doubt the researcher tended to define the extracts as larger and more encompassing in order to capture the entire thought, rather than risk artificially bifurcating statements and losing important context.

Once data had been unitized, it was imported into an Excel spreadsheet, with a column for session number, participant number, and data extract, in order to begin conducting a thematic analysis. In order to maintain systematicity and avoid common pitfalls of thematic analyses, the recommendations laid out by Braun and Clark (2006) were followed. These authors point out several important decisions that must be made prior to coding, and it is necessary for transparency to clearly articulate each of these decisions. Firstly, this analysis was using a theory-based approach, rather than an inductive approach. While inductive approaches are useful for getting a sense of the overall story being told by the data, theory-based approaches are better suited for 
understanding a specific aspect of the data. Since this research is specifically interested in understanding what participants' global schema, appraised meaning, and henosis experiences look like, more so than the full range of meaningful experiences, a theorydriven approach was deemed the most appropriate.

A second decision was to search for both semantic and latent themes. Semantic themes are directly evident in the data, whereas latent themes add an interpretive layer as they represent underlying ideas that are present in participant responses. Semantic themes are useful inasmuch as participants directly talk about their global schema, appraised meaning, and henosis experiences in some fashion, but familiarization and transcription of the data made it quickly apparent that many of these themes, while present, were more often latent than semantic. Hence, both were coded for, with latent themes indicated in the data with parentheses to distinguish them from semantic themes.

Thirdly, though this is less a decision and more an outlook, this project utilizes what Braun and Clark (2006) refer to as an essentialist, or realist, epistemological standpoint, rather than a constructivist standpoint, understood, in line with these authors' explication, to mean that this project assumes a direct relationship between meaning and experience and is less concerned with experience as socially constructed. While certainly, the ways in which people develop global schema and appraised meaning are likely to be influenced by social forces, this project is chiefly concerned with uncovering whether these things do exist, and what the experience is like to actual gamers. Importantly, during open coding, data extracts could be assigned multiple codes for any of the three types of coding (global schema, appraised meaning, disequilibrium reduction). 
The thematic analysis involved first the generation of codes. Henosis has been explicated previously as the attempted synchronization of dissonance between global schema and appraised meaning - hence, there are three components that must be identified to establish the existence of this mental process: global schema, appraised meaning, and the process by which people attempt to reduce or resolve disconnects between the two. Thus, the researcher read through the entire data corpus and coded three times - once for global schema, once for appraised meaning, and once for the disequilibrium reduction. Given the small sample size, it was decided that patterns would be documented even for infrequently mentioned themes to account for the possibility that the lack of mentions was due to the small number of overall participants. Global schemas were coded first.

As discussed in the literature review, global schemas can be understood as a highlevel schema that dictate how one understands the world, including values, attitudes, and general expectations. Based on extensive research prior to data collection, the researcher began this coding process with a number of sensitizing concepts (the "background ideas that inform the overall research problem,” Charmaz, 2013, p. 259) which guided the identification of codes in the data. Firstly, based on prior research, several global schemas have been identified-specifically, schemas regarding the benevolence of the world, the meaningfulness of the world, and the worthiness of the self all served as sensitizing concept for global schema. Furthermore, it became apparent early in the coding process that the distinction between global schema and other schema (which may be important but are not as all-encompassing as the global schema construct described) is somewhat murky in practice. Indeed, based on prior familiarization, the data appeared to contain 
numerous examples of schema violations which, while not global schema violations, could in theory lead to similar dissonance-reduction processes and possibly experiences of meaning as a result. To allow for this possibility, and to prevent overlooking what might be new global schemas undiscovered by prior research, the researcher attempted to decipher the schemas being violated during any unexpected events, with less of a focus on exclusively coding for clearly global violations.

Again, parentheses were used to distinguish latent from semantic themes. A latent theme could be found by taking into account the question verbiage as well as participant response. Sometimes participants would bring up an idea along with their attitude toward it (their global schema) and sometimes participants would bring up just the idea of a schema category without mentioning their stance toward this idea (e.g., the idea of one's sense of control over life, without stating how much control they felt they have personally). These distinctions were taken into account in the initial coding process.

Once all coding for global schemas had been completed, the researcher then set out to code for the second henotic (an adjective used here to describe something associated with henosis) component-appraised meaning. Because henosis as conceptualized only occurs because of a disconnect between global schema and appraised meaning, only those data extracts in which a global schema had been identified were coded for appraised meaning. This was necessary since the very nature of appraised meaning is such that all experiences should have an appraised meaning, but only those that also include some global schema as well to which the appraised meaning can be compared are relevant. Of course, this does not mean that appraised meaning does not matter in experiences in which global schemas do not seem to be particularly salient; nor 
does it mean that these experiences are not meaningful. However, without global schema and appraised meaning disconnects, an experience cannot meet the definition established for henosis and is thus outside the scope of this project. Hence, appraised meaning was thus coded as the meaning of the game experience being described in relation to the global schema already identified.

After the coding for appraised meaning began, it became apparent that the henosis process, if it appeared, became easily identifiable once appraised meaning and global schema were identified. In retrospect, the fact that the question guide specifically asked about how people bridge the disconnect between their expectations and what happens was often in fact how the appraised meaning of the situation was revealed. Hence, rather than code appraised meaning through the entire sample and then the henosis experience, both appraised meaning and the henosis process were coded simultaneously, but still as separate variables. Put another way, because appraised meaning and henosis were often brought up together, it made sense to code them in a single pass.

After initial open coding was completed, the codes were collapsed into themes, categories, and subcategories for global schema, appraised meaning, and henosis process based on participants descriptions.

\section{Results}

In engaging the thematic analysis, there were three themes found for global schema, three themes found for appraised meaning, and three themes found for disequilibrium reduction. Overall, henosis did appear to underlie some of the participants' meaningful experiences, but not all of them. Themes for each of the three types of coding are discussed in detail below. 


\section{Global Schema}

As discussed earlier in the method section, the question guide contained questions which asked participants about unexpected experiences they had which were meaningful, as well as experiences that related to an ideal they held. Ideals can also be considered a type of schema - perhaps not global, but certainly an important schema that helps guide behaviors and beliefs. Put another way, part of what constitutes a person's worldview is how that person defines and understands ideas about goodness and virtue-in other words, ideals are themselves part of a person's worldview. Given the nature of the questions asked, it is perhaps not surprising that global schemas of both types--the normalized world and the idealized world_emerged in participants’ recollections. The complete list of global schemas with accompanying examples can be found in Table 1.

Table 1

Global Schema Thematic Analysis

\begin{tabular}{|c|c|c|}
\hline Theme & Category & Examples \\
\hline \multirow[t]{4}{*}{$\begin{array}{l}\text { Idealized or } \\
\text { valued world } \\
(\mathrm{n}=261)\end{array}$} & $\begin{array}{l}\text { Valued } \\
\text { experience } \\
(n=111)\end{array}$ & $\begin{array}{l}\text { I would always play like this Lego Star Wars game with my } \\
\text { brother when we were really little. So like, it, it's more of the } \\
\text { company rather than the game, but I remember that because that } \\
\text { was a lot of fun. }\end{array}$ \\
\hline & $\begin{array}{l}\text { Valued } \\
\text { principle } \\
(\mathrm{n}=43)\end{array}$ & $\begin{array}{l}\text { I guess you could look at it that way to see that if you don't, if } \\
\text { you're not going to invest a certain amount of time into a game } \\
\text { that's not even your life, and you only got to play reality of like } \\
6,7 \text { hours to get in, if you're not willing to work for something } \\
\text { else in your own life at that same duration, like, how much are } \\
\text { you going to get? }\end{array}$ \\
\hline & $\begin{array}{l}\text { Ideal world } \\
(n=66)\end{array}$ & $\begin{array}{l}\text { I feel like the whole purpose of me playing a videogame is to } \\
\text { kind of like, escape the real world and go into like reality } \\
\text { fantasy, kind of like, be able to have like, decisions that are } \\
\text { hard be like a yes or no type thing, you know what I mean? } \\
\text { Because I feel like life's a little easier when it's kind of set up } \\
\text { like that as opposed to, you know what I mean, } 20 \text { decisions } \\
\text { could, you know what I mean, could affect one thing. }\end{array}$ \\
\hline & $\begin{array}{l}\text { Ideal self } \\
(n=56)\end{array}$ & $\begin{array}{l}\text { So I feel like the surprise would be like, when I would have the } \\
\text { crew together and just having everybody together, you know, }\end{array}$ \\
\hline
\end{tabular}




\begin{tabular}{|c|c|c|}
\hline & & $\begin{array}{l}\text { my friends taking me to be the one to make sure that everything } \\
\text { goes as planned. I feel that kind of gave me a sense... I guess I } \\
\text { came from a family where I wasn't always the one to be, to be } \\
\text { the leader, and for them to all look at me as the leader kind of } \\
\text { brought me back to where I was as a child but in a way of just, } \\
\text { like, this is always what I wanted, so this is like actually a } \\
\text { reality, and it would bring me a sense of joy because of that. }\end{array}$ \\
\hline \multirow[t]{2}{*}{$\begin{array}{l}\text { Normalized } \\
\text { or expected } \\
\text { world } \\
(\mathrm{n}=183)\end{array}$} & $\begin{array}{l}\text { Self schema } \\
(n=54)\end{array}$ & $\begin{array}{l}\text { Because you know, I've tried to get into other like competitive } \\
\text { games like League and stuff, I, I can't do it, I don't have the } \\
\text { knack for it, it frustrates me because I'm bad at them and I'm } \\
\text { used to being pretty good at games, so, you know, I need to be } \\
\text { in like, with people who like the same kind of games as me. }\end{array}$ \\
\hline & $\begin{array}{l}\text { Expectations/ } \\
\text { worldviews } \\
\text { for } \\
\text { events/people } \\
(n=128)\end{array}$ & $\begin{array}{l}\text { Yeah, that's how most zombie videogames go as well, and The } \\
\text { Walking Dead for example, they're always fighting different } \\
\text { people. It's always like a bad thing when they see others, and I } \\
\text { think that people would be more helpful with each other. }\end{array}$ \\
\hline \multirow[t]{2}{*}{$\begin{array}{l}\text { Game } \\
\text { Schema }(n= \\
109)\end{array}$} & $\begin{array}{l}\text { Specific game } \\
(n=69)\end{array}$ & $\begin{array}{l}\text { It was, well, the game has an economy, right, so you gotta buy } \\
\text { guns and whatnot, you get rewarded for winning rounds, and } \\
\text { they were at such a loss where they didn't have that much } \\
\text { money to buy good guns, and like Shroud only had his pistol, } \\
\text { like he was that low on ammo, err, that low on like equipment } \\
\text { and money, so, it just came down to him having to be smart, } \\
\text { gutsy, sit in this spot with just his pistol and pray that they don't } \\
\text { check, and then, they didn't, so, you know, it just altered that } \\
\text { spot, altered that map forever. }\end{array}$ \\
\hline & $\begin{array}{l}\text { Games } \\
\text { generally } \\
(n=40)\end{array}$ & $\begin{array}{l}\text { I had a real problem with all those survival games and } \\
\text { everything. Like I felt not very comfortable with all that. So, } \\
\text { but still, even now, I play quite often video games like } \\
\text { Monopoly and Sudoku, which are as well video games, but I } \\
\text { didn't consider them actually as video games, but then I really } \\
\text { realized that these are video games from the definition. }\end{array}$ \\
\hline
\end{tabular}

Idealized/valued world. The first category to be discussed is the idealized or valued world. These are schemas that participants hold which comprise their ideas of goodness, perfection, morality, and other forms of ideals. These schemas do not necessarily describe a view of the world as it is, but ideas learned over time that make up their sense of what the best version of things actually looks like. This category of schemas can be subdivided into four broad subcategories: valued experiences, valued principles, ideal worlds, and ideal selves. 
Valued experiences refer to instances when a participant expresses sentiment and personal valuation toward a generalized type of experience (which is often either enabled or thwarted by a game). By expressing valuation toward particular types of experiences, participants suggested that part of their system of understanding the world includes such valuation—a valuation that others with different ways of seeing the world might not hold. For example, many participants listed competitive multiplayer games as one of their most meaningful game experiences, and when asked to explain why, explanations often consisted of indicating an experience that they generally value, such as competition, or sharing experiences with others. These statements indicated either explicitly or implicitly a valuation that transcended any single game experience. For example, one participant (Participant 0121_1030_1) stated, “Yeah, I, I just always like, there's something about like, being really competitive, that has like, really driven me.”. In this example, the valuation is clearly stated: competition is something this participant values. In another example, the participant is more interested just in sharing experiences. In explaining why they enjoy playing in co-located settings rather than online, one participant stated:

I think it's more meaningful because you can, I just feel you are having more of a social interaction with the presence of people. I mean you can feel their energy, and I feel like I feel the emotions a little bit more versus just hearing somebody that I don't see their facial reactions. (Participant 0124_1230_1)

In this example, the participant considers the experience of others to be a particularly valuable experience. Both describe different experiences, but both also have in common that they suggest a global valuation of a certain type of experience. 
A similar category of ideal schema was that of a valued principle. Valued principles were identified when participants would specifically discuss things they value which do not describe a specific experience so much as they describe a concept or idea that participants hold to be valuable (often discussed in the context of describing why meaningful experiences are experienced as such). For example, several participants mentioned the value of hard work, and how all things worth having require effort to obtain:

I guess you could look at it that way to see that if you don't, if you're not going to invest a certain amount of time into a game that's not even your life, and you only got to play reality of like 6,7 hours to get in, if you're not willing to work for something else in your own life at that same duration, like, how much are you going to get? (Participant 0129_1630_3)

The second subcategory under idealized/valued world has is a schema denoting what comprises a participant's ideal world. These worlds encompass both aesthetic ideas as well as ideal behavior of others. Ideal worlds are typically referenced when participants make some indication, implicit or explicit, of their ideal world or the way the world "should be." This could take the form of explicitly talking about the world, or it could be implied by a statement of regret that the world is not one way or another. Sometimes, ideal worlds revealed themselves through participants desire to use games to access worlds that are more aligned with what they would like the world to be, and sometimes participants would even make active attempts to shape the game world in line with their ideal world. In responding to queries about game experiences that make them 
reflect on their ideal world, some (though not all) participants did indeed indicate their thoughts about an ideal world. For example:

Just give it your all at the end of the day and try to make the right decisions. That's kind of my philosophy. The ideal, I guess, I do like video games because I can create that ideal world, or even if I was going to create a video game I could make it how I would want to envision the world. (Participant 0124_1230_1)

The fourth category of ideals was the ideal self. This category refers to participants' ideal versions of themselves — the person they would like to become, or some aspect or characteristic of that person they would like to have. These selves represent traits participants highly value and want to possess. Participants who bring up ideal selves will often reveal these selves through the rules that games allow them to play, particularly when those roles embody a trait they already wished to possess (see Markus \& Nurius, 1986). Through gameplay, those traits can be learned and absorbed into the self, becoming part of a person's self schema.

Many participants made direct or indirect reference to video games that allow them to in some sense embody an ideal self in relation to one quality or another (leadership, being a winner, etc.), or highlight their distance from an ideal self. For example:

I know like, growing up...I was trying to like find like my identity, and like who I was and... what I wanted to be, so a lot of times like I would make these... obscure...people and characters that looked nothing like me. It was kind of like an image of what I wanted to be, you know, or what I 
thought I should be, or, you know. It's weird, I never thought about it before. (Participant 0121_1430_1)

Normalized/expected world. The second category of global schema identified are more in line with the concept of global schema outlined in the initial theorizing about the nature of henosis. That is, they are top-level mental structures about the world, humanity, etc., that guide expectations about fundamental reality. That said, the data that emerged from focus groups, while often indicating expectations and ideas that constitute participants' schema for normal life, these schema only sometimes seem to be at the same level of abstraction as the global schema described by the meaning-making model (Park, 2010). The researcher identified two categories of normality schemas based on whether the schemas were internally vs. externally focused schema-schemas for one's own self, and schema for the world in which a person lives and the people who inhabit that world.

Unlike the ideal self schema, which are mental structures regarding how people would like to see themselves, self schema are structures that govern how people actually do see themselves. These are often not in synchrony, and indeed, as will be discussed later, games often serve to highlight the disconnect between the two. Often video games seem to be appealing by allowing people to embody selves other than those they see themselves as (sometimes ideal selves), and occasionally inhabiting these selves can cause the self-schema to be adjusted to be more in line with those ideal selves. This is one of the primary ways that self schema manifested in the data, though at other times, participants simply described how they see themselves in general terms.

As an example of a self schema being discussed in relation to moves learned form a basketball video game, one participant (Participant 0124_1030_2) stated, “Right, it was 
kind of like a, I think I could do that but there's no way that I can move my body like that, no way I could get my arm behind my back, or whatever, something like that.”

The second category was general expectations about the world and humanity. This category refers to the set of knowledge and expectations people have about the world, society, and other humans, and can take many forms, including a person's basic beliefs about the goodness of humanity, or a person's understanding of the world as one of consequence, or one of moral ambiguity. This is not how participants wish the world would be, in other words; it is how they believe the world to actually be. As an example, one participant discussed a world schema in terms of the ambiguity of morality:

I mean, growing up I always felt like the, the world just like, you know, good and bad like Team Rocket, and then like, you know, Ash and his friends, but then I learned that it's not like that, you know. It's kinda like, the bad guys don't always announce themselves when they come into the room. (Participant 0121_1430_1) In this example, the participant reveals both their schema for the world in regards to moral ambiguity as well as the fact that their game choice does not reflect the world they expect to encounter on a day-to-day basis outside of the game.

Game schema. Finally, it would appear that many of the participants have separate schema for video games that sometimes dictate expectations of what will happen in the game. This is perhaps not surprising, given that media audiences form narrative schema that influence expectations about noninteractive media in a similar fashion (Raney, 2011). There are, however, important differences between the interactive and noninteractive media, and game schemas are only sometimes employed by participants. For example, game schemas often provide an explanatory mechanism that is used to help 
mend discrepancies between a participants’ world schema and game experiences (game experiences are seen as more normal than they would be outside of a game because games come with their own rules and participants have expectations built from repeated gameplay experiences). The notion of a game-specific schema aligns well with the idea of the magic circle (Huizinga, 2016), which is that games, by their very nature, exist as a set of rules, restrictions, and affordances that are distinct from those found in reality. These rules are ultimately arbitrary, but they must be accepted in order to experience the game. Some have argued that there is no magic circle, as people will ultimately bring their own unique experiences and lenses into the video game context during the experience (Consalvo, 2009). However, the fact that so many focus group respondents indicated they were able to understand events because they were "just a game” suggests that players believe that there is something like a magic circle that separates the game world from the real world (at least, in retrospect). Thus, even though it may be the case that game schema ultimately constitute a piece of what is really a person's world schema (i.e., there is no magic circle), it is useful to distinguish the two from one another because players in the focus groups indicated they consistently understand games and reality as somewhat discrete from one another.

As with normality schemas, even though these game schemas might not be necessarily "global” in the sense outlined in the literature review, players do sometimes discuss their violation as one path to meaningfulness. For instance, some participants are blown away by the impact their choices can have on game characters, stories, and worlds, suggesting that their previous schema for what games could offer in this domain have been violated - and it is these experiences which participants describe as the source of 
experiencing meaningfulness. Thus, the third theme found for global schemas were video game schemas, with two categories: schemas for a specific game, and schema for games in general.

Specific game schemas are schemas for specific games or game franchises-for example, Call of Duty (Infinity Ward, 2009) or Zelda (Nintendo, 2017)—usually built up from repeated gameplay experiences. Specific game schemas are violated when something happens that runs counter to the expectations a player has built up around the game they are currently playing. For example, a player could have extensive experience with a competitive multiplayer game, and so have a well-developed sense of how competitive outcomes are likely to play out given different variables relevant to the game outcome (evidenced player skill level, game match rules, affordances and limitations of game rules, etc.) These expectations could be violated when a player or team wins or loses a game unexpectedly, or a player or team that appears to be of low skill suddenly demonstrates incredible skill. They can also be violated when expectations based on the storyline established by the game and built up throughout an extensive narrative are suddenly violated, as might happen when the story takes a sudden unexpected twist. An example of a specific game schema being violated shows up in this participants' recounting of a particularly pivotal moment in a competitive match:

It was, well, the game has an economy, right, so you gotta buy guns and whatnot, you get rewarded for winning rounds, and they were at such a loss where they didn't have that much money to buy good guns, and like Shroud only had his pistol, like he was that low on ammo, err, that low on like equipment and money, so, it just came down to him having to be smart, gutsy, sit in this spot with just his 
pistol and pray that they don't check, and then, they didn't, so, you know, it just altered that spot, altered that map forever. (Participant 0121_1030_1)

In this example, there is an implicit schema indicated by the intricate knowledge of the game itself. The alteration of the map "forever" indicates this schema was altered for the participant (and possibly for the player base) because of this schema-violating play.

General game schemas are schemas that players have around video games in general. These schemas can be violated when games do something that players have never experienced before, such as offering an unprecedented amount of control over the game world, or an area to explore larger than ever seen before. New affordances or mechanics can serve to violate and possibly update/alter these game schemas. Further, general game schema can refer to notions about video games that arise from other sources, particularly for participants that do not have a lot of experience playing video games but have general impressions about the medium based on indirect experience through friends, media coverage, observation, etc. For example, one participant (Participant 0129_1030_1) described how their understanding of what games were for and what they could do changed based on their experiences playing Monopoly on mobile phones (specific version unspecified by participant), stating, "That's the most surprising, not in the game, but the fact that I play the game, I would say, as like that.”

\section{Appraised Meaning}

Appraised meaning is the specific meaning in a gameplay experience that does not require further elaboration to arrive at (Park, 2010). It refers to the immediate perceptions of the player while they are playing the game. It is conflicts between appraised meaning and global schema that can lead to henosis, so it is important to know 
Table 2

Appraised Meaning Thematic Analysis

\begin{tabular}{|c|c|c|c|}
\hline Theme & Category & Subcategories & \\
\hline \multirow{3}{*}{$\begin{array}{l}\text { Seeing } \\
\text { Self }\end{array}$} & Emotional & & It makes sense that it would elicit certain emotions, like, uh. like during say, \\
\hline & $\begin{array}{l}\text { Reaction to } \\
\text { Self }\end{array}$ & & $\begin{array}{l}\text { near the end of the tournament, if I even get that far, and during those last } \\
\text { few matches, my stress does in fact raise, quite a bit. }\end{array}$ \\
\hline & $\begin{array}{l}\text { Observation } \\
\text { of Self }\end{array}$ & $\begin{array}{l}\text { Self/avatar similarity } \\
\text { Self } \\
\text { accomplishment/mastery } \\
\text { Self agency/avatar control } \\
\text { Self-other interaction }\end{array}$ & $\begin{array}{l}\text { I feel like recently it's been more so like myself, but I feel like that kind of } \\
\text { goes hand in hand with my life right now, I was very like, kinda coming into } \\
\text { who I am, so I feel like every aspect around me, including like video games } \\
\text { and like other stuff, like I'm kind of more, more on like trying to make it fit } \\
\text { my personal, like, because I want everything like, organized and put } \\
\text { together, and like, kinda like, closer to home. }\end{array}$ \\
\hline \multirow{3}{*}{$\begin{array}{l}\text { Seeing } \\
\text { Others }\end{array}$} & Emotional & & I actually went to a LAN, ah, back in high school, so it was like 5 years ago \\
\hline & $\begin{array}{l}\text { Reaction } \\
\text { to/of Others }\end{array}$ & & $\begin{array}{l}\text { now, and it was probably the best weekend of my entire life, like that I just } \\
\text { never felt so excit-, like there's just a bunch of people that same mentality... }\end{array}$ \\
\hline & $\begin{array}{l}\text { Observation } \\
\text { of Others }\end{array}$ & $\begin{array}{l}\text { Morality/goodness } \\
\text { Working with/against } \\
\text { player } \\
\text { Other in-game events } \\
\text { Other players in general } \\
\text { Performance of others }\end{array}$ & $\begin{array}{l}\text { I'm playing with my brother, I'm playing with my friends where I'll be in a } \\
\text { situation and I won't know how to make a move or I won't know how to } \\
\text { switch my gun or something, and this individual will be like hey, this is what } \\
\text { you hit, or, after the game you know, they'll be like, hey, great game, like } \\
\text { they'll message me on Xbox whatever it is and just be like, hey great game, } \\
\text { or send like a smiley face. }\end{array}$ \\
\hline \multirow[t]{2}{*}{$\begin{array}{l}\text { Seeing } \\
\text { the } \\
\text { World }\end{array}$} & $\begin{array}{l}\text { Emotional } \\
\text { Reaction to } \\
\text { World }\end{array}$ & & $\begin{array}{l}\text { When I'm } 14 \text { thinking about a zombie apocalypse, it's more a fear instead of } \\
\text { now it's like tactical so I guess I acted there to make a decision out of fear for } \\
\text { the possibilities and now I'd be different based upon survival chances. }\end{array}$ \\
\hline & $\begin{array}{l}\text { Observations } \\
\text { about the } \\
\text { (game)world }\end{array}$ & $\begin{array}{l}\text { Gameplay } \\
\text { Game narrative } \\
\text { Game reality } \\
\text { Games overall }\end{array}$ & $\begin{array}{l}\text { You have to level up to prestige, and } 2 \mathrm{~K} \text { you got to play to get your, your } \\
\text { stats up, because you want to be better than everyone else, you want to be } \\
\text { able to compete more. }\end{array}$ \\
\hline
\end{tabular}


what exactly the appraised meaning is that might be causing potential disconnects. In other words, what are the categories of meanings around which henosis is arising in this sample? There are three key themes that emerged: seeing the self, seeing others, and seeing the world. Appraised meaning themes, categories, and subcategories can be found in Table 2.

Seeing the self. This category refers to instances in which participants have some sort of awareness of themselves during a gameplay experience. Two categories emerged here: emotional reactions to the self, and observations of the self, reflecting affective and cognitive elements of meaning, respectively.

Emotional reactions to the self was a broad category encompassing various affective response participants reported to their immediate experiences, including anxiety, inspiration, and adrenaline rushes. For this theme, participants would include an emotional component to their descriptions of a game experience relative to the self. For example, this participant described his reactions to an important event for him—game tournaments:

It makes sense that it would elicit certain emotions, like, uh...like during say, near the end of the tournament, if I even get that far, and during those last few matches, my stress does in fact raise, quite a bit. (Participant 0123_0930_4)

While this category did appear in the data, it occurred relatively less often $(n=22)$ than the other major category: observations of the self. Further, the codes subsumed under this category were quite varied, and as such there were not meaningful subcategories to further subdivide this category. 
The second category to emerge in the seeing the self theme was observations of the self. By far most of the open codes under seeing the self fell into this category $(n=$ 105). Five subcategories emerged under observations of the self: self/avatar similarity ( $n$ $=20)$, self accomplishment/mastery $(n=68)$, self agency/avatar control $(n=30)$, and self-other interaction $(n=17)$

The self/avatar similarity subcategory describes instances in which players draw comparisons/contrasts between themselves and the avatar they play as. This similarity manifested in different ways, with participants talking about their similarity to their avatars in terms of attractiveness, physical capability, and even morality. For example, this participant describes a transition between creating avatars representing any traits they wanted to have to creating avatars that represent the participant's actual self:

I feel like recently it's been more so like myself, but I feel like that kind of goes hand in hand with my life right now, I was very like, kinda coming into who I am, so I feel like every aspect around me, including like video games and like other stuff, like I'm kind of more... more on like trying to make it fit my personal, like, because I want everything like, organized and put together, and like kinda like, closer to home. (Participant 0121_1430_1)

The second subcategory is self accomplishment/mastery. This subcategory refers to instances in which participants mentioned how they saw themselves in relation to some personally held and/or game-encouraged goal, state, or status. This could take the form of seeing one’s self as having accomplished one’s goal, won the game, or achieved a satisfactory state of mastery. Conversely, this category could also include instances in 
which a participant did not achieve these ends in spite of efforts to do so. Accomplishing goals or attaining mastery could be expected or unexpected, and it could be purposively sought after or accidentally obtained. An example of this subcategory:

When they click on leaderboards they see your name, and that's just... a really fun feeling...I had a buddy he's like, hey, is that your name I see on like the top of the leaderboards, and I'm like, yeah that's me, ha. (Participant 0123_0930_2)

The third subcategory is self agency/avatar control. This subcategory describes instances in which the game highlights or the player reflects upon the extent to which they feel a sense of efficacy and freedom to accomplish whatever ends they please in whatever ways they would like to do so. This could take the form of being able to make moral choices as one would prefer to make them without being forced down specific moral tracks. It could also take the more basic form of a player feeling like they have a high sense of control of their character's physical actions. Players might experience a sense of agency due to careful game design aimed at this purpose, or they might achieve a sense of agency by violating game parameters in ways game developers did not attend. An example of this subcategory in action is:

But in a game, you know, you can choose to hit a button anytime and anything, you can take the shot in $2 \mathrm{~K}$, take the shot in COD, do whatever. And you have the actual power to modify the script instead of just watching it. (Participant 0129_1630_3)

The fourth subcategory is self-other interaction. This subcategory refers to instances in which participants actually interact with either other players or other NPCs 
(non-player characters controlled by the computer), and specifically refers to players reflections on their own selves in relation to these other players or NPCs. This could manifest as acknowledgement of a role assigned to the player by NPCs or by other players during cooperative team-based gameplay. It could also be a reflection on one’s inability or failure to occupy a desired role in relation to other players or NPCs, such as letting teammates down in a competitive scenario. An example of this subcategory is:

I was chosen out of my group of friends to be the captain and the crew, which I felt like I had to make sure everybody was doing what they were supposed to do in order for our crew to strive and fight other crews. (Participant 0124_1230_1)

Seeing others. The second theme that emerged for appraised meaning was seeing others - this theme encompasses all instances in which participants describe observing, reacting to, or reflecting on the presence and/or actions of other entities in the game, whether that be NPCs or other players. Similar to seeing the self, there were two main themes that emerged under seeing others: emotional reaction to/of others and observations of others. At this stage a pertinent question might be why self and others were chosen as the primary themes rather than emotional reactions and observations. One reason behind this decision is that there were overall far fewer instances of emotional reactions compared to observations regardless of if the focus is self, others, or the world. Categorizing the data according to the focus rather than observations vs. emotional reactions creates much more substantive categories that more accurately represent the split of the data. Secondly, the difference between self and other represents an internal and external focus on which appraised meaning is based, and this internal/external focus 
was thought to be potentially quite important for different ways people can experience meaningfulness given its relevance for distinguishing the self-focused and selftranscendent forms of meaningfulness described by Oliver and colleagues (2018).

Emotional reactions to/of others was once again much smaller of a category $(n=$ 21) than observations of the self $(n=141)$, and the codes that fell under emotional reactions were not sufficient in number nor did they group together in a meaningful enough way to be further divided into subcategories. The codes in this category involved a range of reported affective reactions, including empathy with characters, bonding over competitive and cooperative gaming, intimidation by other player, sadness over character deaths, and upset over losing a game. For example:

I actually went to a LAN, ah, back in high school, so it was like 5 years ago now, and it was probably the best weekend of my entire life, like that I just never felt so excit-like there's just a bunch of people that same mentality around me. (Participant 0121_1030_1)

Observations of others comprised most of the codes that fell under the seeing others theme. There were once again five subcategories here: morality/goodness $(n=20)$, working with/against player $(n=62)$, other in-game events $(n=25)$, other players in general $(n=3)$, and the performance of others $(n=14)$.

The morality/goodness was used to describe instances in which participants observed what they perceived to be a morally relevant action on the part of other players or NPCs. Codes that fell into this subcategory involved perceiving characters in a game to be moral or immoral, or observations/perceptions of the game as demonstrating the value of human life. One instance even drew unfavorable comparisons between game 
NPC narratively-driven actions and people in the real world, with a participant suggesting that people in the real world would be as hostile as they often appear in video games:

Yeah, that's how most zombie videogames go as well, and The

Walking Dead for example, they're always fighting different

people. It's always like a bad thing when they see others, and I

think that people would be more helpful with each other.

(Participant 0122_1230_1)

The working with/against player subcategory subsumed instances in which players made observations or perceived something about other players' actions as being either in concert with or actively opposed to the player's own goals and actions. Several of these experiences had to do with other players behaving in an uncharacteristically cooperative or friendly manner. Other codes simply referred to a participant's perceptions of the other player's presence in the game with them, or in the room with them, which could itself be a source of meaning for players regardless of if this presence is of a cooperative or competitive nature within the game confines.

I'm playing with my brother, I'm playing with my friends where I'll be in a situation and I won't know how to make a move or I won't know how to switch my gun or something, and this individual will be like hey, this is what you hit, or, after the game you know, they'll be like, hey, great game, like they'll message me on Xbox whatever it is and just be like, hey great game, or send like a smiley face. (Participant 0124_1030_2) 
The third subcategory was other in-game events, which was used as something of a catch-all for other behaviors observed in other players/NPCs which players noted as being a salient part of the meaning in their specifically described experience. This subcategory included instances in which participants noted that NPCs behaved in a similar way to actual-world human beings, or instances where AI-controlled entities made seemingly irrational decisions. Unexpected narrative events also fell into this category, such as the unexpected death or injury of another player or an NPC, or unexpected betrayals. For example:

Yeah, when I used to play Call of Duty, I know one of those campaigns, I think it was like you are a sergeant or something, like every time your life was in danger he would like, come out of nowhere and just like save your life, and eventually towards the end he ended up trying to kill you. (Participant 0124_1430_3) In addition to observations about other players in specific instances, some players described meanings derived from experiences that speak to larger trends or ideas about gamers, which fell into the fourth subcategory: other players in general. Interpreting the behavior of other gamers to be indicative of a general tendency to overindulge in games is one example. Another would be the observation based on on-line experiences that gamers do have different norms and playstyles across cultures (and that these can be learned about through online play with international teammates/opponents). For example:

In Fortnite you are able to play with random people, so people that you don't know, people that you've never even talked to that might not even be in this country, so I think that aspect, that gives life 
lessons because, when you're playing with different skill levels, you're playing with different people who don't have the same norms as you, different goals. (Participant 0124_1030_2)

The fifth category described observations of others level of performance. Such observations could be of excessive skill or lack thereof, or simply that a person performs differently than expected. Also, this could occur during a match with another player in which the participant was actively involved or could be an observation that occurs in a match observed but not participated in, such as a tournament that the participant spectated. Several participants talked about experiences where a player surprised them with unexpected skill:

If I go online, someone is picking like a bottom tier character, my expectations are going to be real low. I'm just going to swoop this guy. But then like they kick my butt because one, I had low expectations and two, they're obviously really good despite it being a really low-tier character. (Participant 0124_1430_7)

Seeing the game world. The final theme for appraised meaning codes was seeing the world. In comparison to meanings regarding the self and others, this category describes more broadly the world of the game and the reality this world contains. It can also encompass observations that have to do with discrepancies between the game world and the actual world. Once again, there were two categories under this theme: emotional reactions to the (game) world and observations of the (game) world.

Emotional reactions to the game world once again were far less prominent $(n=5)$ than observations of the game world $(n=165)$ and did not group together sufficiently to 
merit subcategorization. Reactions included feeling like the game is deeper and more meaningful than expected, disagreeing strongly with the game content/rules, experiencing anger at negative but noncompetition-related game events, or simply fear in response to the game world. For example:

When I'm 14 thinking about a zombie apocalypse, it's more a fear instead of now it's like tactical so I guess I acted there to make a decision out of fear for the possibilities and now I'd be different based upon survival chances. (Participant 0129_1630_3)

Observations of the game world was the larger category. This category consisted of observations related to gameplay ( $n=54)$, game narrative $(n=25)$, the game reality ( $n$ $=78)$, and about games overall $(n=8)$.

Observations of gameplay included statements participants made about the nature of the game in terms of its ludic structure and mechanics. There was a wide range of comments that participants made about various aspects of the gameplay, including descriptions of the game's complexity, difficulty, and emphasis (teamwork, strategy, competition, etc.). When questioned about why a game was meaningful, often the answer included a response that described some element of the gameplay. For example, one participant (Participant 0129_1630_2) stated, “You have to level up to prestige, and 2K you got to play to get your, your stats up, because you want to be better than everyone else, you want to be able to compete more.”

Observations of the game narrative encompassed any statements participants made about story-related elements of their particular gameplay experience and varied as widely as the number of games the participants described. Surprising story events would 
fall under this category. One common theme brought up was how the game world handled issues of morality, such as with the somewhat well-known sequence in Call of Duty: Modern Warfare 2 (Infinity Ward, 2009) requiring the murder of unarmed civilians in an airport:

I mean, where, in Call of Duty where you have kill all those Russians in the airport. It's much different than the ending of the Departed because of... you know you're actually doing it, and it's weird okay, and it's uh...it almost makes it, the game, less human because you're required to do something so ridiculous. (Participant 0122_1230_1)

The third subcategory was game reality, and encompassed instances where participants described the realness of a game (or lack thereof). Some participants talked about how games are unrealistic. Others described instances where games were too much like reality, which hampered their experience. Still others talked about how games are used to escape their own reality. For example, one participant (Participant 0129_1430_1) described, “I don't know, it just gives you like an alternate little reality to go to, like, you know what I mean. Life's not as fun I guess.”

Finally, some participants described how their ideas about games overall was made salient and sometimes altered by game experience. For example, some participants describe how games can aid in concentration, or surprise at how meaningful games can be based on a game experience. These meanings seemed to 
be indicative that the participants saw their experiences as exemplars of games as a medium in a way that sometimes changed their opinions. For example:

And the last thing I wanted to add is like, without, you know, not thinking about it, just going to the game usually just playing whatever game just to try to win, didn't really realize how many, after, you know speaking, after speaking, I didn't really realize how many meaningful life lessons, or how many meaningful things that I've learned from video games. (Participant 0124_1030_2)

As mentioned, appraised meaning was coded at the same time as disequilibrium reduction. Disequilibrium reduction, the key mechanism of henosis, will be discussed next.

\section{Disequilibrium Reduction}

The final set of coding was for the actual mechanisms by which participants attempted to bridge any disequilibrium that was caused by discrepancies between global schema and appraised meaning. Five main themes were induced here: reappraisal, schema adjustment, restorative action, no adjustment, or none mentioned. The first two themes, reappraisal and schema adjustment, align closely with the assimilation and accommodation processes aforementioned (Janoff-Bulman, 1989; Park, 2010), while the third theme may be one unique to, or at least especially prevalent in, video games (compared to other media) due to the unique affordances offered by interactive entertainment. The final two themes indicated either that participant responses suggested no adjustment was made in response to a discrepancy between global schema and 
Table 3

Disequilibrium Reduction Thematic Analysis

\begin{tabular}{|c|c|c|c|}
\hline Themes & Categories & Subcategories & Sample \\
\hline \multirow[t]{2}{*}{$\begin{array}{l}\text { Restorative } \\
\text { action }\end{array}$} & $\begin{array}{l}\text { Actively } \\
\text { creating/altering } \\
\text { game experience } \\
\text { to align with } \\
\text { normality }(n=7)\end{array}$ & $\begin{array}{l}\text { Attempts to align game with } \\
\text { expected world } \\
\text { Attempts to align game self with } \\
\text { real self }\end{array}$ & $\begin{array}{l}\text { Like when I was younger me and my sister would } \\
\text { try to replicate like, our house on the Sims. And try } \\
\text { to make it exactly, as close as we could, and then } \\
\text { we would make like, the people in my family. So } \\
\text { we would be playing like our families technically, } \\
\text { so that was kinda cool. }\end{array}$ \\
\hline & $\begin{array}{l}\text { Actively } \\
\text { creating/altering } \\
\text { game experience } \\
\text { to align with ideal } \\
(\mathrm{n}=35)\end{array}$ & $\begin{array}{l}\text { Attempts to align game with ideal } \\
\text { world } \\
\text { Attempts to align game self with } \\
\text { ideal self } \\
\text { Attempts to align gameplay with } \\
\text { valued experience } \\
\text { Seeking out valued experiences; } \\
\text { avoiding negative experiences }\end{array}$ & $\begin{array}{l}\text { Minecraft. Like you get to build whatever you } \\
\text { want. Like...if this was like Minecraft and I could } \\
\text { control everything, I would have like a huge roller } \\
\text { coasters everywhere and things like that. So to me, } \\
\text { for that, I'm creating a piece that I can appreciate } \\
\text { because visually I want it to look like this. }\end{array}$ \\
\hline No adjustment & $(n=144)$ & $\begin{array}{l}\text { Awareness of disconnect without } \\
\text { resolution } \\
\text { No disconnect } \\
\text { Upset at disconnect without any } \\
\text { bridging } \\
\text { None - enjoyment stems from } \\
\text { awareness of disconnect } \\
\text { None - immersed in game }\end{array}$ & $\begin{array}{l}\text { There's games that predicting like what the world } \\
\text { will be like, like in a certain time frame or } \\
\text { whatever, and whenever I play...often getting really } \\
\text { mad, because it's nothing like what earth is, there's } \\
\text { like, flying cars, and there's people with like } \\
\text { futuristic tech, and then there supposed to be in this } \\
\text { year, but then when I...I get so upset like, like, we } \\
\text { don't have flying cars, we don't have snowboards } \\
\text { that can fly, guns that shoot laser, anything like } \\
\text { that. }\end{array}$ \\
\hline
\end{tabular}




\begin{tabular}{|c|c|c|c|}
\hline None mentioned & $(n=77)$ & $<$ no subcategories $>$ & $\begin{array}{l}\text { It doesn't show like, the hard parts of life. Like the } \\
\text { complications, and heartaches. There's not really } \\
\text { any of them. }\end{array}$ \\
\hline \multirow[t]{3}{*}{ Reappraisal } & $\begin{array}{l}\text { Reappraisal of } \\
\text { normality deviation } \\
(\mathrm{n}=9)\end{array}$ & $\begin{array}{l}\text { Reappraisal of game event using } \\
\text { world schema } \\
\text { Reappraisal of competition using } \\
\text { game schema } \\
\text { Reappraisal of game events using } \\
\text { empathy/knowledge of others } \\
\text { Reappraisal of the game self as } \\
\text { distinct from the real self }\end{array}$ & $\begin{array}{l}\text { I would process this by putting myself in their } \\
\text { shoes and wondering, okay, how does someone } \\
\text { make that decision, like how could someone do } \\
\text { that, but you know, then you think from their shoes, } \\
\text { you know, I love this person. He thought of her as } \\
\text { his child at the end and he would do anything for } \\
\text { her. Yeah, I just try to put myself in their shoes }\end{array}$ \\
\hline & $\begin{array}{l}\text { Reappraisal of } \\
\text { game schema } \\
\text { deviation }(n=5)\end{array}$ & $\begin{array}{l}\text { Reappraisal of unexpected event to } \\
\text { match game schema expectations } \\
\text { Reappraisal of in-game others using } \\
\text { game schema } \\
\text { Reappraisal of game experience } \\
\text { using world schema }\end{array}$ & $\begin{array}{l}\text { We do also kinda have the idea that I don't think } \\
\text { they were trying very hard at the beginning, they } \\
\text { were like, who are these guys, like, cuz, second half } \\
\text { they won every single round, so we kinda think like } \\
\text { they just took it easy the first half, kinda messed } \\
\text { with us }\end{array}$ \\
\hline & $\begin{array}{l}\text { Reappraisal of ideal } \\
\text { schema violation (n } \\
=65)\end{array}$ & $\begin{array}{l}\text { Reappraisal of unvalued experience } \\
\text { using game schema } \\
\text { Reappraisal of ideal violations as } \\
\text { harmless and separate from reality } \\
\text { Reappraisal of unvalued experience } \\
\text { using different valued experience } \\
\text { Reappraisal of unvalued experience } \\
\text { using world schema } \\
\text { Reappraisal of unvalued world } \\
\text { using world schema }\end{array}$ & $\begin{array}{l}\text { Cuz like when you started, and, you know, oh crap, } \\
\text { I'm about to shoot up an airport. That's not cool. } \\
\text { But then, I have such a disconnect from the games } \\
\text { most of the time, well I just like, it's a video game, } \\
\text { you know. It shouldn't mean anything }\end{array}$ \\
\hline
\end{tabular}




\begin{tabular}{|c|c|c|c|}
\hline \multirow[t]{3}{*}{$\begin{array}{l}\text { Schema } \\
\text { Adjustment }\end{array}$} & $\begin{array}{l}\text { Adjustment to } \\
\text { normality violation } \\
(\mathrm{n}=127)\end{array}$ & $\begin{array}{l}\text { Adjustment of world schema to } \\
\text { account for game events } \\
\text { Schema for normal world } \\
\text { approaches ideal world (outside the } \\
\text { game) } \\
\text { Schema for normal world } \\
\text { approaches ideal world } \\
\text { (temporarily) } \\
\text { Schema for self approaches a } \\
\text { different self (temporarily) } \\
\text { Schema for self approaches ideal } \\
\text { self (lastingly) } \\
\text { Schema for self approaches ideal } \\
\text { self (temporarily) } \\
\text { Self schema adjusted based on } \\
\text { game events }\end{array}$ & $\begin{array}{l}\text { I used to love artificial intelligence, like I used, like } \\
\text { I love Siri, I love Alexa on Amazon, so I used to } \\
\text { think that they're just like, they're trying to help } \\
\text { us, they're just trying to obey our orders, in doing } \\
\text { things are making our lives much easier than } \\
\text { before, and then when I play the game I just } \\
\text { realized that artificial intelligence might be } \\
\text { dangerous to humans. }\end{array}$ \\
\hline & $\begin{array}{l}\text { Adjustment to ideal } \\
\text { violation } \\
(\mathrm{n}=6)\end{array}$ & $\begin{array}{l}\text { Adjustment of ideal based on game } \\
\text { experiences }\end{array}$ & $\begin{array}{l}\text { It taught me the value of teamwork that I later on } \\
\text { would bring to like, if I would do sports or } \\
\text { something, you know, you have to help everybody } \\
\text { on the team. }\end{array}$ \\
\hline & $\begin{array}{l}\text { Adjustment to } \\
\text { game schema } \\
\text { violation }(n=32)\end{array}$ & $\begin{array}{l}\text { Adjustment of game schema to } \\
\text { account for adjusted world schema } \\
\text { outside of game } \\
\text { Adjustment of game schema to } \\
\text { account for game events } \\
\text { Adjustment of game schema to } \\
\text { account for real world values }\end{array}$ & $\begin{array}{l}\text { Now I had a brother that, he suffered from like drug } \\
\text { addiction, like opiates and whatnot. he got off of } \\
\text { that and he turned that addiction into video games, } \\
\text { and it really kind of unexpectedly changed his life } \\
\text { for the better, and I feel like that could be } \\
\text { something you could argue like, video games do } \\
\text { help people, like it does keep your mind focused, } \\
\text { especially somebody going through problems like } \\
\text { that, and I was very very surprised that...I mean it } \\
\text { opened my eyes to what video games can really do. }\end{array}$ \\
\hline
\end{tabular}


appraised meaning, or that no adjustment was explicitly mentioned by the participant. Each of these themes will be described in detail below. The themes, and their categories and subcategories, can be found in Table 3. It should be noted for some of the subcategories of these henosis themes, there were rather small numbers of mentions. However, as was mentioned earlier, it is unknown whether this is the result of such a small and demographically limited sample size, and since the mechanisms identified line up with those predicted by the previously laid out theory, said subcategories will be reported here.

Reappraisal. Reappraisal refers to instances in which participants adjusted their perceptions of events in order to line up with existing schema. Put another way, participants adjust the appraised meaning of an event to be more in line with a global schema. Janoff-Bulman (1989) refers to this as assimilation, because new information is incorporated into existing understandings of the world, instead of changing those understandings. In this context, reappraisal occurs when a participant experiences some game event that is unaligned with their schema-driven expectations, but then reappraised that event using either other some other interpretation derived from the schema that was violated, or some other schema altogether. In practice this often took the form of participants reappraising an event as normal because, even though it does not normally happen in real life, it does happen a lot in video games, so it is not so surprising after all. In order to identify categories within this theme, commonalities were identified in terms of what type of expectation was being specifically being violated (normality, ideal, or game schema). Thus, the three categories that emerged were reappraisals of normality schema violations $(n=9)$, reappraisals of game schema violations $(n=5)$, and 
reappraisals of ideal schema violations $(n=65)$, in line with the global schema categories already identified. The subcategories that emerged under each one refer to how these violations are reappraised.

Reappraisals of normality schema occurred when something happened in a game that participants found to be in violation of their expectations about how the actual world is, or how people are expected to act, or their expectations about their own self and the role that they are accustomed to occupying in relation to others and the world. In response to this violation, participants discussed implicitly or explicitly how they were able to understand the event by looking at it and reinterpreting it in a different way. Four subcategories emerged here: reappraisals of a game event using world schema, reappraisal of competition using game schema, reappraisal of game events using empathy/knowledge of others, and reappraisal of the game self as distinct from the real self.

Reappraisal of competition using game schema involves instances where something happens in competitive play_often something not expected or wanted by the participant, such as a loss or bad play—and the participant then reappraises this event as a reasonable outcome in competitions, e.g., nobody can win all the time, as in this example: I mean it really hurts, but then one thing that I can tell myself is you don't need to belittle people, you know, when you are going for something, you have to go with your all, not thinking that I can win, or they're going to be a loser or something. You just go and then do your best, but I keep telling myself to feel comfortable, 
because then, yeah, or else I start feeling defeated, and all other stuff. (Participant 0124_1430_9)

Reappraisal of game events using empathy/knowledge of others refers to instances where participants do not initially understand the actions of other players or NPCs, but then after engaging in perspective taking are able to understand why a person behaved the way they did. For example, one participant described being very surprised that a seemingly moral main character Joel in the game The Last of Us (Naughty Dog, 2013) made a decision that harmed all of humanity just to save one girl, but then later coming to an understanding of why he would behave that way by relating it to his own knowledge of how people behave towards their loved ones:

I would process this by putting myself in their shoes and wondering, okay, how does someone make that decision, like how could someone do that, but you know, then you think from their shoes, you know, I love this person. He thought of her as his child at the end and he would do anything for her. Yeah I just try to put myself in their shoes. (Participant 0122_1230_1)

Reappraisal of the game self as distinct from the real self occurs when participants actively draw a distinction between their game self and their actual self. In this dataset, this manifested as a realization while performing impressive athletic moves in a game, and imagining performing similar moves in physical athletics, that such moves would be beyond the participant's physical abilities: 
Right, it was kind of like a, I think I could do that but there's no way that I can move my body like that, no way I could get my arm behind my back, or whatever, something like that. (Participant 0124_1030_2)

Though this form of reappraisal did not manifest often in the data, some experienced described by participants, such as being forced to behave counter to their moral preference, could conceivably result in a similar response, where a participant draws a distinction between themselves and their game avatar. This would be consistent with some of the avatar relationships found by Banks and Bowman (2016)—specifically, the relationship wherein the player sees the avatar as a separate social entity.

Reappraisal of a game event using world schema refers to instances where something does not make sense in the game until reappraised as being consistent with other aspects of a participant's worldview. For example, one way this manifested as an explanation of why game characters would suddenly betray the player:

I knew it was a game, or game, and I knew a lot of people are like that in real life, so it's just like, it's whatever. Like, if humans were all trustworthy, like, the world would be a lot different today. (Participant 0129_1430_1)

The next category of reappraisal is the reappraisal of game schema deviations. Sometimes, the player would experience something that would violate not their expectations about normality, but rather their expectations for what video games are. The reappraisals that manifested in response to these violations of game schema are 
reappraisals to match game schema expectations, and reappraisal of in-game others using game schema.

The first subcategory, reappraisal of unexpected events to match game schema expectations, came up when participants would talk about competition. For example, some participants described how they would have certain expectations about how a competitive match would turn out, but these expectations would not be met. While sometimes this resulted in adjusted expectations, in the case of reappraisal this resulted in explaining the unexpected event as a fluke or an intentional throwing of the match. For example:

We do also kinda have the idea that I don't think they were trying very hard at the beginning, they were like, who are these guys, like, cuz, second half they won every single round, so we kinda think like they just took it easy the first half, kinda messed with us, like I won this 1v3 clutch and was like, freaking out, so happy about it, but you know going back and thinking, yeah, you know, they probably weren't trying very hard against us. (Participant 0121_1030_1)

The second subcategory was reappraisal of in-game others using game schema. Here, participants indicated they would build up a relationship with a character in the game that felt close, but then reappraised this relationship as not real. For example, one participant (Participant 0129_1430_3) stated, "You built like a relationship with these people, or the animals or whatever, even though obviously it wasn't a real relationship.” 
The final category for reappraisals were reappraisals of ideal schema violations. This was by far the largest category under reappraisal $(n=65)$. Five subcategories emerged here: reappraisal of unvalued experience using game schema, reappraisal of ideal violations as harmless and separate from reality, reappraisal of unvalued experience using different valued experience, reappraisal of unvalued experience using world schema, and reappraisal of unvalued world using world schema.

Reappraisal of an unvalued experience using game schema describes instances in which participants are playing a game that fails to achieve some valued experience they are searching for (immersion, a win-state, teamwork, etc.), but reappraises the game experience as valuable using game schema. For example, a player could experience a loss in a game match that matters a great deal to them, but reappraise this loss as something inherent to how competitive games work:

If I do win the tournament, or if I lose, there is that moment of extreme catharsis, or the opposite, I don't know the term. But then like, immediately afterwards, I'm over it, like that's just how competitive games work. Like you get far, if you get far, then, you will feel some extreme emotions. Not too extreme, but you know... you're invested is what I'm trying to say. (Participant

0124_1030_2)

Reappraisal of ideal violations as harmless and/or separate was one of the larger subcategories $(n=29)$, and describes situations wherein the participant experiences an event that deviates from some ideal they hold, but then the participant reasons that because this is a video game, the events are ultimately inconsequential and not "real." 
Participants who reappraised in this manner often mentioned a sentiment suggesting the situation is just a game and not real life. Some participants mentioned this in relation to the morality of the actions they engaged in during the game:

Cuz like when you started, and, you know, oh crap, I'm about to shoot up an airport. That's not cool. But then, I have such a disconnect from the games most of the time, well I just like, it’s a video game, you know. It shouldn't mean anything, except for it’s part of the storyline, so it didn't matter to me too much.

(Participant 0124_1030_4)

In other cases, participants would experience something that violated some ideal or value that they hold, but would reappraise the event as valuable when looked in in relation to a different value they hold. For example, several participants reported experiencing a negative reaction to losing or a failing at a game, but then reappraising the experience as an opportunity to improve themselves. In turn, improving oneself is itself a valuable experience, thereby changing the appraisal of the event to something positive and in line with an ideal held by the participant. For example:

I think it drives me. I think it, like, you know, I guess upset or frustrated. If I'm expecting to win and I lose I get upset and frustrated, but it motivates me, drives me to learn what I did wrong and how I can fix what I did wrong. (Participant 0124_1030_2)

In other instances, participants would reappraise a loss as positive because it helped maintain or strengthen a friendship cultivated through gameplay: 
When I started meeting more people who played the game, like I felt bad about knocking them out of the brackets in tournaments, so I like purposefully lost a few times, like I purposely held myself back so that they can have a few more rounds. (Participant 0124_0930_4)

Finally, some participants reappraised something that violated an ideal or value they held by simply reverting to their normal world schema. That is, participants reappraised a surprising violation of their values as understandable because it reflects what they would expect to happen, even if it isn’t what they would like to happen. For example, one participant talked at length about the relation between a mobile version of classic board game Monopoly (specific version unspecified by participant) and the system of capitalism it is purported to roughly model, commenting on the conflict between the rules of the game and the ideals the participant personally holds:

I think that it's interesting because it doesn't change you completely but, like in my case about Monopoly still, like there is a confrontation of ideals with the rules of the game. And you kind of understand that there are still some rules to comply with, and for that I just, I just remember a phrase I've heard before, someone told that well oh, there are a lot of people when they are in a lower position, just like employee and so on and so forth, they think oh, those bosses they are so and so, and they do some nasty things and everything they do actually is wrong, but when the same person achieves a higher place in the hierarchy they actually act as their bosses. (Participant 0129_1030_1) 
Schema adjustment. Schema adjustment emerged as the second major theme for how participants deal with discrepancies between global schema and appraised meaning. Schema adjustments occur when a participant encounters some discrepancy between global schema and appraised meaning and it causes them to actually change their global schema - that is, the participant resolves the disconnect by changing something about their worldview to account for the new information. This is essentially what JanoffBulman (1989) calls accommodation, which makes this response fit nicely with existing theory. Again, three major categories of schema adjustment were identified corresponding to the three types of global schemas that could be violated. Hence, the three categories are adjustments to normality violations, adjustments to ideal violations, and adjustment to game schema violations. Each of these categories also has subcategories corresponding the method by which participants adjusted to each type of schema violation.

Throughout this section, the term approaches is used to describe schema adjustments, which merits some clarification. Global schemas were previously conceptualized as top-level frameworks by which people understand their world, which include both expectations and values. However, these results have indicated several branches of schema that, while still roughly fitting into the general concept of a global schema, vary in their focus and content—namely, participants talked about how they think the world is (normality schema) and how they think the world should be (ideal schema). Ideal schema can still be considered part of global schema because they help define and shape a person's notions of what values like goodness actually look like, which is part of a person's overall worldview. However, sometimes (it would appear) the 
normality schema can be adjusted towards an ideal schema. In other words, a person’s idea about what the world is like can change to more closely resemble what they wish the world looked like. Similarly, looking at the categories of appraised meaning identified by participants in this study, a person's schema about what other people are like and what they themselves are like can be adjusted to more closely resemble what they wish people or themselves were like. As another example, game schemas represent a person's ideas and expectations for what video games are like, and sometimes ideas about normality can be adjusted to align more with these game schemas. When this manuscript speaks of one schema approaching another, this is what is meant. This does not mean that all schema adjustments are in relation to schema identified here by participants; it is just one pattern that seemed to emerge somewhat prominently.

By far, the largest category of schema adjustments was adjustments to normality violations $(n=127)$. Five total subcategories emerged representing different schema adjustments that happened in response to normality schema violations. The subcategories were: adjustment of world schema to account for game events $(n=56)$, schema for normal world approaches ideal world $(n=11)$, schema for self approaches a different self $(n=5)$, schema for self approaches ideal self (lastingly) $(n=15)$, schema for self approaches ideal self (temporarily) $(n=32)$.

The subcategory of adjustment of world schema to account for game events refers to instances in which participants' worldview changed in some lasting way in response to their game experience. This specifically implies that a person's schema for the external world is altered, and not their schema for themselves or their role in the world. Schema 
adjustments of this type could happen when people develop a different point of view about society, as in this example:

But throughout the game he kind of like, starts to snap a bit, and will go to like, any lengths to keep his world... alive, and it later bites, not only his but oh, but the whole gang's. And you begin to realize that both in the game and outside, that whenever change happens in society or whatever, you're going to kind of have to go with it, because it's kind of hard to fight it all by yourself. (Participant 0124_1430_7)

Another example demonstrates a similar adjustment happening in relation to a person's view of the role and value of artificial intelligence before and after playing a game featuring themes related to this subject:

I used to love artificial intelligence, like I used, like I love Siri, I love Alexa on Amazon, so I used to think that they're just like, they're trying to help us, they're just trying to obey our orders, in doing things are making our lives much easier than before, and then when I play the game I just realized that artificial intelligence might be dangerous to humans. (Participant 0129_1030_2)

In these examples, the adjustment to schema is to align with the experience in the game, but they are not adjusted in relation to a different already-held schema for ideals or game-schema. The next subcategory describes an adjustment to a person's schema for normal world specifically towards an ideal. This adjustment subcategory describes instances when a person's world schema is adjusted to more closely resemble the world they wish existed in some way. For example, during an exchange about instances in 
which other players provide unexpected aid to newer and inexperienced players rather than just mercilessly defeat them, one participant commented:

I definitely think it does. I think it gives me a more, a better perspective of humanity, that people aren't just out to get me all the time. There are always, you know, there are great people in this world that are going to help, that want to see everybody succeed, and I think that definitely changed my perspective of who people are and what they want to do. (Participant 0124_1030_1)

Another participant (Participant 0122_1230_1), describing a narrative event in which a character sacrificed themselves, talked about how the experience had really stuck with them because of the way it had made them reflect on humanity, commenting simply, "I thought it taught me humanity was very cool. Yeah.”

Also in this subcategory are participants who stated that their worldview adjusts while playing the game in an immersed state, such that they feel like the world more closely resembles one they wish existed. For example, this participant described their experience in a game as one of black and white morality, which made the world simpler and easier to digest:

I feel like when I play video games, I just like, get lost in it. I feel like the whole purpose of me playing a videogame is to kind of like, escape the real world and go into like reality fantasy kind of like, be able to have like, decisions that are hard be like a yes or no type thing, you know what I mean. Because I feel like life's a little easier when it's kind of set up like 
that as opposed to, you know what I mean, 20 decisions could, you know what I mean, could affect one thing, you know. (Participant 0121_1430_1)

Changing to a more inward focus, the next subcategory of schema adjustment describes instances in which a participant adjusts their self schema based on the character they embody in the game. In all instances, participants who reported this type of adjustment were describing temporary rather than long-lasting self schema adjustments. Some participants described this as a deliberate choice on their part to further appreciate the game:

I think that's how I got the most out of the game, to feel like I was going through it, because if I just...hit A, and chose whatever random [choice] was A, then...I wouldn't have much invested in the game, but because I saw it from my point of view, putting myself in the game, then it changed like for me, it became important. (Participant 0129_1630_3)

Others saw games as opportunities to simply feel what it's like to be someone else: I'm allowed to do things the way I don't usually do them because I know it's a game, and it's just to like, oh I wonder what would happen if I tried this, and it's like, kind of experiencing it but not really. You know it's a game but it's like all right, just gives an opportunity to be someone else. (Participant 0129_1630_2)

A related subcategory described instances where self schemas not only adjusted, but adjusted towards what a person saw as their ideal self. This participant exemplifies this: I feel you can almost, it's, in a way with video games it kind of just, it kind of can bring out an alter ego or, you can do anything really what you 
wanted, what you find a dream of. I feel video games kind of help you live out your dreams in a way even if you can't really achieve them.

(Participant 0124_1230_1)

Two similar subcategories occurred here: self schema approaches an ideal self temporarily, and self schema approaches an ideal self lastingly. In the former, participants described experiences in which they felt temporarily like they got to possess traits and accomplish tasks that make them feel like an ideal self; in the latter, participants describe experiences that they feel helped make them actually change as people outside of the game into the person they had wished to become.

For temporary self schema adjustments, multiple participants mentioned playing games that allow them to feel like their childhood self, such as this participant: It's like Crash Bandicoot and, I don't know, just like, all of these games that are being revamped recently, it just kinda like brings you back to like growing up, and like, being a so eager on Christmas morning to have like the latest like Spyro or Crash, or Pokemon, Digimon game in my Christmas stocking, you know what I mean. (Participant 0123_0930_1) Other participants talked about being the best as one of their ideals, and described experiences that made them feel this way. For example, one participant (Participant 0121_1030_1) states, “That experience of going to that LAN - that's like the closest I could get to actually feeling like the best.” Others described the desire to control one's own destiny and how games allowed them to experience this control, particularly as children: 
I think what I liked was being like that gosh maybe 5 year old or like, 10 year old, like just having that power and control to do, to like control your own destiny in like this video game concept. (Participant 0124_1030_1)

In terms of lasting changes to self schema, one theme that came up was that of leadership. Several participants mentioned that video games allowed them to not only exert leadership within the game context, but also learn leadership skills that made them more of a leader outside of the game as well:

When I would have the crew together and just having everybody together, you know, my friends taking me to be the one to make sure that everything goes as planned. I feel that kind of gave me a sense... I guess I came from a family where I wasn't always the one to be, to be the leader, and for them to all look at me as the leader kind of brought me back to where I was as a child but in a way of sense, like, this is always what I wanted, so this is like actually a reality, and it would bring me a sense of joy because of that. (Participant 0124_1230_1)

The next category of schema adjustments is adjustments to ideal violations. There were far fewer examples for this category than adjustments to normality violations $(n=6)$. There were too few to further subcategorize this type of schema adjustment. The category describes instances where ideals themselves are actually adjusted based on game events. This could happen if participants realize some new important value, such a newfound appreciation for the value of human life. For example, one participant (Participant 0129_1030_2) commented, “It did make me realize like, all human lives are really important, like, no matter where you come from, who are you, and what are your beliefs, 
your realities, your goals, and your ambitions.” Another participant (Participant

0124_1230_1) talked about how they gained a newfound valuation of teamwork, stating, "It taught me the value of teamwork that I later on would bring to like, if I would do sports or something, you know, you have to help everybody on the team.”

Notably, in this dataset, schema adjustments to ideal violations were exclusively positive adjustments—participants gained newfound appreciation of something. Finally, the third category of schema adjustments were adjustments to game schema violations. Again, there were too few data points to subdivide this type of schema adjustment into subcategories (though other subcategories may exist).

Adjustments to game schema violations described instances in which participants’ schema for a particular game, or for games in general, was altered based on what they experienced in the game. Sometimes this took the form of changing people's expectations for what effects games can have, as this participant recounts:

Now I had a brother that, he suffered from like drug addiction, like opiates and whatnot. He got off of that and he turned that addiction into video games, and it really kind of unexpectedly changed his life for the better, and I feel like that could be something you could argue like, video games do help people, like it does keep your mind focused, especially somebody going through problems like that, and I was very, very surprised that...I mean it opened my eyes to what video games can really do. (Participant 0124_1230_1)

It could also take the form of particularly memorable events that change how the participant sees a specific game, as this participant recounts: 
And there was like this one crazy play that like, to this day has a mark on the game, cuz like, when you go play that map, you hear people talk about, they call it the Shroud Spot...[Shroud] had this amazing, unbelievable play where he ...was like sitting in his shroud spot...he snuck up behind them, took em all out, and like, everyone went wild... and I'm like right there freaking out too and like, it's that kind of unexpected mind blowing experience...I witnessed that game-changing, it's like forever gonna alter the game. (Participant 0121_1030_1)

Restorative action. Video games are interactive, and thus allow users to change the form and content of their entertainment experience (Steuer, 1992). As such, when encountering game experiences that violate one's schema for normality, ideals, or games, players not only have the option to alter their schemas or perceptions; they can also take active steps to change the content to align with an existing schema. This third theme describes instances when participants do just this. There were two categories that emerged_-actively creating/altering game experience to align with normality, and actively creating/altering game experience to align with ideals.

For actions aimed at aligning with normality, there were too few $(n=7)$ mentions in the data for this category to be subcategorized. This category subsumes both attempts to align the game world with an expected world, and to align a game self with one's actual self. Several participants talked about their experiences with games that allow for a lot of freedom in shaping the game world, such as The Sims (Maxis, 2000). One participant discussed how they would go to lengths to make their game world resemble their own: 
Like when I was younger me and my sister would try to replicate like, our house on The Sims. And try to make it exactly, as close as we could, and then we would make like, the people in my family. So we would be playing like our families technically, so that was kinda cool. (Participant 0123_0930_1)

Other participants discussed how they wanted to try to make their game self resemble their actual self as much as possible. One way this manifests is through participants making moral decisions in games that reflect their own morality:

I feel like I always made the good choices which reflected me, reflecting on my life just in general. I feel that, that reality I tried to mimic into the reality that I live today. Just always do the right thing, and I know some people, they might like doing a bad thing and what not, but I feel that kind of stemmed as a meaningful experience from that game to where I am now. (Participant 0124_1230_1)

The second category in this theme was actively creating/altering game experiences to align with ideal. This was much more common $(n=35)$ than aligning the game world with normality, and had four subcategories: attempts to align the game with an ideal world ( $n=12)$, attempts to align game self with ideal self $(n=2)$, attempts to align gameplay with valued experience $(n=10)$, and seeking out valued experiences/avoiding negative experiences $(n=11)$.

Some participants described actions in which they attempted to reshape the world towards how they wish the world would be, particularly in games that allow for high world customizability (the world can be changed in many ways) and emphasize building mechanics: 
Minecraft. Like you get to build whatever you want. Like...if this was like Minecraft and I could control everything, I would have like huge roller coasters everywhere and things like that. So to me, for that, I'm creating a piece that I can appreciate because visually I want it to look like this. (Participant 0122_1630_1)

Other participants talked about using various affordances of self-expression, such as avatar creation, narrative choices, and grinding to improve skill, to craft their game self into the self they wish they were. For example, competitive players talked about putting forth considerable effort to achieve a sense of mastery with their game self:

I'd say being competitive, and wanting to be the best that you can, is definitely an ideal that I have. In any game that I play, I wanna be at the top of the leaderboards. I try to grind it as much as I can. (Participant 0121_1030_1) Others talked about making their avatars look more attractive, such as one participant (Participant 0123_0930_3) describing their experience creating an avatar in The Sims (Maxis, 2000) in relation to their own self-concept, stating that these avatars would be “maybe a little prettier. Because that'll make you feel good about yourself.”

Several participants described experiences where they would actively attempt to shape the gameplay to suit what their desires were, sometimes even extending beyond the explicit purpose of the game designers. For instance, one participant described how several of his friends teamed up in a game that does not typically encourage doing so and started a business to obtain in-game wealth much quicker than would be possible alone, while also enjoying the shared experience with friends: 
I had one, I'd say a couple years ago. Me and my buddy, a couple of them were really into GTA online. And there's like, you sorta can run your own business on there. And so our goal was to just build a big business sort of empire, and just sort of run in a bunch of money. And it was sort of a lot of fun just like doing it once every day, or every other day, just alright let's get to it. (Participant 0124_1430_5) Finally, some participants simply said they made active attempts to seek out game experiences they have learned from experience are valuable to them, and to avoid game experiences that they have learned through experience are not valuable to them. For instance:

I've tried to get into other like competitive games like League and stuff, I, I can't do it, I don't have the knack for it, it frustrates me because I'm bad at them and I'm used to being pretty good at games. (Participant 0121_1030_1)

No adjustment. A fourth theme that was found in the data was that many participants describing meaningful gaming experiences did not experience any global schema-appraised meaning disconnect, and some who did experience a disconnect did not experience any adjustment. Indeed, of the described experiences that mentioned global schema, $n=120$ of them did not experience any disconnect from that global schema. Of those that did, one subcategory was that some participants gleaned enjoyment from the very fact that the game did not line up with their expectations for normality. For example, one participant (Participant 0129_1430_1), describing their experience playing games in fantasy realms, stated, “I don't know, it just gives you like an alternate little reality to go to, like, you know what I mean. Life's not as fun I guess.” 
A second subcategory was that participants would be upset at the disconnect between their experience and their schema-derived expectations,

There's games that, predicting like what the world will be like, like in a certain time frame or whatever, and whenever I play...often getting really mad, because it's nothing like what earth is, there's like, flying cars, and there's people with like futuristic tech, and then they're supposed to be in this year, but then when I...I get so upset like, like, we don't have flying cars, we don't have snowboards that can fly, guns that shoot lasers, anything like that. (Participant 0122_1630_1)

None mentioned. Finally, some participants made no indication one way or another on whether there was any bridging of a disconnect between global schema and appraised meaning. This theme did not have any categories or subcategories, and simply was used for all instances where participants mentioned a disconnect without offering any insight about whether or how that disconnect might have been resolved. For example, one participant (Participant 0123_0930_3) described how their experience with The Sims (Maxis, 2000) does not show the hardships of life, but they made no mention of how this disconnect between their ideas of reality and the reality presented by the game is bridged, simply stating, “It doesn't show like, the hard parts of life. Like the complications, and heartaches. There's not really any of them.”

With the thematic analysis complete, the next phase of the project was to transform the themes, categories, and subcategories obtained in this analysis into a series of items to be used to measure henosis. 


\section{CHAPTER 3}

\section{PHASE 2: DEVELOPING THE HENOSIS SCALE}

\section{Transitioning from Themes to Items}

The previous phase achieved its aim of illuminating ways that players experience henosis while they play video games. Specifically, three types of global schema, three categories of appraised meaning, and three forms of disequilibrium reduction were identified by participants in the focus groups. The implications of these themes are discussed fully in the discussion section of this manuscript; however, it is worthwhile to briefly contextualize these findings in the extant literature here in order to A) help illuminate how this structure can be transformed into a measurement tool, and B) highlight how henosis is positioned as distinct construct against other seemingly similar meaningful media experiences which can be useful for validation purposes.

One trend that emerged for both global schema and appraised meaning was that there is a distinction between experiences people had in video games relative to themselves, and experiences relative to others and/or the world. Interestingly, this lines up quite well with the notion that meaningful media experiences exist on a continuum of self-focused to self-transcendent emotions (Oliver et al., 2018). While it has been suggested that much of the extant work on meaningful media experiences has examined self-focused experiences, these results imply henosis can be used for experiences that fall into both categories. Therefore, it was essential to try and capture this with item development (as is outlined below).

However, one side effect of the broad applicability of the henosis construct is that it now runs the risk of overlapping with a number of other already-specified meaningful 
media experiences, such as appreciation (Oliver \& Raney, 2011), nostalgia (Sedikides, 2015), and intrinsic need satisfaction (Rigby \& Ryan, 2017). The purpose of this manuscript is to add clarity to meaningful media research by specifying a distinct mechanism that can be measured, not to muddy the waters with yet another construct, so before moving into the development of items it is important to delineate how henosis remains its own distinct construct, and how other measures of meaningful media experiences can be used to validate the henosis measure.

Firstly, as mentioned above, perhaps the most broadly applicable term used to describe meaningful media experiences is appreciation. Appreciation is often measured with three items simply asking participants to indicate how meaningful they thought a particular piece of media was. For the purposes of this scale development project then, appreciation can serve as a useful way to measure convergent validity. Indeed, the fact that so many types of experiences are often labeled meaningful media experiences might suggest that any of them might serve as convergent validity measures.

Another similar experience is that of nostalgia. According to Sedikides (2015), nostalgia consists of several components, including self-oriented functions and sociality functions, which, again, map well onto the categories of henotic experiences identified in the phase 1 results. These authors also describe how nostalgia can be a source of meaning in life, which is also conceptually connected to henosis. One way that nostalgia can be elicited is by external experiences that remind people of pleasant and meaningful experiences from the past (Sedikides et al., 2015), and this has been shown to be a motivating reason why some video games are played (Wulf, Bowman, Rieger, Velez, \& Breuer, 2018). Given that henotic experiences tap into the very foundational assumptions 
people have about their world, it seems likely that reflecting back on these experiences should result in nostalgia, which makes this good measure of predictive validity.

All this said, it is equally important to understand what these results are suggesting about what henosis is not. Hence, an argument is put forth here that henosis represents a distinct, and theoretically unrelated mechanism to that of another meaningful media experience: intrinsic need satisfaction. According to self-determination theory, humans are driven to satisfy three basic psychological needs: autonomy, competence, and relatedness (Deci \& Ryan, 2000) and the satisfaction of these needs are known to drive video game play (Ryan, Rigby, \& Przybylski, 2006) and to be connected to meaningful media experiences (Rigby \& Ryan, 2017). Intrinsic needs are definitionally characteristics of an individual, and the satisfaction of them is a self-focused endeavor. Hence, an argument can be made that those henotic experiences identified by participants in phase 1 which focused on external schema violations (e.g., others, the world), are certainly qualitatively different experiences than the need satisfaction experiences described by self-determination theory. However, this does not say anything about the self-focused henotic experiences, and on their face, it is tempting to think that need satisfaction and henotic experiences related to a self-schema violation are quite similar, or at least likely to be related. Here, it becomes useful to re-examine the mechanisms that underlie each of these experiences.

Both henosis and intrinsic need satisfaction arise from psychological drives to resolve an undesired stimulus. In the former, a person encounters a situation via media which violates the basic assumptions that person has about the world, and is driven to resolve it either through reappraising it using existing mental structures, changing the 
mental structures themselves, or (as phase 1 results suggest) taking active measures to alter the situation such that it aligns with expectations. The drive to satisfy an intrinsic need can similarly arise from a mediated stimulus which highlights that such a need is not being met, or which presents a means by which a need can be met (Ryan et al., 2006). However, a critical difference between the two experiences is that a person's global schema for the world or themselves need not include a version of themselves in which needs are satisfied. Global schema might in fact be comprised of expectations that needs are not satisfied; that is, people could characterize the world as one in which undesirably low levels of autonomy, competence, or relatedness is normality. For example, people vary on how much autonomy they feel they have in work settings (e.g., Grandey, Dickter, \& Sin, 2004), and it stands to reason that over time this could develop into a schemaderived expectation to have low autonomy. In this scenario, need satisfaction would actually be the schema violation and catalyst of a henotic response, and henosis might even theoretically result in a loss of that need satisfaction if the violation is reappraised to be in line with an expectation that one does not experience of autonomy. As another example, a person may have a self schema that they are not particularly good at certain activities (low competence). For such a person, performing unexpectedly good at an activity would be a schema violation, and henosis is not guaranteed to ultimately result in a maintaining of this competence satisfaction.

As these examples illustrate, need satisfaction is not necessarily the result of restoring disequilibrium between global schema and appraised meaning (though it could happen). A counterpoint here can further illustrate this point. The fact that people play video games in order to satisfy intrinsic needs (Ryan et al., 2006) indicates that players 
expect to satisfy needs when playing video games. In other words, the satisfaction of intrinsic needs when playing video games may be the schema-derived expectation. Hence, need satisfaction can occur without henosis happening. Taken together, intrinsic need satisfaction can occur without henosis, and henosis can occur without intrinsic need satisfaction. Furthermore, henosis is not necessarily going to satisfy intrinsic needs even when the schema violation is one in which a person's expectations related to their own autonomy, competence, and relatedness are violated. For example, games can deprive players of agency deliberately to limit their autonomy and competence, such as the game Blind Trust (Good Vibrations Games, 2016), which simulates experiences of blindness and deafness in players. Such games can violate a player's expectation of autonomy and competence, but henosis, rather than restoring these need satisfactions, could instead take the form of a schema adjustment such that the player now understands the perspectives of others differently. Altogether, then, henosis, represents quite a different experience than intrinsic need satisfaction. Hence, it represents a good discriminant validity measure.

With the current results positioned within existing theory, and theoretical arguments put forth regarding how other measures can serve as convergent, predictive, and discriminant validity checks on henosis, the next step is to develop a measure to capture henosis experiences using the results from phase 1.

\section{Method}

\section{Item Pool Development: Overview}

According to Morgan (1997) there are three ways that focus group data can be used to develop items for quantitative surveys: “(a) by capturing all the domains that need to be measured in the survey, (b) by determining the dimensions that make up each of 
these domains, and (c) by providing item wordings that effectively convey the researcher's intent to the survey respondent,” (p. 26). The domain that was intended to be measured in this survey is henosis—specifically, recollection of resolving discrepancies between their appraised experience and their global schema, whether that was through reappraisal, schema adjustment, or active attempts to alter the situation to align with expectations/ideals. Further, the qualitative data from the focus groups yielded language players use to describe various henotic game experiences in their own words. Using the language patterns and themes revealed in the qualitative data, items were crafted to tap into participants experiences of henosis.

This scale was designed to capture the henosis experience. From the results listed above, each of the two components of henosis yielded three broad themes. Global schemas mentioned by participants broadly grouped into idealized world, normalized/expected world, and game schema. Appraised meaning grouped into observations of the self, others, and the world. Henosis itself grouped into reappraisal, schema adjustment, and active attempts to adjust experience, as well as no adjustment made and no adjustment mentioned. Since the latter two are literally describing the absence of the phenomenon of interest, these were not used in crafting the henosis measurement tool.

Of the three components (global schema, appraised meaning, henosis), the henosis component is the most directly relevant to constructing the measurement tool. However, given the various referents around which henotic experiences were discussed (the themes identified as global schema and as appraised meaning), it could be expected that henosis might subdivide with relation to which global schema is being adjusted (or 
reappraised to), or subdivided based on the appraised meaning which generates the disequilibrium reduction process. Furthermore, the patterns described by participants often involved more than one schema or appraised meaning. For example, a person might adjust their self schema to align more with an already-existing ideal-self schema (e.g., I've always wanted to be a leader, and the game allowed me to embody that and now I feel like my real self is more of a leader). A person might adjust their worldview to align with a game-specific schema (e.g., the game built up expectations that people will act selfishly, and this impacted how I feel about people in the real world). Alternatively, a person might reappraise an unexpected event using alternative schema-derived expectations (e.g., I don’t typically expect people to get murdered, but when I saw those people get murdered in the game I reasoned that this is just what happens in games so it's not unusual). This is not to suggest that all schema adjustments or reappraisals are made using alternate existing schema - just some of them. Hence, to holistically capture henosis, the measurement tool needed to be able to capture this rather large range of experiences, or else reduce the focus to specific kinds of henosis. Ultimately, the former was chosen since, as a new construct, it is unknown which, if any, theorized aspects of henosis will turn out to be more important and which might turn out to be less important. Including the full range of possible henosis iterations based on the combinations of global and appraised meaning themes was chosen in order to cover as many iterations as possible. To this end, items were constructed in the following manner.

The actual process of disequilibrium reduction (specifically, recollections of this process) is what will ultimately be assessed by the proposed measurement. Items assessing each of the three henotic processes (schema adjustment, reappraisal, restorative 
action) were constructed separately, but in parallel fashion. First, for each process, there are three possible global schemas that could be violated: normality, ideals, and games. Pulling from the meaning making model (Park, 2010), global schemas are what triggers the search for meaning (seeking to reduce the disequilibrium), these were used as broad categories in which items would be constructed. For each of these global schema categories (normality, ideals, games), there are three possible topics of focus based on the three categories of appraised meaning (self, others, world). For instance, an experience could violate a person's normality schema for their selves, or for others, or for the world. Furthermore, as mentioned above, these violations can result in adjustments or reappraisals in different directions. For example, a normality schema for self could be adjusted towards an ideal schema, or towards a game schema, or just towards the experience itself. Thus, we are left with a matrix of three types of global schema violations, for which there are three possible categories of meaning, and for each of these categories there are three possible adjustments. This leads to twenty-seven possible forms of henosis. For each of these types of henosis, one item was created.

An example may help illustrate. A person could experience a schema adjustment after a game event violates their normality schema for the world, and this adjustment could be towards what that person's ideal world schema looks like. For this combination, one item would be constructed. Intuitively this might lead to an item like, "When the game violated my expectations for what the world is like, it made me see the world as more like my ideal world.” However, there are several problems with this. One issue is that the question is double barreled — that is, it is actually asking if the participant has had an experience like that, and whether they responded to it in a certain way. Agreement 
with this statement or disagreement could be with either parts of this question. Another issue is that the language branches from the theoretical background thus far laid out in this manuscript, but it is unlikely to be easily understood by average gamers. Hence, items had to be retooled to avoid these problems. After some deliberation, it was decided that since the actual adjustment is what constitutes henosis, the items for schema adjustment should focus on this process. Furthermore, the qualitative data was scoured for any instances in which this particular combination was discussed by experience in order to see if any language could be borrowed from participant talk. Ultimately, this led to the question "I began to feel like the world is a good place.” This item manages to capture the actual adjustment towards an ideal, as "began” implies this is something that happened because of gameplay, "good place” is open to interpretation and thus represents whatever that participant's notions of an good place (an ideal world) are, and saying that the world is a good place implicitly indicates that it was the normal world schema that was adjusted. In this manner items were constructed for all possible combinations. This is detailed below for each type of disequilibrium adjustment.

Item development: schema adjustment. The basic idea of a schema adjustment is that a person has a set of expectations about the world, and something happens that causes a person to alter this set of understandings and expectations. Since three global schemas were identified, there should be three types of schema adjustments: adjustments to ideal schema, adjustments to normality schemas, and adjustments to game schema. However, adding in the further complication that schemas seem to be adjusted in relation to other schema, this yields now nine possibilities of schema adjustment just looking at these three global schema. For example, a normality schema could be adjusted without 
reference to any other schema, or it could be adjusted to align with an ideal schema, or it could be adjusted to align with a game schema. The other two schema (ideals, game schema) could similarly be adjusted in general (as a response to a game event) or in the direction of the other two global schema categories. This yields nine categories of potential adjustments.

Table 4

Schema Adjustment Item Construction

\begin{tabular}{|c|c|c|}
\hline Adjustment of... & Meaning category & Toward \\
\hline \multirow[t]{3}{*}{ Normality schema } & Self & $\begin{array}{l}\text { Self evidenced in event (nonspecific) } \\
\text { Ideal Self } \\
\text { Perceived game version of self }\end{array}$ \\
\hline & Others & $\begin{array}{l}\text { Others evidenced in event (nonspecific) } \\
\text { Ideal version of others } \\
\text { Others are represented in game }\end{array}$ \\
\hline & World & $\begin{array}{l}\text { World as represented in event (nonspecific) } \\
\text { Ideal world } \\
\text { Game world }\end{array}$ \\
\hline \multirow[t]{3}{*}{ Ideal schema } & Self & $\begin{array}{l}\text { Self evidenced in event (nonspecific) } \\
\text { Normal self } \\
\text { Perceived game version of self }\end{array}$ \\
\hline & Others & $\begin{array}{l}\text { Others evidenced in event (nonspecific) } \\
\text { Normal others } \\
\text { Others are represented in game }\end{array}$ \\
\hline & World & $\begin{array}{l}\text { World as represented in event (nonspecific) } \\
\text { Normal world } \\
\text { Game world }\end{array}$ \\
\hline \multirow[t]{3}{*}{ Game schema } & Self & $\begin{array}{l}\text { Self evidenced in event (nonspecific) } \\
\text { Ideal self } \\
\text { Normal self }\end{array}$ \\
\hline & Others & $\begin{array}{l}\text { Ideal version of others } \\
\text { Normal others } \\
\text { Others evidenced in event (nonspecific) }\end{array}$ \\
\hline & World & $\begin{array}{l}\text { World as represented in event (nonspecific) } \\
\text { Normal world } \\
\text { Ideal world }\end{array}$ \\
\hline
\end{tabular}

In order to actually craft items for each of these categories, the three themes from appraised meaning were used, with one item for each category of appraised meaning 
(self, other, world). For a schema adjustment of normality toward an ideal, for example, there would be an item about how a schema for one’s normal self was adjusted to align with the game self, an item for a schema for one’s ideas about normal others was adjusted to align with how others are in the game, and an item for when a schema for one's ideas about the normal world was adjusted to align with how the world was in the game. In addition, there would also be an item for when a normal self schema is adjusted to align with an ideal self, normal others to ideal others, and normal world to ideal world. Finally, three items would talk about an adjustment in relation to the game events but not in relation to any other schema (schema for normal self, normal others, and normal world are adjusted). The researcher attempted to find language in the dataset which reflected each combination of global schema, appraised meaning, and disequilibrium reduction, and where possible, utilize these language patterns to phrase each item as appropriate. Items were crafted in this manner for schema adjustments for idealized world and game schema as well, resulting in 27 total items for schema adjustment (see Table 4).

Item development: appraised meaning adjustment. Reappraisals involve adjusting one's interpretation of appraised meaning such that it aligns with existing schema. Again, there are three types of global schema which can be initially violated meriting this reappraisal. Further, there are also three options for how each schema violation might be reappraised in relation to other schema. For example, a violation of a normality schema could be reappraised as understandable when viewed through a game schema, or an ideal schema. Furthermore, a normality schema violation might just be reappraised by simply reinterpreting it to be in line with the initial schema (e.g., actually it is normal that this happened when I think about it in a different way). Hence, a 
violation of each global schema can be reappraised in at least three different ways. Once again, in order to craft specific items querying whether reappraisal has occurred, the appraised meaning categories were used (self, others, world).

Table 5

Reappraisal Item Construction

\begin{tabular}{|c|c|c|}
\hline $\begin{array}{l}\text { Reappraisal of } \\
\text { violation of... }\end{array}$ & Meaning category & To align with... \\
\hline \multirow[t]{9}{*}{ Normality schema } & Self & Normal self \\
\hline & & Ideal Self \\
\hline & & Perceived game version of self \\
\hline & Others & Normal others \\
\hline & & Ideal version of others \\
\hline & & Others as represented in game \\
\hline & World & Normal world \\
\hline & & Ideal world \\
\hline & & Game world \\
\hline \multirow[t]{9}{*}{ Ideal schema } & Self & Ideal self \\
\hline & & Normal self \\
\hline & & Perceived game version of self \\
\hline & Others & Ideal version of others \\
\hline & & Normal others \\
\hline & & Others as represented in game \\
\hline & World & Ideal world \\
\hline & & Normal world \\
\hline & & Game world \\
\hline \multirow[t]{9}{*}{ Game schema } & Self & Perceived game version of self \\
\hline & & Ideal self \\
\hline & & Normal self \\
\hline & Others & Ideal version of others \\
\hline & & Normal others \\
\hline & & Others as represented in game \\
\hline & World & Game world \\
\hline & & Normal world \\
\hline & & Ideal world \\
\hline
\end{tabular}

To walk through an example of a game schema violation being reappraised using a normality schema, there would be an item for A) a violation of a what a game self is expected to be is reappraised as normal using a normal self schema, B) a violation of how 
others are expected to act in video games is reappraised as how people normally behave outside the game, and C) a violation of what game worlds are normally like is reappraised as aligned with how the normal world is like. Once again, 27 items were crafted using this method (see Table 5).

Item development: restorative action. Finally, for restorative action, this idea was mentioned a relatively few number of times and no one mentioned multiple schemas in such instances. If any actions were taken as a result of a schema violation, these actions were aimed at restoring the situation to align with that schema; never with a different schema. Therefore, there were 9 items for this category of henosis: three items for attempts to align experience with ideal self, others, or world; three items to align experience with normal self, others, or world; and three items to align with game schema self, others, and world (see Table 6).

Table 6

Restorative Action Item Construction

\begin{tabular}{ll}
\hline Actions to restore... & Meaning category \\
\hline Normality schema & Self \\
& Others \\
& World \\
\cline { 2 - 2 } Ideal schema & Self \\
& Others \\
Game schema & World \\
\cline { 2 - 2 } & Self \\
& Others \\
& World \\
\hline
\end{tabular}


Table 7

Complete Item Pool

\begin{tabular}{|c|c|c|c|c|}
\hline Henosis & $\begin{array}{l}\text { Global } \\
\text { schema }\end{array}$ & $\begin{array}{l}\text { App. } \\
\text { Mean }\end{array}$ & $\begin{array}{l}\text { Align } \\
\text { w/ }\end{array}$ & Item \\
\hline \multirow{22}{*}{$\begin{array}{l}\text { Schema } \\
\text { adj. }\end{array}$} & \multirow[t]{8}{*}{ Norm. } & \multirow[t]{2}{*}{ Self } & Norm & The way I see myself in everyday life had an impact on how I saw myself in the game. \\
\hline & & & $\begin{array}{l}\text { Ideal } \\
\text { Game }\end{array}$ & I changed how I see myself to be more like the person I've always wanted to be. \\
\hline & & \multirow[t]{3}{*}{ Others } & Norm & The way I see others in my everyday life had an impact on how I saw others in the game. \\
\hline & & & Ideal & I gained a better outlook on humanity. \\
\hline & & & Game & I changed the way I see others in the actual world based on how others behaved in the game. \\
\hline & & \multirow[t]{3}{*}{ World } & Norm & The way I see the actual world had an impact on how I see the game world. \\
\hline & & & Ideal & I began to feel like the world is a good place. \\
\hline & & & Game & I began to see the actual world as similar to the game world. \\
\hline & \multirow[t]{9}{*}{ Ideal } & \multirow[t]{3}{*}{ Self } & Ideal & I developed higher aspirations about who I want to be in my everyday life. \\
\hline & & & Norm & I felt like my personal aspirations became more realistic. \\
\hline & & & Game & I changed my ideas of who I want to be based on the character I played as in the game. \\
\hline & & \multirow[t]{3}{*}{ Others } & Ideal & I started to have higher hopes for humanity. \\
\hline & & & Norm & I gained more realistic hopes for what to expect from others. \\
\hline & & & Game & $\begin{array}{l}\text { I changed my ideas about what the best of humanity looks like based on how I saw others } \\
\text { behave in the game. }\end{array}$ \\
\hline & & \multirow[t]{3}{*}{ World } & Ideal & I gained higher hopes for the possibility of an ideal world. \\
\hline & & & Norm & I changed my ideas about an ideal world to be more realistic. \\
\hline & & & Game & I changed my ideas about what an ideal world would be like based on the world in the game. \\
\hline & \multirow[t]{5}{*}{ Game } & \multirow[t]{3}{*}{ Self } & Game & I changed my ideas about what I can be and do in games. \\
\hline & & & Ideal & The game experience raised the bar for what you can be and do in a game. \\
\hline & & & Norm & I changed my expectations for how much I can really be myself in a game. \\
\hline & & \multirow[t]{2}{*}{ Others } & Ideal & The game experience raised the bar for what interacting with others can be like. \\
\hline & & & Norm & Actions of others changed my expectations for just how real interactions in games can feel. \\
\hline
\end{tabular}




\begin{tabular}{|c|c|c|c|c|}
\hline & & World & $\begin{array}{l}\text { Game } \\
\text { Game } \\
\text { Norm } \\
\text { Ideal }\end{array}$ & $\begin{array}{l}\text { I changed my ideas about what others can be and do. } \\
\text { I changed my expectations about games in general. } \\
\text { The game world changed my expectations for how much a game can feel like the actual } \\
\text { world. } \\
\text { The game experience raised the bar for what game worlds can be like. }\end{array}$ \\
\hline \multirow{19}{*}{$\begin{array}{l}\text { Re- } \\
\text { appraisal }\end{array}$} & \multirow[t]{9}{*}{ Norm } & Self & Norm & I got to act like myself in some ways to make up for not being able to in other ways. \\
\hline & & & Ideal & My character began to feel closer to how I wish I was than how I actually am. \\
\hline & & & Game & $\begin{array}{l}\text { I got used to the differences between the character I played in this game compared to who I } \\
\text { am in real life. }\end{array}$ \\
\hline & & Others & Norm & I reflected on what I know about others until their actions made sense. \\
\hline & & & Ideal & Others acted more like I wish people would act than how I expect people to act. \\
\hline & & & Game & $\begin{array}{l}\text { Differences in how others act in the game compared to how people act in real life are just } \\
\text { because games and real life are different. }\end{array}$ \\
\hline & & World & Norm & The game was realistic in some ways to make up for being unrealistic in other ways. \\
\hline & & & Ideal & Unexpected things in the game world represented how I wish the world was. \\
\hline & & & Game & It made sense that the game world was different from the actual world. \\
\hline & \multirow[t]{9}{*}{ Ideal } & Self & Ideal & I saw any setbacks I experienced as opportunities to improve. \\
\hline & & & Norm & $\begin{array}{l}\text { I found it true to reality when the game would prevent me from doing something I thought } \\
\text { should be done. }\end{array}$ \\
\hline & & & Game & I felt I was just playing a video game without any larger moral or social implications. \\
\hline & & Others & Ideal & Even when others behaved in ways I didn't like, I knew they had good reason. \\
\hline & & & Norm & I found it realistic when others acted differently than I thought they should. \\
\hline & & & Game & I saw others' negative behavior as just something that happens in games. \\
\hline & & World & Ideal & $\begin{array}{l}\text { The things I didn't like about the game world were outweighed by the things I did like about } \\
\text { the game world. }\end{array}$ \\
\hline & & & Norm & I found it realistic when the game world wasn't a perfect world. \\
\hline & & & Game & $\begin{array}{l}\text { I saw any differences between the game world and my ideal world as just the way games are } \\
\text { sometimes. }\end{array}$ \\
\hline & ame & Self & & Over time, I didn't see my character as all that different from any other video game character. \\
\hline
\end{tabular}


Ideal I began to like the character I played in this game more than those I've played in other games.

Norm The character I played was more like my actual self than characters in other games I've played.

Others Ideal I prefer how others acted in this game compared to other games I've played.

Norm Others behaved more realistically compared to other games I've played.

Game If others did unexpected things, I figured that it's all just part of the game.

World Game I was eventually able to see how the game was similar to other games.

Norm The game world was more like the actual world than in other games I've played.

Ideal Compared to other games, the game world was like how I wish the actual world would be.

\begin{tabular}{|c|c|c|c|c|}
\hline \multirow{9}{*}{$\begin{array}{l}\text { Restor- } \\
\text { ative } \\
\text { action }\end{array}$} & Norm. & Self & $\mathrm{n} / \mathrm{a}$ & I tried to make my character reflect the person that I am. \\
\hline & & Others & $\mathrm{n} / \mathrm{a}$ & I tried to make others behave as they would in the actual world. \\
\hline & & World & $\mathrm{n} / \mathrm{a}$ & I tried to make the game world reflect the way that I see the actual world. \\
\hline & Ideal & Self & $\mathrm{n} / \mathrm{a}$ & I tried to make my game character like the person I wish I was. \\
\hline & & Others & $\mathrm{n} / \mathrm{a}$ & I tried to get others to act the way I think they should. \\
\hline & & World & $\mathrm{n} / \mathrm{a}$ & I tried to make the game world reflect the way I wish the world actually was. \\
\hline & Game & Self & $\mathrm{n} / \mathrm{a}$ & I tried to make my character reflect what I think video game characters are usually like. \\
\hline & & Others & $\mathrm{n} / \mathrm{a}$ & I tried to make others behave in ways that are appropriate for a video game. \\
\hline & & World & $\mathrm{n} / \mathrm{a}$ & I tried to make the world reflect what I think a video game world is usually like. \\
\hline
\end{tabular}


Final item pool. The complete item pool along with the survey can be found in Table 7 . Table 7 lists out the matrix of disequilibrium reduction strategy, global schema violation, appraised meaning category, and adjustment vector (which global schema the event was reappraised or adjusted to align with), with the item that emerged from each of these combinations. Items that were ultimately retained are in bold.

\section{Participants}

Again, participants needed some existing experience with video games in order to participate in the study, as nongamers were unlikely to be able to provide responses to items querying video game experiences. Also, a limitation of the qualitative data was that it was collected entirely from a small sample of college students from a single campus, and it was desirable to expand the sample beyond this in order to enhance the generalizability of any findings. Hence, all recruitment specified that some gaming experience was required, and participants were recruited from several existing pools of gamers. Some participants were again recruited from the existing student body. Links to the study were provided via emails sent to other professors to share with their class, a mass-email survey invitation sent campus wide every Tuesday, and posting in both online and digital research recruitment bulletin boards.

To diversify the sample, participants were also recruited via social media and MTurk. Regarding social media outlets, the researcher posted a recruitment script on Facebook and requested that the information be shared. A link to the study was included in the post, and the researcher requested in the post the survey 
be shared with anyone who might be interested. Additionally, a recruitment invitation was posted in an online community in which video game enthusiasts congregate, Reddit's r/gamersbeingbros subreddit. All of these participants were offered a chance to win a \$100 Amazon gift card. Finally, participants were recruited from Amazon's MTurk platform, an online work-outsourcing platform in which participants receive small monetary compensation for taking surveys. These participants were unable to be entered into the drawing for the gift card due to privacy restrictions on the platform, and they were instead provided with $\$ .50$ as compensation for taking the survey.

A general rule of thumb is to have at least ten participants per item (Nunnally \& Bernstein, 1994), so this research aimed to recruit at least 630 participants. All told, 297 participants were recruited from MTurk and 735 more participants were recruited from other sources. However, after cleaning the data (described below), only 560 cases remained. Of these participants, 297 selfidentified as male, 250 identified as female, and 13 did not self-identify as male or female (either leaving it blank or indicating some other gender). The majority of participants were Caucasian $(n=403)$, followed by Asian $(n=66)$, black $(n=23)$, and Hispanic ( $n=18$ ), with fewer than 15 participants in the remaining selfidentified ethnicities. American was the most commonly self-identified nationality ( $n=379)$, followed by Indian $(n=49)$, with the remaining 86 participants representing an array of different nationalities.

\section{Survey Procedure}


A survey was administered to participants (see Appendix B) which included all of the newly created items from the previous section. Participants were told to imagine a video game experience that was particularly meaningful to them. They were then asked to identify what game they are thinking of and briefly describe the experience and why it was meaningful. This prompt was intended to prime participants' memories to think about a specific henotic video game experience.

The format of the items in the main item pool was 7-point Likert-type items, with 7 indicating strongly agree and 1 indicating strongly disagree. Evidence shows that scale reliability and validity increase with scale points up to seven (Preston \& Colman, 2000). Care was taken to ensure that the wording of the items did not result in factual statements, or statements that have multiple possible interpretations, or items that contain multiple ideas at once (i.e., double-barreled items), as these items might confuse participants and make results difficult to interpret as it is unknown which of the two parts of the question participants are agreeing or disagreeing with. Once all items were drafted, they were collected into a survey along with validity measures (detailed below). The survey was pretested using subject-matter experts familiar with video games to ensure the items are understandable to the intended participants, after which the survey was administered to participants.

Measures. In addition to the henosis item pool, other items will also be added in order to assess various types of validity in the scale. The specific mechanism outlined here-henosis_-is conceptually similar and likely to be 
correlated with other measures of meaningful media experiences. Thus, existing measures of meaningful media experiences provide a good way to measure the convergent validity of the measurement, since one would expect measures of these effects would correlate with the henosis measure. Hence, existing scales for appreciation (Oliver \& Bartsch, 2010) and inspiration (Thrash \& Elliot, 2003) were used. Appreciation showed good reliability, $\alpha=.812, M=5.27, S D=1.46$, as did inspiration, $\alpha=.942, M=4.61, S D=1.68$. For discriminant validity, selfdetermination need satisfaction was assessed using the Player Experience of Need Satisfaction (PENS) (Ryan et al., 2006). Self-determination theory posits that people seek out the satisfaction of competency, autonomy, and relatedness needs, and this need satisfaction has been linked to both enjoyment (Tamborini, Bowman, Eden, Grizzard, \& Organ, 2010) and meaningfulness (Rigby \& Ryan, 2017) of entertainment media. As outlined above, however, need satisfaction is a distinct process from that outlined by henosis. Specifically, henosis can result in need satisfaction, or it could stymie need satisfaction, or it could be unrelated. One might thus expect that there should not be a noticeable relationship between need satisfaction and henosis. Henosis can thus serve as a good measure of discriminant validity. Reliabilities were good to acceptable for competence satisfaction $(\alpha=.820, M=5.50, S D=1.22)$, autonomy satisfaction $(\alpha=.785, M=$ $5.47, S D=1.27)$, and relatedness satisfaction $(\alpha=.702, M=4.73, S D=1.49)$. Finally, meaningful experiences resultant from henosis, as experiences that involve either reinforcing or altering the very cognitive structures through which people interpret their world, are likely to leave strong and typically positive 
impressions, and thus, per Sedikides (2015) should result in fond memories and nostalgia when looking back on these experiences. Therefore nostalgia (Sedikides et al., 2015) will serve as a predictive validity measurement, $\alpha=.928, M=5.10$, $S D=1.64$. All measures are close-ended measurements that yield numerical scores, which will then be compared to measures of the corresponding dimension of henotic gratifications to see if henotic gratifications do indeed predict, converge with, and discriminate from these constructs as they theoretically should.

\section{Results}

\section{Data Preparation}

Since data was collected from two sources, both datasets had to be downloaded and cleaned before combining them together. The first dataset, which included all participants that came from campus recruitment, social media, and all other sources that were not MTurk, consisted of $n=735$ participants. However, all cases that were less than 74\% complete were purged from the file (74\% indicates that the participant filled out all survey items except for demographic variables). One participant completed $74 \%$ of the survey items, so following this purge, all but this one participant completed either $96 \%$ or $100 \%$ of the survey items (96\% indicates the participant filled out all questions but failed to hit the final submit button at the end of the survey). This left $n=454$ cases.

The Mturk data was contained many automated bots which had to be weeded out from the dataset. When the dataset was downloaded, there were $n=$ 297 cases. For this version of the survey, participants who completed $82 \%$ of the 
survey had completed everything but the demographic section. All participants who had completed less than $82 \%$ of the survey were purged from the dataset. Next, all cases in which the participants named a physical sport as their favorite video game, and whose description of the experience clearly indicated they were discussing the sport and not a video game version of the sport, were purged from the data. Specifically, 33 participants indicated their favorite game was "cricket" and were deleted. Fifteen cases indicated “football” or some iteration thereof (e.g., food ball), eleven of which were either talking about the sport or were simply bots inserting random text found on the web that contains the word football, and thus were deleted. After this, it became clear there was a bot problem, and the researcher scoured every case, checking the descriptions of the meaningful experience to make sure they were not pasted from some other source. Sources found for these plagiarized survey responses included excerpts from Forbes reviews, Quora forums, and even a few academic abstracts from the likes of Mary Beth Oliver, Jaime Banks, and Nicholas Bowman. All such cases were summarily deleted. Ultimately, this left $n=106$ cases were yielded from the Mturk sample. This combined with the other sample to get a total of 560 cases. An additional column was created in order to identify which sample the data came from.

\section{Scale Development: Exploratory Factor Analysis}

Assumptions of sampling adequacy were met (Kaiser-Meyer-Olkin = .976 ; Bartlett's test chi-square $=22810.180, p<.001$.) Hence, the analysis can move forward. 
An exploratory factor analysis was conducted on all 63 items in the item pool. The extraction method used was be principle axis factoring (PAF). Principle axis factoring is preferable to principle components analysis (PCA) because PCA assumes perfect measurement/reliability, which is extremely unlikely in any social science research—particularly in developing a new scale. PAF does not make this assumption, and allows one to analyze common variance while also modeling error-it accounts for the inevitable imperfection in the measurement tool (Morrison, 2009). PCAs are also generally more for weeding out extra items, whereas PAF is more for identifying latent factor structures (Fabrigar, Wegener, MacCallum, \& Strahan, 1999), and is thus more appropriate for a project aimed at identifying an underlying factor structure.

In the PAF, the factors were rotated using oblique rotation. Orthogonal rotation methods such as varimax, quartimax, and equamax rotation all assume that the factors are uncorrelated, but this assumption does not make conceptual sense in this study because one would expect that different dimensions of the same construct are likely to be correlated (Kline, 2013). Hence, oblique rotation will be used, which estimates and allows for factors to be correlatedspecifically, promax rotation, following recommendations of Kline (2013).

In the initial EFA, factors were retained if they have eigenvalues greater than 1 which would indicate that the factor explains more variance than any one item alone (Kaiser, 1960). The first analysis revealed seven factors with eigenvalues greater than 1 . To retain items, the $60-40$ rule was employed-that is, items must load .600 or greater on one factor and .400 or less on all other factors 
in order to be retained for that factor (McCroskey \& Young, 1979). Items that did not meet this criterion were removed as candidate items. In this first pass, 14 items met the criteria and were retained initially. The EFA was repeated with just these items, resulting in three factors with eigenvalues greater than 1. Evaluation of the pattern matrix resulted in dropping three more items. Repeating the process once more yielded a stable two-factor solution consisting of 11 items (7 items on factor 1 , and 4 items on factor 2) and no cross loadings greater than .400 . All items loaded on exclusively one of the factors. Table 8 presents the factor loadings, along with item wordings.

Table 8

Factor Loadings of Henosis Dimensions

\begin{tabular}{|c|c|c|}
\hline Item & $\begin{array}{l}\text { Factor 1: Experience } \\
\text { Adjustment } \\
\alpha=.912, M=3.82 \\
S D=1.57\end{array}$ & $\begin{array}{l}\text { Factor 2: Schema } \\
\text { Adjustment } \\
\alpha=.867, M=3.95, \\
S D=1.55\end{array}$ \\
\hline $\begin{array}{l}\text { I tried to make my } \\
\text { game character like the } \\
\text { person I wish I was. }\end{array}$ & .871 & -.075 \\
\hline $\begin{array}{l}\text { I tried to make the } \\
\text { game world reflect the } \\
\text { way I wish the world } \\
\text { actually was. }\end{array}$ & .639 & .181 \\
\hline $\begin{array}{l}\text { I tried to make my } \\
\text { character reflect the } \\
\text { person that I am. }\end{array}$ & .640 & .117 \\
\hline $\begin{array}{l}\text { I tried to make the } \\
\text { game world reflect the } \\
\text { way that I see the } \\
\text { actual world. }\end{array}$ & .700 & .079 \\
\hline $\begin{array}{l}\text { The character I played } \\
\text { was more like my } \\
\text { actual self than } \\
\text { characters in other } \\
\text { games I've played. }\end{array}$ & .700 & .079 \\
\hline
\end{tabular}


My character began to $\quad \mathbf{. 6 7 6}$

.154

feel closer to how I

wish I was than how I

actually am.

The way I see myself

.683

.088

in everyday life had an

impact on how I saw

myself in the game.

I gained a better

$-.014$

.793

outlook on humanity.

I began to feel like the

.021

.698

world is a good place.

I started to have higher $\quad-.010$

hopes for humanity.

I gained higher hopes

.173

.840

for the possibility of an

ideal world.

\section{Interpreting the Factor Structure of the Henosis Experience (HEX) Scale}

The two factors which emerged from the exploratory factor analysis are interpretable in relation to the theorized henosis framework. Together the scale is referred to as the henosis experience scale, or HEX scale.

Experience adjustment. I interpret the first factor to comprise items detailing experience adjustment. Experience adjustment is defined here as adjusting one's experience through actions or reappraisal in order to align it with an existing schema. In the initial theorizing, the distinction between assimilation and accommodation was made (Park, 2010), wherein assimilation refers to the incorporation of new events into existing mental structures while accommodation refers to the alteration of existing mental structures to account for new events. Assimilation, put another way, is a reinterpretation of an aberrant experience in such a way that it is no longer aberrant. The reappraisal category found in phase 1 lines up well with the notion of assimilation. However, this category includes 
items derived to tap both reappraisal and restorative action experiences. Thus, assimilation does not describe the entirety of this factor. What is common, though, is that both restorative action and reappraisal involve an alteration of incoming information to fit existing schema, rather than an alteration to the schema. The moniker of experience adjustment seems to best capture that notion. Items in this factor have in common a response to disequilibrium that brings about purposive alignment with a player's normality or ideal schema for the self or the world. That is, these items refer to adjusting the appraised meaning of the situation through action or emergent observations. As evidenced in Table 7, the items "I tried to make my game character like the person I wish I was," "I tried to make the game world reflect the way I wish the world actually was," "I tried to make my character reflect the person that I am," and "I tried to make the game world reflect the way that I see the actual world,” are all items intended to tap into restorative action. These items describe instances in which players utilize the interactive affordances of the game to literally change their experience to align with either their ideas about normality or an ideal that they hold. Indeed, these items represented responses to violations of both normal and ideal schemas, and they make reference to both the world and the self domains of appraised meaning. An interesting observation here is that the inclusion of restorative action indicates this factor could not have emerged for items tapping experiences with noninteractive media. While this limits the potential applicability, it does indicate that video games do indeed have ways of experiencing henosis that are unique. 
The items, “The character I played was more like my actual self than characters in other games I've played," "My character began to feel closer to how I wish I was than how I actually am,” were both items designed to tap reappraisal, as they both describe instances in which a player reappraises their experience to align with a schema. The item, “The way I see myself in everyday life had an impact on how I saw myself in the game” was constructed to tap schema adjustment, with the idea that a schema for games was adjusted towards normality, but in retrospect the item can also be interpreted to indicate that an unexpected event in the game was reinterpreted to align with normality.

Hence, all of these items involve reverting incoming information back to an existing mental structure rather than altering any mental structures. While there were many items that were dropped during the factor analysis, the emergence of this experience adjustment factor lines up fairly well with the qualitative content in which many people indicated that they engaged in activities designed to avoid unpleasant experiences. Furthermore, with the explained exception of the one schema adjustment item, these items fall somewhat into the factor structure implicated by the way matrix used to construct the items. That is, the items were constructed under three broad categories, and experience adjustment combines two of them without cross-loading with the other anticipated factor of schema adjustment. Notably, this factor does fail to pull in items designed to tap reappraisal following an ideal schema violation. However, it may be the case that the interactive nature of games makes players particularly apt to try and actively change the game to represent an ideal, more so than simply reappraising it after 
the fact. Regardless, the experience adjustment factor represents a clear pattern of altering one’s experience, through action or interpretation, rather than altering one’s global schema.

Schema adjustment. Contrary to the experience adjustment factor, I interpret the second factor to encompass the experience of schema adjustment. Schema adjustment refers to gameplay experiences in which players alter their schema to reduce the disequilibrium emerging from a schema-violating experience, rather than altering the appraised meaning of an event so that it aligns with an existing schema. Items in this factor include "I gained a better outlook on humanity," "I began to feel like the world is a good place," "I started to have higher hopes for humanity," and "I gained higher hopes for the possibility of an ideal world.” Each of these items, per Table 7, were intended to measure schema adjustment, and aligns well with the notion of accommodation outlined above (Park, 2010). Interestingly, all of these items refer to schema adjustments whereby cognitive frameworks for humanity and the world are shifted toward an ideal. The first two items query experiences in which a person's normality schema is adjusted towards an ideal, and the second two factors involve an adjustment of an ideal schema itself. Though perhaps not representative of the full range of experiences uncovered in phase 1 , there is nevertheless a strong thematic connection between these items in that they all have to do with altering one's schema relative to ideals.

Furthermore, in terms of the appraised meaning categories, all of these items were designed to tap into either humanity or the world; none have to do 
with a normal or an ideal self. This aligns well with the schema adjustment category for which the item was derived, though it seems more specific than anticipated since it only taps items related to ideals. Put simply, this factor consists of items that query both higher expectations and higher hopes for humanity and the world—which, as will be discussed below, is quite reminiscent of the self-transcendent emotions described by Oliver and colleagues (2018).

\section{Initial Validations}

The two HEX factors both empirically and conceptually represent different henotic processes, but they are correlated $(r=.714, p<.001)$. In establishing scale validity, then, multivariate analyses will be run to account for shared variance among the two HEX factors.

Convergent validity. This research made general predictions about how the henosis factor structure would look. The structure did not emerge exactly as predicted, but the two factors that emerged do line up with the original predictions somewhat in that A) there was indeed a schema adjustment dimension, and B) the other dimension seems to be an amalgam of the other two henotic processes predicted. There was not an issue of items intended to measure different henotic processes loading onto a common factor. Therefore, the general predictions regarding how henotic processes will be related to the validation measures remain in place.

First, to establish convergent validity, the construct being validated should be correlated with constructs that they are conceptually similar to. In this case, the two HEX factors should be correlated with appreciation. Appreciation as 
measured asks participants to answer three items indicating how meaningful and thought-provoking their experiences were. Both henotic processes identified, schema adjustment and experience adjustment, are theorized as mechanisms by which people experience meaningfulness, and therefore both should be related to appreciation. Initial tests demonstrated that both experience adjustment and schema adjustment were correlated with appreciation (experience adjustment: $r=$ $.445, p<.001$; schema adjustment, $r=.422, p<.001$. These zero-order correlations of both experience adjustment and schema adjustment with appreciation provide some evidence of convergent validity.

However, since the two HEX factors were highly correlated with one another, the unique contribution of each to appreciation was also tested. Both experience adjustment and schema adjustment were entered into a regression analysis with appreciation as the dependent variable. To address the potential for multicollinearity, tolerance was calculated at .490 and the variance inflation factor was 2.04, which indicate that multicollinearity was not a problem. A DurbinWatson test was also conducted, and the returned value of 1.90 indicates that independence of error terms can indeed be assumed. The overall regression was significant, $F(2,557)=78.56, p<.001, R^{2}=.220$. Results indicated that both experience adjustment $\left(B=.271, S E=.049, r_{\text {partial }}=.205, p<.001\right)$ and schema adjustment $\left(B=.200, S E=.050, r_{\text {partial }}=.149, p<.001\right)$ were significant predictors of appreciation. Hence, there is evidence here of convergent validity, since both would be expected to be related to the experiences of meaningfulness that comprise appreciation. 
To further establish convergent validity, both experience adjustment and schema adjustment were examined in relation to another experience that conceptually should be very much related: inspiration. Thrash and Elliot (2003) point out that inspiration has several commonalities: it motivates people, it is evoked by an outside stimulus, and it involves transcending ordinary occupations. Henosis in turn involves a global schema violation which similarly motivates people to action either literally or cognitively. It is similarly caused by outside stimuli, and the fact that it is a reaction to a schema violation means that it definitionally falls outside of normal preoccupations (which would be schemaconsistent). Inspiration is also another means by which people experience a sense of meaningfulness in media (Janicke \& Oliver, 2017). Inspiration thus has sizable conceptual overlap with henotic experiences and should be expected to have a strong association with the two HEX factors. Two simple bivariate correlation analyses do show that both factors correlate with inspiration, experience adjustment: $r=.537, p<.001$; schema adjustment: $r=.596, p<.001$. These correlations are even larger than those for appreciation, providing some additional evidence of convergent validity, though again, since the factors were correlated with one another the unique shared variance of each was also investigated. To test the unique contribution of each factor to inspiration, a linear regression was run with experience adjustment and schema adjustment entered as independent variables and inspiration as the dependent variable. The Durbin-Watson test value was 2.07, indicating independence of error terms could be assumed, and the variance inflation factor of 2.04 and tolerance of .491 again indicated 
multicollinearity was not a problem (a slight change here due to a loss of 2 degrees of freedom from two participants who did not complete this measure in its entirety). The overall regression was significant, $F(2,555)=170.78, p<.001$, $R^{2}=.381$. Once again, both experience adjustment $\left(B=.243, S E=.051, r_{\text {partial }}=\right.$ $.159, p<.001)$ and schema adjustment $\left(B=.471, S E=.052, r_{\text {partial }}=.304, p<\right.$ .001) were significant positive predictors of inspiration. Once again, these results provide additional support for convergent validity, as inspiration, another construct that is theorized to a be a process by which people can alter their perceptions towards an ideal, shares some conceptual commonality with both experience adjustment and schema adjustment.

Discriminant validity. Henosis is conceptualized here as only one of several mechanisms by which gamers may experience meaningfulness, via either experience adjustment or schema adjustment. Among the most commonly referenced meaningfulness mechanisms is the satisfaction of intrinsic needs specified by self-determination theory (Rigby \& Ryan, 2017). As previously discussed, intrinsic need satisfaction is a seemingly similar construct which should ultimately demonstrate little relationship to henosis. Hence, intrinsic need satisfaction offers an opportunity to investigate discriminant validity, as this is a different mechanism from henosis and the scale should be able to demonstrate that it is not measuring intrinsic need satisfaction.

Table 9 shows the correlations for both HEX factors, as well as appreciation, inspiration, and the three intrinsic need satisfaction dimensions of competence, autonomy, and relatedness. 
Table 9

HEX Factor Correlations

\begin{tabular}{llllllllll}
\hline & $\mathrm{M}$ & $\mathrm{SD}$ & 1 & 2 & 3 & 4 & 5 & 6 & 7 \\
\hline $\begin{array}{l}\text { 1. Experience } \\
\text { adjustment }\end{array}$ & 3.82 & 1.57 & & & & & & & \\
$\begin{array}{l}\text { 2. Schema } \\
\quad \text { adjustment }\end{array}$ & 3.95 & 1.55 & .714 & & & & & & \\
3. Appreciation & 5.27 & 1.46 & .445 & .422 & & & & & \\
4. Inspiration & 4.61 & 1.68 & .537 & .596 & .587 & & & & \\
5. Competence & 5.50 & 1.22 & .230 & .257 & .435 & .368 & & & \\
6. Autonomy & 5.47 & 1.27 & .337 & .269 & .493 & .381 & .596 & & \\
7. Relatedness & 4.73 & 1.49 & .238 & .300 & .296 & .272 & .317 & .295 & \\
8. Nostalgia & 5.10 & 1.64 & .164 & .220 & .109 & .195 & .276 & .234 & .189 \\
\hline All correlions & & & & & & & & \\
\hline
\end{tabular}

All correlations significant at the $p<.001$ level

The experience adjustment factor was positively correlated with all three measures, autonomy: $r=.337, p<.000$; competence: $r=.230, p<.001$; relatedness: $r=.238, p<.001$. Schema adjustment was also positively correlated with all three intrinsic need satisfaction measures, autonomy: $r=.269, p<.000$; competence: $r=.257, p<.000$; relatedness: $r=.300, p<.001$. These correlations, though statistically significant, are rather small, but this information alone does not provide sufficient evidence that intrinsic need satisfactions are distinct constructs from HEX factors. Experience adjustment and schema adjustment share less variance with intrinsic need satisfaction than they do with appreciation or inspiration, but again, this is not sufficient to establish discriminant validity. A look into the unique relationships of each factor to need satisfaction together presents a clearer picture. To examine the unique relationships of each factor to each need satisfaction variable, three regressions were calculated with the two HEX factors as independent variables and each need satisfaction dimension as the 
dependent variable. No participants were lost for any of these three measures, so the VIF remained at 2.04 and tolerance at .490 .

For autonomy, the Durbin-Watson test returned the value of 1.95, indicating independence of errors could be assumed. The overall regression was significant, $F(2,557)=36.22, p<.001, R^{2}=.115$. However, only experience adjustment achieved statistical significance, $B=.238, S E=.046, r_{\text {partial }}=.206, p<$ .001. Schema adjustment was not significantly associated with autonomy satisfaction, $B=.048, S E=.047, r_{\text {partial }}=.041, p=.304$. The lack of a significant correlation between schema adjustment and autonomy satisfaction provides a strong case for discriminant validity. However, experience adjustment's partial correlation with autonomy indicates that discriminant validity cannot be established for experience adjustment from autonomy satisfaction based on this data. However, reviewing the items in this factor, this might actually provide some unexpected evidence of construct validity, as will be elaborated on in the discussion.

For competence, the Durbin-Watson test returned the value of 1.80, indicating independence of errors could be assumed. The overall regression was significant, $F(2,557)=21.10, p<.001, R^{2}=.070$. However, this time only schema adjustment achieved statistical significance, $B=.149, S E=.046, r_{\text {partial }}=$ $.132, p=.001$. Experience adjustment did not attain statistical significance, $B=$ $.074, S E=.045, r_{\text {partial }}=.067, p=.102$. In this case, the lack of relationship between experience adjustment and competence satisfaction provides good evidence of discriminant validity — the two variables are indeed separate. 
However, schema adjustment's discriminant validity is less clear, as the partial correlation between schema adjustment and the competence satisfaction suggests some commonality with competence satisfaction. Thus, there is not evidence for discriminant validity here. Again, while surprising, these findings actually have some unexpected implications to be elaborated on in the discussion.

Finally looking at relatedness, the Durbin-Watson test returned the value of 2.06, indicating independence of errors could be assumed. The overall regression was significant, $F(2,557)=27.94, p<.001, R^{2}=.091$. Once again, schema adjustment achieved significant association with the SDT dimension, $B=$ $.255, S E=.055, r_{\text {partial }}=.186, p<.001$, while experience adjustment did not, $B=$ $.046, S E=.055, r_{\text {partial }}=.034, p=.399$. Again, this is good evidence for discriminant validity for experience adjustment, as it is uncorrelated with relatedness satisfaction. Schema adjustment, on the other hand, is correlated, and stronger than it was for competence satisfaction, or even appreciation. Hence, discriminant validity cannot be established for schema adjustment and relatedness satisfaction.

Predictive validity. To establish predictive validity, henosis should be able to predict nostalgia: that is, if henosis has indeed transpired and players are reflecting (as directed by the survey instrument) on that disequilibrium adjustment ostensibly resulting in meaningfulness, it could be expected that they would feel nostalgia for that experience, as recalled in that moment of taking the survey. In other words, a person who has either engaged in positive schema adjustment (an experience that is likely to have long-lasting impact and be remembered 
positively) or experience adjustment (in which a person is adjusted the meaning of a game to fit into an existing schema and experienced meaningfulness as a result) upon reflecting should feel many of the positive feelings that come with remembering meaningful experiences which characterize nostalgia (Sedikides et al., 2015). A regression analysis was run with nostalgia as the dependent variable and both HEX factors as predictors. Degrees of freedom remained the same so multicollinearity was unaffected, and the Durbin-Watson test indicated a value of 1.98. The overall model was significant, $F(2,557)=11.88, p<.001, R^{2}=.041$. However, only schema adjustment predicted nostalgia, $B=.179, S E=.063, r_{\text {partial }}$ $=.119, p=.004$. Experience adjustment was not a significant predictor, $B=.045$, $S E=.62, r_{\text {partial }}=.030 p=.474$. Hence, there is evidence for the value of predicting nostalgia via schema adjustment, but not via experience adjustment.

\section{Further validations}

Based on the results seen in Table 9, it seems clear that many validation measures are intercorrelated with one another. Since these validations are all intercorrelated, it makes sense to enter them all into a regression equation with the validation items predicting each of the HEX factors. First, this was conducted with experience adjustment as the predicted variable. Results indicated a significant overall regression, $F(6,551)=45.45, p<.001, R^{2}=.575$. Coefficients can be found in Table 10 .

As evidenced in Table 10, experience adjustment was significantly predicted by appreciation, inspiration, competence, and autonomy, but not by relatedness or nostalgia. Furthermore, inspiration was the largest predictor of 
experience adjustment. Notably, unlike the previous tests, this model did not provide evidence for discriminant validity between competence and experience adjustment.

Table 10

Experience adjustment validations

\begin{tabular}{lllll}
\hline $\begin{array}{l}\text { Validation } \\
\text { measure }\end{array}$ & $\boldsymbol{B}$ & $\boldsymbol{S E}$ & $\boldsymbol{t}$ & $\boldsymbol{p}$ \\
\hline $\begin{array}{l}\text { Appreciation } \\
\text { Inspiration }\end{array}$ & .163 & .051 & 3.195 & .001 \\
Competence & -.125 & .041 & 9.163 & $<.001$ \\
Autonomy & .174 & .059 & -2.139 & .033 \\
Relatedness & .065 & .057 & 3.041 & .002 \\
Nostalgia & .048 & .040 & 1.636 & .103 \\
\hline
\end{tabular}

This procedure was repeated for schema adjustment. The overall regression was significant, $F(6,551)=57.07, p<.001, R^{2}=.619$. A substantial portion of the variance was accounted for by the predictor variables. Coefficients for individual predictors can be found in Table 11.

Table 11

Schema adjustment validations

\begin{tabular}{lllll}
\hline $\begin{array}{l}\text { Validation } \\
\text { measure }\end{array}$ & $\boldsymbol{B}$ & $\boldsymbol{S E}$ & $\boldsymbol{t}$ & $\boldsymbol{p}$ \\
\hline Appreciation & .098 & .048 & 2.028 & .043 \\
Inspiration & .467 & .039 & 11.948 & $<.001$ \\
Competence & -.030 & .055 & -.543 & .588 \\
Autonomy & -.011 & .054 & -.200 & .842 \\
Relatedness & .133 & .038 & 3.515 & $<.001$ \\
Nostalgia & .068 & .034 & 2.022 & .044 \\
\hline
\end{tabular}

As these results indicate, appreciation, inspiration, relatedness, and nostalgia were related to schema adjustment, but competence and autonomy were not. Hence, of the three intrinsic need satisfaction variables, autonomy and 
competence were related to experience adjustment but not schema adjustment, and relatedness was just the opposite. Notably, this is a slight change from the previous analyses which utilized separate models for each validity measurenamely, there is now evidence that competence and schema adjustment discriminate from one another, whereas these two variables were shown in the other models to be related. Once again, by far the largest predictor of schema adjustment was inspiration. 


\section{CHAPTER 4}

\section{DISCUSSION}

This project set out to explore the possibility of a novel mechanism of meaningful video game experiences - henosis, defined as the process of reducing disequilibrium between global schema and appraised meaning. Through a series of focus groups, henosis has been established as a phenomenon that indeed underscores some meaningful gaming experiences. From this a scale (the HEX scale) was constructed and the factor structure examined, revealing two distinct HEX factors: experience adjustment and schema adjustment. This research has implications for entertainment theory, video game research, and psychological research on meaning-making. These implications will be discussed forthwith.

\section{Phase 1: Exploration of Henosis Among Gamers’ Meaningful Experiences}

Altogether, the thematic analysis of players' discussion of meaningful experiences suggests that henosis does indeed exist and accounts for a portion of the meaningful video game experiences players described. Hence, research aim 1, which was to investigate whether henosis exists, has been achieved. Ample evidence has been presented to suggest that for some players, there have indeed been times in which their global schema have not lined up with the appraised meaning of a game experience, and in some (though not all) of these cases, participants have engaged in some kind of strategy to reduce the disequilibrium between the two. Three kinds of schemas were identified: normality schemas, ideal schemas, and game schemas. Appraised meaning in violation of any of these three can result in henotic processes. Analysis of appraised meaning identified 
three topics around which these henotic processes tend to occur: the self, others, and the world. Finally, three forms of henosis were identified: reappraisal, schema adjustment, and active attempts to align experience with ideals/expectations. The first two mirror the assimilation and accommodation processes predicted by the meaning making model (Park, 2010). The final one was less prominent, but may be a form of henosis unique to interactive media. Nevertheless, the focus groups ultimately did provide evidence that henosis is at play in some experiences of meaningfulness.

That said, it should also be acknowledged that henosis was not the explanatory factor for all of the meaningful experiences described by participants. Less than half of the total codes that came out of the transcribed focus groups $(n=$ 483, out of a total of $n=1296$ codes) contained explicit or implicit evidence of a global schema. Of those that did, more than a third were coded as either no adjustment $(n=144)$ or none mentioned $(n=38)$. It bears repeating here that these participants were all prompted at the beginning of the focus groups to imagine a meaningful video game experience from their memories and to speak on this experience, because it means that while henosis is one route to meaningfulness, it is far from the only one.

Looking at the overall number of mentions of the three different types of schemas, there were more mentions of ideal schemas than there were for normality schemas or for game schemas. This may speak to the importance of ideals in henotic experiences, though caution is advised when interpreting results from such a small convenience sample. One interpretation might be that video 
games are often seen as a form of escapism (Calleja, 2010) and as such people might expect to be able to experience something subjectively better than their own lives (and be particularly attentive to when games fail to accomplish this task). Indeed, it is perhaps not surprising that ideal selves, and games that allow participants to embody these ideal selves, would be mentioned in discussions of meaningful games. Research indeed shows that games that allow the embodying of an ideal self are more intrinsically rewarding (Przybylski, Weinstein, Murayama, Lynch, \& Ryan, 2012), and that players are more likely to create avatars similar to their ideal self than their actual self (Bessière, Seay, \& Kiesler, 2007). In short, it is not just ideal selves, but discrepancies between them and the ability to bridge those discrepancies through video games, which lines up quite well with the findings of these focus groups that people sometimes experience meaning in video games by bridging the gap between their self schema and their ideal self. This data thus supports existing findings regarding the meaningfulness of ideal selves. The henosis construct is evidenced here to encompass schema adjustments beyond those that are towards an ideal self, to include the adjustments towards ideal worlds and towards valued experiences as well.

As mentioned earlier, people have narrative schemas built up over repeated exposure to stories that can shape perceptions of traditional entertainment media (Raney, 2011). In the same way, game schemas may shape perceptions of games. The present analysis offered evidence that some players do not experience disconnects between appraised meaning and global schema because they see the game reality as separate than their own, and that those who 
do experience such disconnects can reappraise the situation as being “just a game,” which essentially reinterprets the appraised meaning through a lens that makes it make sense. Of course, game schemas are not on the same global level as the schemas initially described in the literature review, and they may in fact comprise some aspect of a global schema for the world overall. However, functionally they seem to work distinctly, in that people think of games and the rules that comprise them as separate from their normal world, with different rules built in—similar to Huizinga’s (2016) magic circle.

However, while several of the codes yielded insights into what these game schemas might include (e.g., knowledge of rules and affordances, expectations regarding outcome likelihoods), there is still much that is not known about the content of game schemas. It would be a worthwhile pursuit to begin to investigate what kind of patterns tend to emerge in players who frequently play video games in terms of their schemas for games. It is likely that to the extent that narrative is a part of a game, then narrative schemas from traditional media will also come into play, but this is only a piece of what comprises the schemas which dictate players' expectations about video games. As an example, we know that heroes winning and villains losing is something of a narrative schema that dictates how audiences expect narratives to play out (Raney, 2011). What are the equivalent schema for gameplay? How and when do schemas about game puzzles, common mechanics, strategies, and rules interact with or override these narrative expectations? Put another way, the evidence here demonstrates that game 
schemas are an important aspect of henosis, but future research should investigate what players might generally mean by “just a game”.

Of import, reappraisals and schema adjustments were not equally distributed between normality, ideal, and game schema violations. That is, when ideal schemas were violated, a majority of the henotic responses described were reappraisals ( $n=65)$ rather than schema adjustments $(n=7)$, and when normality schemas were violated, the majority henotic responses described were schema adjustments $(n=133)$ compared to reappraisals $(n=12)$. A chi-square analysis crossing the type of adjustment (no adjustment, none mentioned, reappraisal, schema adjustment, restorative action) did demonstrate there are significant differences between categories, Chi-square $=424.04, p<.001$. Though chisquares analyses do not specify where the differences lie, it seems likely given the huge differences between counts that both ideals and normality schema violations tend to favor reappraisal and schema adjustment, respectively. Put simply, when something violates an ideal, people tend to reappraise the situation so that this ideal is not violated, but when something violates normality expectations, people tend to adjust those expectations. One explanation for this might again have to do with the perception of games as an alternate reality in which people can escape their lives and enter a fantasy of their choosing. Many participants mentioned something along these lines as a reason why they play video games. If it is indeed the case that participants tend to expect and even want video games to present them with some kind of ideal world, ideal self, valued experience, or valued principle, it could be the case that people will, whenever possible, find a way for 
games to do just that even when games fail to live up to this expectation. In other words, when games fail to deliver an ideal, players will find some alternative way to align their experience with an ideal because doing so is the very reason they picked up the game in the first place. Concordantly, many of the schema adjustments in response to normality violations were adjustments toward some ideal, whether it was toward an ideal self, ideal world, or valued experience. It may just be the case that, as with other media entertainment (Vorderer, Klimmt, \& Ritterfeld, 2004), people are motivated to maintain their enjoyment and will engage in both schema adjustment and reappraisal with faced with meaningschema discrepancies in order to do so. Following this, the finding that people will take active steps to change their experience to align with a normality schema, game schema, or ideal schema was unique to this study, and indicates that the interactivity of video games may allow for more agency in terms of how meaning is (literally) constructed. In line with the previous point, far more people constructed their experience to align with an ideal rather than with a normality schema.

There also appear to be elements of other known media psychology phenomena embedded in the henosis process. For example, some participants were able to reappraise schema violations through empathizing and perspective taking, through which they could then understand the motivations behind character actions. This holds much conceptual similarity to character identification. Identification is the experience by which a media viewer takes on the perspective of a media character or persona, such that they feel what the 
character feels, adopt the character's goals, and lose some degree of selfawareness (Cohen, 2001). It makes sense that such a process might aid in reappraising schema-violating content, as it introduces a new perspective from which previously inscrutable behavior can be more easily understood. Indeed, future research might benefit from investigating the relationship between identification and henosis. Similarly, some players described situations in which they were able to experience meaning in the game through imagining what they would do if they were in the shoes of a character. This is not quite the same as identification, because imagining an event happening to oneself seems to imply less of a self-awareness loss than one would have during identification—at least, identification as defined by Cohen (2001). However, this experience would be in line with known player-avatar relationships. Banks and Bowman (2016) identified four distinct ways in which players can relate to avatars: avatar-as-me, avatar-astool, avatar-as-social-other, and avatar-as-symbiote. Imagining oneself experiencing a video game scenario suggests that a player might be taking on an avatar-as-me orientation in order to obtain the necessary perspective to reappraise a schema-violating situation such that it makes sense. The implication then is that player-avatar relationship type might also contribute to henosis, and it would be interesting to see whether the other player-avatar orientations might contribute to henosis in other ways.

Finally, the emergence of a restorative action form of henosis is one that was not predicted, but makes sense when considering the interactivity of games. With both the traumatic events being described by the original meaning making 
model (Park, 2010) and the traditional contexts in which people encounter meaningful experiences via media, little agency is offered to the person experiencing the event outside of their own mental processes being used to deal with said event. With interactive media like video games, players have the ability to alter the game outcomes and change the game worlds to varying degrees (Steuer, 1992). Faced with an event that mismatches with one's existing global schema, these results indicate that a player can change the situation itself, rather than just their perception of it. This has powerful implications for how meaningful experiences are delivered via media, as it is unknown how these experiences compare to noninteractive henotic experiences in terms of their salience or effects. It may be the case that interactive meaningful experiences are thought to be more meaningful because of heightened engagement (see Oh, Bellur, \& Sundar, 2018).

One other area that might be interesting for future interest is looking at the role of henosis in enjoyment. The prompts in this study all asked participants to imagine a meaningful video game experience, but it would be interesting to see how answers might change if they were prompted to imagine an enjoyable experience. To be sure, the language participants used sometimes indicated that they were indeed describing an enjoyable experience, which makes sense, as enjoyment and meaningfulness are often correlated (Oliver et al. 2016). It may be the case that participants did not always distinguish the two, or it may be the case that they co-occur quite often in games because participants expect games to be enjoyable, and thus enjoyability is something of a metric for how meaningful a game is. Future research could probe such questions. 


\section{Implications for Development of a Henosis Scale}

Based on this evidence, there are clearly some gamers who have experienced meaningfulness through henosis. This thematic analysis revealed three clear themes for global schema, appraised meaning, and disequilibrium reduction (not counting the two themes which imply no henosis occurred. This provided a useful framework to start developing questions, and indeed, it was this framework which did eventually guide the creation of the scale's item pool. The next step after phase 1 completed was to construct said item pool, the details of which are in the methods section for Phase 2.

In terms of the factor structure, the different processes by which henosis can occur suggested a multidimensional structure involving reappraisal, schema adjustment, and restorative action. In addition to these three dimensions, the factors may further separate out based on what global schema is salient, or based on commonalities in appraised meaning. For this reason, and because it is unknown whether particular global schema violations or appraised meanings are more common or salient than others in terms of their role in henotic experiences, it was decided that the item pool would be expanded to include as many possibilities as could logically be deduced based on the three sets of global schema, appraised meaning, and henotic processes. However, the actual mechanisms seemed likely to be the primary variable which determines the factor structure of henosis.

\section{Limitations}


There were several limitations which must be addressed in this study. First and foremost, the sample size consisted of a limited set of college students all attending university in the same region of the country, and it may be the case that college students experience meaningfulness much differently than those of different age groups and socioeconomic status. The small sample size means that it is the generalizability of these findings is severely compromised. It is thus a strong possibility that there are probably ways of experiencing henosis that were not discovered in this sample group. For instance, no participants indicated any instances in which they reappraised a game schema deviation using an ideal schema, and few instances described schema adjustments in response to violations of ideal schemas. Yet, adjustments to one’s ideals in response to an outside stimulus seem likely to occur. For instance, both awe (Keltner \& Haidt, 2003) and moral elevation (Algoe \& Haidt, 2009) describe experience when a person witnesses something that exceeds their understanding for what aesthetic or moral beauty can be. In the case of awe, the inability to assimilate (reappraise) the experience and the need to accommodate (adjust schema) is built into these authors' definition (Keltner \& Haidt, 2003), indicating that surely at least in some cases ideals can indeed be adjusted. Perhaps it is the case that video games do not often engender awe and elevation responses, but it could also be the case that the small sample size prevented getting input from students who have had such an experience. It is for this reason that in the item construction process, the modes of henosis found in this data were extrapolated to include unseen but theoretically 
reasonable modes of henosis, based on the global schema and appraised meaning categories that were found.

A related limitation is that the focus groups varied in size, with some groups being essentially interviews due to only one participant showing up. This seemed to result in quite a difference in terms of how much depth participants were willing to go into, though again, the small sample size makes it difficult to draw any concrete conclusions on the magnitude of this effect. Nevertheless, it remains true that differences in group size could have made some participants more loquacious than others and prevented getting insight into some participant experience. Relatedly, there were some questions that some participants did not seem to understand, but participant's reticence to talk about their experiences due to group size may also have come with a reticence to ask clarifying questions. In the future, it would be prudent to more thoroughly test the question guide before administering the focus groups.

During focus group conducting, there is also always the risk of the researcher accidentally giving off subtle verbal or nonverbal signals that guide participants to answer in some ways and not others. The researcher in this case made every effort to avoid this, but it is still possible that this could have happened, and with only one person conducting the focus groups it is impossible to determine the extent to which this is true. Future replication and extension should include multiple researchers to mitigate such effects and allow for their identification. Furthermore, the analysis of the data could also be subject to researcher bias. Other researchers with different sensitizing concepts and biases 
might have come up with different categorizations for the focus group data, which would have resulted in different items and emergent factors. Though researcher bias is always going to be present when engaging in interpretive work, future research could utilize multiple researchers in the analysis process to come to a consensual categorization system less prone to individual researcher bias.

Finally, it should be acknowledged that these findings rely on an assumption that people can be aware of and remember henotic experiences. It should be acknowledged that what the items purport to tap into are actually evaluations of a process of henosis after participants have experienced the effect (meaningfulness). That said, that people were able to recall, in great detail in some cases, experiences that perfectly lined up with the theorized henotic experience is encouraging.

\section{Phase 2: Measuring Henosis as Adjustments to Experience and Schema}

Chapter 3 outlined the results of the henosis experience (HEX) scale development initiative, ultimately developing a two-factor, 11-item solution, with initial indicators of convergent, discriminant, and predictive validity.

Given those findings, evidence would all suggest there are at least two dimensions of henosis experiences: experience adjustment and schema adjustment. Recall that participants were all prompted to remember meaningful video game experiences at the beginning of the study, which means that these two dimensions were both connected to experiences of meaning, as anticipated, and as supported by the significant association of both dimensions with appreciation. However, the HEX factors appear to be quite different experiences from one 
another, each one roughly reflects one of the henotic processes described in the literature review. Specifically, the experience adjustment dimension is an amalgam of reappraisal and restorative action, while the schema adjustment dimension reflects the schema adjustment process described by the meaningmaking model (Park, 2010), though with an interesting caveat - all schema adjustment items were positive.

Experience adjustment reflects, overall, an experience where players make purposive attempts to align their game experience with their current schemas. As evidenced by the variety of items that loaded on this factor, this can take a number of forms, and the schema with which the players are aligning their experience could be either normality schemas or ideal schemas. This also lines up with other literature demonstrating the gamers often engage in play that is outside the bounds of what the programmers intended (Bakioglu, 2011) Indeed, that players adjust their experiences to align with their schemas is not to say that these players are always aligning their experience with what they would expect from normal life; rather, they align it with some existing mental structure, which could be their current ideas about what an ideal world would look like. The important distinction between this factor and the other identified is that players mental structures do not change. These are experiences of assimilation (Janoff-Bulman, 1989), in that information is adapted to existing mental structures rather than causing changes in those structures. One implication of this factor's illumination is that players do not need to alter their mental structures for normality or for their ideals in order to 
have a meaningful experience, and the act of fitting a surprising experience into an existing mental structure is (or can be) meaningful.

Furthermore, the fact that this factor included restorative action items suggests that the factor being measured may be unique to games. It is possible that experience adjustment might look different were participants to get a different prompting to imagine a meaningful media experience that was less interactive. It is also possible that the participants, being video game players, may be more likely to glean meaningful experiences from interactive than noninteractive media due to common personality traits that underlie their liking of video games. Regardless, the inclusion of restorative action items demonstrates that people will go beyond internal mental processes in order to maintain their existing understandings of the world. This information could be helpful for research looking into how people use positive and maladaptive responses when coping with unexpected changes in their environments, such as changing social conditions.

Schema adjustments, on the other hand, do involve the alteration of existing mental structures in response to a game experience- that is, existing schema accommodate to the new information (Janoff-Bulman, 1989). That video games can do this is itself something of an important finding, and it can help partially explain why players find video games to be meaningful (Oliver et al., 2016) Not all gamers experience this, but at least some of those who do discussed how video games are a hugely important influence on their lives. This mechanism thus has implications for enacting change on an individual, and perhaps even a 
societal level. The idea of video games aimed at accomplishing social goals, socalled serious games, is not new (Klimmt, 2009). However, henosis that results in schema adjustment has the potential to actually change how people perceive their world, and designing a game with social purposes in mind that is able to tap into this mechanism could prove to be a very effective means of accomplishing social change.

Interestingly, as mentioned, all of the schema adjustment items under schema adjustment involved an ideal, suggesting, perhaps not surprisingly, that experiences which relate to a participant's ideal world or ideals about humanity can be a source of meaningfulness. It does raise the question, though about whether schema adjustments that align with something other than an ideal, such as learning about a problem in the world previously unknown, occurs as often. Research in both the aforementioned serious games (Klimmt, 2009) would benefit from knowing more about this question. Furthermore, gamification-the idea of using game elements for nongame purposes, such as motivating a workforce (Deterding, Dixon, Khaled, \& Nacke, 2011)—might also benefit from implementing game mechanics that foster henosis. However, applying henosis here would also need to be able to facilitate schema adjustments that are not just towards a person's ideal world. Hence, to reiterate, an important direction for future study is figuring out the extent to which schema adjustment can be accomplished not in the direction of an ideal via the henosis process.

Another question that might be asked is the extent to which schema adjustment and experience adjustment can co-occur. As reported above, the two 
HEX factors were correlated, which suggests that people might be engaging in both processes simultaneously. That is, people may attempt to fit their experience to their existing mental structures as much as possible, while at the same time adjusting their mental structures to try to match the experience. Ultimately, the resultant meaning could be the result of both processes at once. Future research could seek to isolate these experiences through more pointed interview questions, or perhaps via experimental manipulations designed to specifically isolate each process. This work serves as a first step towards answering such questions.

The results presented here are in line with the meaning-making model’s predictions (Park, 2010) in that the model describes similar experiences following the disruption of a global schema. However, it extends this logic beyond the model's initial purpose. The meaning-making model was originally conceived to describe how people deal with traumatic real-life events, which it describes as violating a person's basic ideas and expectations about the world. Meaningmaking is understood as the process by which people attempt to mend this rift between expectations and reality. The fact that schema adjustments are indeed evidenced here to be a component of some meaningful video game experiences demonstrates that meaning as a result of reducing discrepancies between global schema and the appraised meaning of one's current reality can occur even in video games.

\section{Theoretical Implications for Meaningfulness in Gaming}

Even though the open-ended data was categorized into three henotic processes, two of them were subsumed into a single factor. This indicates that 
participants may not distinguish between actions in which they align their experience with expectations/ideals, and reappraisals of the meaning of their experiences to similarly align with expectations/ideals. Originally, the difference between these two was conceptualized as one of thought processes versus action, but such a difference did not show up here. Perhaps it is the case that participants do not see their activities in video games as sufficiently active to be qualitatively different from simply reappraising an event in their head to match expectations. This explanation would conflict with the fact that several participants from the open-ended research talked about the physiological experiences in response to video games being similar to those that would happen when encountering similar situations in their physical reality, a finding supported by some research (Anderson \& Bushman, 2001). Another explanation is that all of the items in this factor involved the self in some way-they either described a perception of the self, or they described actions performed by the self. As such they all evoked the self in one way or another, and participants may view all of these experiences as similar on the basis of their relevance to the self. Conversely, the schema adjustment items all had to do with humanity or the world, and none talked about the self. Therefore, it may be the case that participants see both reappraisals and actions as more self-relevant and the schema adjustment items more selftranscendent. This would line up quite well with Oliver et al.'s (2018) distinction between meaningful experiences that are self-relevant, which include eudaimonia and intrinsic need satisfaction, and meaningful experiences that are selftranscendent, such as awe and elevation. 


\section{Henosis in Relation to Self-determination}

When testing for discriminant validity, one result that arose was that schema adjustment was not associated with autonomy satisfaction, whereas experience adjustment was positively associated with autonomy satisfaction. This was true in the analyses which looked at each validation measure separately, and in the model which included them all together to account for shared variance. This finding is counter to the initial predictions for discriminant validity which were that need satisfaction should be unrelated to henosis of any type. In retrospect, not knowing how the factor structure would emerge is a serious limitation when attempting to devise measures of discriminant validity, as it is unknown a priori what exactly is going to be discriminating against the validity measures. Theoretical reasons were offered for why henosis might as a whole discriminate from need satisfaction, but predictions cannot be made for how need satisfaction will relate to specific dimensions that are not known.

All that said, these results can be understood when reinterpreted. Autonomy refers to a person's sense of being in control of their actions (Deci \& Ryan, 2000), and the experience adjustment items were much more focused on purposive action on the part of the player. Video games are known to satisfy autonomy, competence, and relatedness needs (Tamborini et al., 2010), and players who feel sufficiently free to reinterpret and to alter their experience in the ways described by the experience adjustment items may reasonably be expected to also consistently report higher levels of autonomy need satisfaction. Conversely, the schema adjustments towards ideals may not be perceived as being 
as much under the control of the player. That is, when players encounter situations that cause them to rethink their ideas about humanity or the goodness of the world, they may not be self-focused enough to be aware of their own identities and agencies in the game in order to experience autonomy satisfactionparticularly if it is indeed the case that these responses are characterized by selftranscendent emotions.

The relationship of henosis and competence satisfaction appears less straightforward. Initially, a reverse pattern was found for competence satisfaction; that is, schema adjustment was found to be positively related to competence satisfaction, whereas experience adjustment was not. This was rather puzzling, as it seems to contradict the logic just outlined-if schema adjustment is more of a self-transcendent experience, then why would it be associated with a sense of competence, which would seemingly require some sense of self-awareness? One explanation may have to do with the cognitive bandwidth required for schema adjustments. All video games have some amount of demand placed on the player (Bowman, 2015), which must be met in order to actualize the experience. If a game is perceived as difficult or a player is particularly immersed in it (as in a flow state; see Sherry, 2004), the cognitive demand in particular is likely to be very high, and they are not likely to see it as very satisfactory with reference to their competence needs. However, if a game has lower challenge and/or the player is high in skill, not only will this likely result in higher levels of competence need satisfaction; it is also likely to produce lower cognitive demand. Put simply, if a player is experiencing high competence need satisfaction, they may have lower 
cognitive demand than those that are lower in competence need satisfaction. If it is indeed the case that experiencing schema adjustments requires some level of reflection on the meaning of an event and its relationship to the player's larger worldview, it could be that players low in competence satisfaction are so cognitively occupied with the gameplay that they do not have the cognitive bandwidth available to engage in such reflection. Those who are doing well at the game—and therefore, experiencing more competence need satisfaction—may have more cognitive bandwidth available to contemplate the larger meaning of their gameplay experience.

That said, the analysis which included all validity measures together as predictors of each of the two HEX shows a reverse pattern. Competence was no longer able to discriminate from experience adjustment, and competence was now quite clearly distinct from schema adjustment. This seems to make more sense intuitively, and interpreting these analyses seems more appropriate in it can account for the unique variance attributable to competence satisfaction factoring out that attributable to the other measures. That competence is not discriminant from experience adjustment is less surprising, particularly since experience adjustment includes items related to restorative action. Restorative action involves active attempts to alter one's experience to align with one's expectations, and the ability to accomplish this successfully is likely to bestow players with a sense of accomplishment, very much akin to feeling competent. Furthermore, even without restorative action, the act of working an unexplainable event into one's existing mental structures may itself generate feelings of competence and mastery. 
Conversely, schema adjustments involve instances in which people are unable to engage in such actions and therefore must rethink their larger worldviews, which involve shifting focus outward towards the world and the discrepant event-a more self-transcendent experience (Oliver et al., 2018). This shift of focus away from one's own intrinsic needs could explain the lack of relationship between schema adjustment and competence satisfaction.

For relatedness, once again, schema adjustments were positively related to relatedness satisfaction, and experience adjustments were not. Looking at the nature of the schema adjustment items as being often related to humanity in a broad sense, perhaps schema adjustment regarding humanity could result from, or even cause, an increase in relatedness need satisfaction (such a connection to the greater humanity is also characteristic of some self-transcendent emotions, another source of meaningfulness; Oliver et al., 2018). In the former, the schema adjustment regarding the goodness of humanity might make them feel more connected to that humanity, and therefore satisfy relatedness needs. Conversely, a person may play a game, experience a particularly salient and unexpectedly moving interaction with another player or NPC, raising their relatedness need satisfaction while also resulting in a schema adjustment due to the interaction falling beyond what a person could have expected from a game interaction. Indeed, such experiences are known to invoke the emotion of moral elevation (Algoe \& Haidt, 2009), which is an experience defined by witnessing a person behave in a way that exceeds what one could reasonably expect in terms of moral behavior. On the other hand, experience adjustment was not related to relatedness 
need satisfaction. This may again be because experience adjustment seems to be a more self-focused experience, rather than one that focuses on others and one's relation to them.

\section{Reflecting on Henotic Experiences}

Schema adjustment was positively associated with nostalgia, whereas experience adjustment was not. This is in contrast to predictions that nostalgia would be positively associated with both dimensions of henosis (schema adjustment and experience adjustment). The schema adjustment relationship is in line with predictions, perhaps not surprisingly. Nostalgia "arises from fond memories about one's childhood, lose relationships, or atypically positive events," (Sedikides et al., 2015, p. 190). The schema adjustment items all describe experiences that either change a schema towards an ideal schema, or change the ideal schema in a positive direction. In other words, these are atypically positive events—atypical because they violate existing schema, and positive because they all adjust the schema in a positive direction. Furthermore, by definition schemas, including global schemas, are used by people to interpret the events and stimuli that they encounter on a daily basis. Adjustments to these schema, then, mean that future events experienced by that person will be interpreted based on these adjustments. In other words, schema adjustments are lasting effects, and those who experience them are likely to remember them. Since the schema adjustments in the schema adjustment factor in this study are all positive, those who score high on this variable are essentially indicating that they experienced something that was both memorable and positive- - key ingredients in nostalgia. On the other 
hand, when people engage in experience adjustments, they are not making these memorable and lasting changes to their perceptions. This might explain why experience adjustment was unable to predict nostalgia.

\section{Limitations}

Several limitations in phase 2 of this research should be acknowledged. Firstly, one limitation involves the validation measures — specifically the measure for predictive validity. It was argued here that nostalgia experienced while taking the survey is describing an experience felt in the present, and the schema adjustment and experience adjustment factors describe an experience felt in the past. However, future research might better demonstrate predictive validity by establishing a clear time order between the henotic response and the variable that occurs because of it. Nostalgia conceptually can still work as a measure, but to truly establish that it has been predicted by a henotic experience, experimental work which manipulates henosis in some way and then measures nostalgia at some later date would prove a far more compelling argument for predictive validity. That nostalgia was measured concurrently here is thus a limitation of the study.

In line with this, though both concurrent validity measures were successful, the discriminant validity measures were only partially successful in demonstrating the uniqueness of the two henosis factors. That said, SDT need satisfaction and henosis are certainly distinct in how they are conceptualized, and figuring out the relations between two seemingly distinct processes associated with media entertainment presents a compelling area for future theoretical 
development. Intrinsic need satisfaction is concerned with inherent psychological needs (Deci \& Ryan, 2000). To what degree are these needs actually served by the meaning-making processes of henosis? Exploring such questions could help shed light on both phenomena.

A final limitation has to do with representativeness. This survey attempted to expand beyond a college-student population by tapping into various online platforms and utilizing Mturk. However, despite this, the sample remained largely American, white, and the majority of them were college students. This allows the results of this survey to be generalizable to American white college students. This is a limitation, as one goal of this program of research is to be able to identify psychological mechanisms that are common across demographic groups. Future research in this area would benefit from widening the sample, and perhaps using some kind of stratified sampling to ensure a sample more representative of the national or international population.

\section{Overall Theoretical Implications and Future Directions}

The combined work from phase 1 and phase 2 of this research has a) supported the existence of henosis as a construct, b) constructed a survey instrument to assess degree of henotic experience in a recalled meaningful gaming experience, and c) provided partial preliminary evidence of the construct's convergent, discriminant, and predictive validity. The research pulled from existing knowledge in areas of media entertainment research (notably, Oliver et al., 2018) and terror management (Janoff-Bulman, 1989; Park, 2010), and has 
provided information that can help inform both of these areas. It also, being preliminary, offers several potential avenues for future research.

Entertainment theory has established that meaningfulness as a media experience is a conceptually distinct experience from enjoyment (Oliver \& Bartsch, 2010; Oliver \& Raney, 2011). However, the ways in which meaningfulness is experienced in terms of underling psychological processes are less clear. This research offers a clearly defined process, henosis, which can account for some of these experiences of meaningfulness. The focus group data demonstrated that henosis does indeed exist as a phenomenon, as people were able to recall henotic experiences. They did so in the context of talking about meaningful game experiences, clearly connecting the phenomenon to the larger body of research on meaningful media experiences. That said, not all participants were able to recall such experiences. When asked to describe a meaningful experience, many participants described instances in which their expectations were met, rather than violated. For example, participants would describe their drive to competitiveness and their ideal of being a winner, and a meaningful experience which exemplified these things. Without a schema-appraised meaning disconnect, these experiences cannot be said to have been henotic in nature, but they were meaningful nonetheless. Other participants in talking about meaningful experiences they've had did not describe anything that could be taken to describe or implicate a global schema at all. Thus, an important takeaway from this research is that not all meaningful experiences involve henosis, but some of them do. 
It is possible that henosis might have connections with enjoyment as well, as its seeming connection to other pleasurable experiences, such as nostalgia and intrinsic need satisfaction, might suggest. However, enjoyment was measured in the survey in phase 2 of this research, and supplementary exploratory regression analysis did not evidence any connection between either schema adjustment or experience adjustment and enjoyment, $F(2,557)=.363, p=.696, R^{2}=.001$. Thus, the primary application of the henosis construct, as per the purpose behind it's theorizing in the first place, is to help explain a mechanism by which meaningfulness, rather than enjoyment, is experienced.

Henosis as a construct adds to current understandings of media meaningfulness in that it provides a specific mechanism for meaningful experiences in games, but it can also inform other models which also seek to explain meaningfulness. For example, the MIME (Tamborini, 2011) is a model that explains how moral evaluations of media characters and their narrative outcomes can contribute to both enjoyment and appreciation. The key to this model is that if an unambiguously morally justified outcome is reached by narrative, a media consumer will experience enjoyment. However, if a narrative outcome violates a media consumer's sense of morality, they will then come up with moral justifications for the outcome using some alternative moral dimension which was not violated (e.g., it's ok that a character hurt somebody because justice was served). The idea of reinterpreting a mediated event which violated a moral sentiment in order to reduce dissonance is quite similar to the idea of reappraising an event which violates an ideal schema, also to reduce dissonance. 
Hence, the MIME may be describing a specific manifestation of henosis.

However, henosis expands on this premise by allowing for the violation of any global schema to lead to meaning-making through attempts to resolve discrepancies via either schema adjustment or experience adjustment. Future research should investigate other domains in which dissonance of other kinds being reduced by either reappraisal or schema adjustment can deliver meaningful experiences

The henosis construct also expands on the meaning-making model (Park 2010) by demonstrating that meaningfulness produced via resolving discrepancies between global schema and appraised meaning can explicitly occur in response to positive schema violations. The meaning-making model primarily deals with how people deal with responding to traumatic events, but henosis demonstrates that meaningfulness produced in this way can come from any schema-violating event. Indeed, the schema adjustment scale included exclusively items which described positive schema adjustments, and while positive adjustments can ultimately result from traumatic experiences (Park, 2010), henosis highlights a far less emotionally taxing process by which such adjustments can be obtained. This has implications for those who practice persuasive campaigning_if henosis can engender schema adjustment, it could be a powerful persuasion tool. It also has implications for potentially prosocial effects, particularly in fighting prejudice and discrimination. Research on the parasocial contact hypothesis (Schiappa, Gregg, \& Hewes, 2005) has already demonstrated that media exposure to an outgroup member can reduce prejudiced attitudes towards that outgroup member under certain conditions. 
Henosis may be able to partially explain how parasocial contact can reach success. It could be that part of the reason for the success of parasocial contact is that a person's exposure to an outgroup member is a violation of whatever prejudice-laden schema the person has for that group, and given the right conditions are met (see Allport, 1979), that media consumer engaged in schema adjustment, rather than reappraisal, and the result is reduced prejudiced attitudes towards the outgroup.

The fact that two dimensions of henosis emerged that fell so neatly into the reappraisal and schema adjustment processes is encouraging, as it suggests that the theoretical basis which led to this project was well-founded. It is, however, possible that more dimensions of the construct exist. The experience adjustment dimension consisted of items that seem to have a common theme centered around the self and actions taken by the self. The schema adjustment dimension seemed to be more outward focused, but on humanity and the world in general more so than on any specific person or group. There may be another dimension of henosis that arises in relation expectations and unexpected events regarding specific other people (a specific player, a specific NPC). Alternatively, if items focused on other people were to be answered in a more consistent way by participants, they may just fall into the existing two dimensions. Either way, investigating the possibility of additional dimensions of henosis, particularly as relates to schemas and reappraisals that have to do with social others, is an important step as this line of research moves forward. 
That clarification notwithstanding, there are a number of additional paths for future research in this domain. One question that might be asked is whether henosis is more common in some genres than others. Experiences of meaningfulness as a response to traditional media seems to be more common when consuming some genres compared to others (Oliver \& Bartsch, 2010). Theoretically, any kind of gaming experience should be able to provide schemaviolating events which, when the discrepancy is resolved via schema adjustment or experience adjustment, should result in experiences of meaningfulness. However, it could also be the case that participants in some gaming situations approach their experience with different mindsets that are more or less conducive to henosis. For example, it could be that competitive players, particularly those who strive to constantly improve, may spend most of their time gaming in a way that consumes all of their mental energy, leaving little opportunity to contemplate the deeper meaning of unexpected events they encounter. Those who play slowerpaced games which require less strenuous attention might then be more likely to experience henosis by virtue of greater cognitive freedom to process surprising events. In this case, we might expect to see cognitive demand mediating the relationship between game genre and henosis.

Another question that might be asked is whether henosis always results in meaningfulness. Because the focus groups all asked participants to describe meaningful game experiences, and the survey prompted participants to remember a meaningful game experience, there may be an embedded assumption in this research thus far that henosis always leads to meaningfulness, when this is really 
an empirical question. While evidence here clearly shows that henosis can result in meaningfulness, the correlation between both schema adjustment and appreciation, the measure which most closely approximates the concept of meaningfulness, was not 1 , nor was the correlation between experience adjustment and appreciation. If henosis does not result in experiences of meaningfulness, when? Why? These are all empirical questions ripe for future investigation. 


\section{CONCLUSION}

This project began as an interest in understanding more fully what it means for media, and specifically video games, to be meaningful. Ultimately, in doing so, a new perspective has been generated by which meaningful media and game experiences might be a) further understood, and b) purposely constructed to achieve lasting impact. There still remains much to be clarified (e.g., a second data collection to confirm the factor structure). However, the evidence offered here may lead to some promising insight into both self-focused and selftranscendent ways in which people experience gratifications from media that go beyond temporary enjoyment to leave their mark on audiences and players. Specifically, these results show that video games can tap into some of the most basic assumptions people hold about the world, and utilize those to facilitate rewarding experiences of meaning. The practical possibilities for this are enormous. Video games that learn to capitalize on this can change the lives of players in substantial and meaningful ways. Skilled designers can take advantage of henotic experiences for prosocial purposes, for selfish manipulation, or simply because they know how to craft an experience that means something to players. This work pulls a psychological concept meant to explain how people make meaning out of tragedy, and broadens the scope to shine light on how people can make similar meaning through media experiences they likely already enjoy. There is huge potential for this work to help inform media entertainment research through further exploration of its relationship to known theoretical constructs, and it may even be able to highlight heretofore unseen henotic commonalities in the 
cognitive mechanics underpinning said constructs. In summary, henosis originally explained how we deal with existential angst through finding meaning in the hole left by psychological trauma, but if properly harnessed, it appears to have the potential to allow us to build meaning in a lot more places as well. 


\section{REFERENCES}

Algoe, S. B., \& Haidt, J. (2009). Witnessing excellence in action: The 'otherpraising' emotions of elevation, gratitude, and admiration. The Journal of Positive Psychology, 4(2), 105-127. https://doi.org/10.1080/17439760802650519

Allport, G. W. (1979). The nature of prejudice (Unabridged, 25th anniversary ed). Reading, Mass: Addison-Wesley Pub. Co.

Anderson, C. A., \& Bushman, B. J. (2001). Effects of violent video games on aggressive behavior, aggressive cognition, aggressive affect, physiological arousal, and prosocial behavior: A meta-analytic review of the scientific literature. Psychological Science, 12(5), 353-359. https://doi.org/10.1111/1467-9280.00366

Bailey, E. J., \& Ivory, J. D. (2018). The moods meaningful media create: Effects of hedonic and eudaimonic television clips on viewers' affective states and subsequent program selection. Psychology of Popular Media Culture, 7(2), 130-145. https://doi.org/10.1037/ppm0000122

Bakioglu, B. S. (2011). Governance in virtual worlds: Grief play, hacktivism \& leakops in second life. SSRN Electronic Journal. https://doi.org/10.2139/ssrn.2179886

Banks, J., \& Bowman, N. D. (2016). Avatars are (sometimes) people too: Linguistic indicators of parasocial and social ties in player-avatar relationships. New Media \& Society, 18(7), 1257-1276. https://doi.org/10.1177/1461444814554898 
Bessière, K., Seay, A. F., \& Kiesler, S. (2007). The ideal elf: Identity exploration in World of Warcraft. CyberPsychology \& Behavior, 10(4), 530-535. https://doi.org/10.1089/cpb.2007.9994

Bowman, N. D. (2015). “For this much work, I need a Guild card!” Video gameplay as a demanding coproduction. In R. A. Lind (Ed.), Produsing theory in a digital world: the intersection of audiences and production in contemporary theory (pp. 107-124). New York: Peter Lang.

Bowman, N. D. (Ed.). (2018). Video games: A medium that demands our attention. New York, NY: Routledge.

Braun, V., \& Clarke, V. (2006). Using thematic analysis in psychology. Qualitative Research in Psychology, 3(2), 77-101. https://doi.org/10.1191/1478088706qp063oa

Calleja, G. (2007). Digital game involvement: A conceptual model. Games and Culture, 2(3), 236-260. https://doi.org/10.1177/1555412007306206

Calleja, G. (2010). Digital Games and Escapism. Games and Culture, 5(4), 335353. https://doi.org/10.1177/1555412009360412

Cantor, N., \& Mischel, W. (1977). Traits as prototypes: Effects on recognition memory. Journal of Personality and Social Psychology, 35(1), 38-48. https://doi.org/10.1037/0022-3514.35.1.38

Charmaz, K. (2013). Grounded theory: Objectivist and constructivist methods. In N. K. Denzin \& Y. S. Lincoln (Eds.), Strategies of qualitative inquiry (Second Edition, pp. 249-291). Thousand Oaks, CA: SAGE. 
Cohen, J. (2001). Defining identification: A theoretical look at the identification of audiences with media characters. Mass Communication and Society, 4(3), 245-264. https://doi.org/10.1207/S15327825MCS0403_01

Consalvo, M. (2009). There is No Magic Circle. Games and Culture, 4(4), 408417. https://doi.org/10.1177/1555412009343575

Consalvo, M. (2012). Confronting toxic gamer culture: A challenge for feminist game studies scholars. University of Oregon Libraries. https://doi.org/10.7264/n33x84kh

Crescioni, A. W., \& Baumeister, R. F. (2013). The four needs for meaning, the value gap, and how (and whether) society can fill the void. In J. A. Hicks \& C. Routledge (Eds.), The experience of meaning in life: classical perspectives, emerging themes, and controversies (pp. 3-15). Dordrecht: Springer.

De Schutter, B., \& Vanden Abeele, V. (2010). Designing meaningful play within the psycho-social context of older adults. Proceedings of the 3rd International Conference on Fun and Games - Fun and Games '10, 8493. https://doi.org/10.1145/1823818.1823827

Deci, E. L., \& Ryan, R. M. (2000). The "What” and "Why” of Goal Pursuits: Human Needs and the Self-Determination of Behavior. Psychological Inquiry, 11(4), 227-268. https://doi.org/10.1207/S15327965PLI1104_01

Deterding, S., Dixon, D., Khaled, R., \& Nacke, L. (2011). From Game Design Elements to Gamefulness: Defining “Gamification.” 7. 
Downs, E., Bowman, N. D., \& Banks, J. (2017). A polythetic model of playeravatar identification: Synthesizing multiple mechanisms. Psychology of Popular Media Culture. https://doi.org/10.1037/ppm0000170

Elson, M., Breuer, J., Ivory, J. D., \& Quandt, T. (2014). More than stories with buttons: Narrative, mechanics, and context as determinants of player experience in digital games. Journal of Communication, 64(3), 521-542. https://doi.org/10.1111/jcom.12096

Fabrigar, L. R., Wegener, D. T., MacCallum, R. C., \& Strahan, E. J. (1999). Evaluating the use of exploratory factor analysis in psychological research. Psychological Methods, 4, 272-299. https://doi.org/1082989X/99/S3.00

Festinger, L. (2001). A theory of cognitive dissonance (Reissued by Stanford Univ. Press in 1962, renewed 1985 by author, [Nachdr.]). Stanford: Stanford Univ. Press.

Figley, C. R., \& Janoff-Bulman, R. (Eds.). (1985). The aftermath of victimization: Rebuilding shattered assumptions. In Trauma and its wake: The study and treatment of post-traumatic stress disorder (pp. 15-35). New York: Brunner Mazel.

Fiske, S. T., \& Taylor, S. E. (1991). Social cognition. New York, NY: McGrawHill.

Good Vibrations Games. (2016). Blind Trust [Windows]. Salt Lake City, UT: Good Vibrations Games. 
Grandey, A. A., Dickter, D. N., \& Sin, H.-P. (2004). The customer is not always right: Customer aggression and emotion regulation of service employees. Journal of Organizational Behavior, 25(3), 397-418. https://doi.org/10.1002/job.252

Green, M. C., \& Brock, T. C. (2000). The role of transportation in the persuasiveness of public narratives. Journal of Personality and Social Psychology, 79(5), 701-721. https://doi.org/10.1037//0022-3514.79.5.701

Hartmann, T., \& Vorderer, P. (2010). It’s okay to shoot a character: Moral disengagement in violent video games. Journal of Communication, 60(1), 94-119. https://doi.org/10.1111/j.1460-2466.2009.01459.x

Heidegger, M., Macquarrie, J., \& Robinson, E. (1962). Being and time. Malden, MA: Blackwell.

Heintzelman, S. J., \& King, L. A. (2013). The origins of meaning: Objective reality, the unconscious mind, and awareness. In J. A. Hicks \& C. Routledge (Eds.), The experience of meaning in life: classical perspectives, emerging themes, and controversies (pp. 87-99). Dordrecht: Springer.

Hicks, J. A., \& Routledge, C. (Eds.). (2013). The experience of meaning in life: Classical perspectives, emerging themes, and controversies. Dordrecht: Springer.

Hollander, J. A. (2004). The social contexts of focus groups. Journal of Contemporary Ethnography, 33(5), 602-637. https://doi.org/10.1177/0891241604266988 
Huizinga, J. (2016). Homo ludens a study of the play-element in culture.

Infinity Ward (2009). Call of Duty: Modern Warfare 2 [Microsoft Xbox 360]. Santa Monica, CA: Activision.

Janicke, S. H., \& Oliver, M. B. (2017). The relationship between elevation, connectedness, and compassionate love in meaningful films. Psychology of Popular Media Culture, 6(3), 274-289. https://doi.org/10.1037/ppm0000105

Janoff-Bulman, R. (1989). Assumptive worlds and the stress of traumatic events: Applications of the schema construct. Social Cognition, 7(2), 113-136. https://doi.org/10.1521/soco.1989.7.2.113

Janoff-Bulman, R., \& Frantz, C. M. (1997). The impact of trauma on meaning: From meaningless world to meaningful life. In M. J. Power \& C. Brewin (Eds.), The transformation of meaning in psychological therapies: integrating theory and practice (pp. 91-106). Chichester, England ; New York: Wiley.

Janoff-Bulman, R., \& Frieze, I. H. (1983). A Theoretical Perspective for Understanding Reactions to Victimization. Journal of Social Issues, 39(2), 1-17. https://doi.org/10.1111/j.1540-4560.1983.tb00138.x

Kaiser, H. F. (1960). The application of electronic computers to factor analysis. Educational and Psychological Measurement, 20(1), 141-151. https://doi.org/10.1177/001316446002000116 
Keltner, D., \& Haidt, J. (2003). Approaching awe, a moral, spiritual, and aesthetic emotion. Cognition and Emotion, 17(2), 297-314. https://doi.org/10.1080/02699930302297

Kierkegaard, S. (2009). Writings. 15, 15. Princeton, NJ: Princeton Univ. Press. Klimmt, C. (2009). Serious games and social changes: Why they (should) work. In U. Ritterfeld, M. J. Cody, \& P. Vorderer (Eds.), Serious games: mechanisms and effects (pp. 248-270). New York: Routledge.

Kline, R. (2013). Exploratory and confirmatory factor analysis. In Y. M. Petscher, C. Schatschneider, D. L. Compton, \& Y. M. Petscher (Eds.), Applied quantitative analysis in education and the social sciences (pp. 171-207). Retrieved from http://public.eblib.com/choice/publicfullrecord.aspx?p=1143716

Lazarus, R. S., \& Folkman, S. (1984). Stress, appraisal, and coping (11. [print.]). New York: Springer.

Lindley, C. (2003, October). Game Taxonomies: A High Level Framework for Game Analysis and Design. Retrieved July 9, 2018, from Gamasutra: The art \& business of making games website: https://www.gamasutra.com/view/feature/131205/game_taxonomies_a_hi gh_level_.php

Lindlof, T. R., \& Taylor, B. C. (2011). Qualitative communication research methods (3rd ed). Thousand Oaks, Calif: SAGE. 
Lombard, M., \& Ditton, T. (1997). At the heart of it all: The concept of presence. Journal of Computer-Mediated Communication, 3(2), 0-0. https://doi.org/10.1111/j.1083-6101.1997.tb00072.x

Markus, H., \& Nurius, P. (1986). Possible selves. American Psychologist, 41(9), 954-969. https://doi.org/10.1037//0003-066X.41.9.954

Maxis (2000). The Sims [Windows]. Redwood City, CA: Electronic Arts.

McCroskey, J. C., \& Young, T. J. (1979). The use and abuse of factor analysis in communication research. Human Communication Research, 5(4), 375382. https://doi.org/10.1111/j.1468-2958.1979.tb00651.x

Morgan, D. (1997). Focus Groups as Qualitative Research. https://doi.org/10.4135/9781412984287

Morrison, J. T. (2009). Evaluating factor analysis decisions for scale design in communication research. Communication Methods and Measures, 3(4), 195-215. https://doi.org/10.1080/19312450903378917

Naughty Dog. (2013). The Last of Us [Sony PlayStation 3]. San Mateo, CA: Sony Computer Entertainment.

Nintendo. (1986). The Legend of Zelda [Nintendo Entertainment System]. Kyoto, JP: Nintendo.

Nintendo. (2017). The Legend of Zelda: Breath of the Wild [Nintendo Switch]. Kyoto, JP: Nintendo.

Numinous Games (2016). That Dragon, Cancer [Windows]. Loveland, CO: Numinous Games. 
Nunnally, J. C., \& Bernstein, I. H. (1994). Psychometric theory (3rd ed). New York: McGraw-Hill.

Odă̆, Ö., Uluğ, Ö. M., Arslan, H., \& Schiefer, D. (2018). Culture and media entertainment: A cross-cultural exploration of hedonic and eudaimonic entertainment motivations. International Communication Gazette, 80(7), 637-657. https://doi.org/10.1177/1748048518802215

Oh, J., Bellur, S., \& Sundar, S. S. (2018). Clicking, Assessing, Immersing, and Sharing: An Empirical Model of User Engagement with Interactive Media. Communication Research, 45(5), 737-763. https://doi.org/10.1177/0093650215600493

Oliver, M. B. (1993). Exploring the paradox of the enjoyment of sad films. Human Communication Research, 19(3), 315-342. https://doi.org/10.1111/j.1468-2958.1993.tb00304.x

Oliver, M. B., \& Bartsch, A. (2010). Appreciation as audience response: Exploring entertainment gratifications beyond hedonism. Human Communication Research, 36(1), 53-81. https://doi.org/10.1111/j.14682958.2009.01368.x

Oliver, M. B., Bowman, N. D., Woolley, J. K., Rogers, R., Sherrick, B. I., \& Chung, M.-Y. (2016). Video games as meaningful entertainment experiences. Psychology of Popular Media Culture, 5(4), 390-405. https://doi.org/10.1037/ppm0000066

Oliver, M. B., \& Raney, A. A. (2011). Entertainment as Pleasurable and Meaningful: Identifying Hedonic and Eudaimonic Motivations for 
Entertainment Consumption. Journal of Communication, 61(5), 984-1004. https://doi.org/10.1111/j.1460-2466.2011.01585.x

Oliver, M. B., Raney, A. A., Slater, M. D., Appel, M., Hartmann, T., Bartsch, A., ... Das, E. (2018). Self-transcendent media experiences: Taking meaningful media to a higher level. Journal of Communication, 68(2), 380-389. https://doi.org/10.1093/joc/jqx020

Park, C. L. (2010). Making sense of the meaning literature: An integrative review of meaning making and its effects on adjustment to stressful life events. Psychological Bulletin, 136(2), 257-301. https://doi.org/10.1037/a0018301

Park, C. L. (2013). Trauma and meaning making: Converging conceptualization and emerging evidence. In J. A. Hicks \& C. Routledge (Eds.), The experience of meaning in life: classical perspectives, emerging themes, and controversies (pp. 61-76). Dordrecht: Springer.

Park, C. L., \& Gutierrez, I. A. (2013). Global and situational meanings in the context of trauma: Relations with psychological well-being. Counselling Psychology Quarterly, 26(1), 8-25.

https://doi.org/10.1080/09515070.2012.727547

Piaget, J. (1985). The equilibration of cognitive structures: The central problem of intellectual development. Chicago: University of Chicago Press.

Piaget, J. (2001). The construction of reality in the child.

Preston, C. C., \& Colman, A. M. (2000). Optimal number of response categories in rating scales: Reliability, validity, discriminating power, and respondent 
preferences. Acta Psychologica, 104(1), 1-15.

https://doi.org/10.1016/S0001-6918(99)00050-5

Proulx, T. (2013). Meaning maintenance model: Introducting Soren to existential social psychology. In J. A. Hicks \& C. Routledge (Eds.), The experience of meaning in life: classical perspectives, emerging themes, and controversies (pp. 47-59). Dordrecht: Springer.

Przybylski, A. K., Weinstein, N., Murayama, K., Lynch, M. F., \& Ryan, R. M. (2012). The ideal self at play: The appeal of video games that let you be all you can be. Psychological Science, 23(1), 69-76.

https://doi.org/10.1177/0956797611418676

Raney, A. A. (2011). The role of morality in emotional reactions to and enjoyment of media entertainment. Journal of Media Psychology, 23(1), 18-23. https://doi.org/10.1027/1864-1105/a000027

Reeves, B., \& Nass, C. I. (1998). The media equation: How people treat computers, television, and new media like real people and places (1. paperback ed). Stanford, Calif: CSLI Publ.

Rigby, C. S., \& Ryan, R. M. (2017). Time well spent? Motivation for entertainment media and its eudaimonic aspects through the lens of selfdetermination theory. In L. Reinecke \& M. B. Oliver (Eds.), The Routledge handbook of media use and well-being: international perspectives on theory and research on positive media effects (pp. 34-48). New York: Routledge. 
Rogers, R., Woolley, J., Sherrick, B., Bowman, N. D., \& Oliver, M. B. (2017). Fun versus meaningful video game experiences: A qualitative analysis of user responses. The Computer Games Journal, 6(1-2), 63-79. https://doi.org/10.1007/s40869-016-0029-9

Roth, F. S., Weinmann, C., Schneider, F. M., Hopp, F. R., \& Vorderer, P. (2014). Seriously Entertained: Antecedents and Consequences of Hedonic and Eudaimonic Entertainment Experiences With Political Talk Shows on TV. Mass Communication and Society, 17(3), 379-399. https://doi.org/10.1080/15205436.2014.891135

Ryan, R. M., Rigby, C. S., \& Przybylski, A. (2006). The motivational pull of video games: A self-determination theory approach. Motivation and Emotion, 30(4), 344-360. https://doi.org/10.1007/s11031-006-9051-8

Schafer, S. B., \& Yu, G. (2011). Meaningful video games: Drama-based video games as a transformational experience. In M. M. Cruz-Cunha, V. H. Varvalho, \& P. Tavares (Eds.), Business, Technological, and Social Dimensions of Computer Games: Multidisciplinary Developments (pp. 312-329). https://doi.org/10.4018/978-1-60960-567-4

Schiappa, E., Gregg, P. B., \& Hewes, D. E. (2005). The Parasocial Contact Hypothesis. Communication Monographs, 72(1), 92-115. https://doi.org/10.1080/0363775052000342544

Seaborn, K., Pennefather, P., \& Fels, D. I. (2019). Eudaimonia and hedonia in the design and evaluation of a cooperative game for psychosocial well-being. 
Human-Computer Interaction, 1-49.

https://doi.org/10.1080/07370024.2018.1555481

Secret Lab (2017). Night in the Woods [Windows]. Hobart, AU: Finji.

Sedikides, C., Wildschut, T., Routledge, C., Arndt, J., Hepper, E. G., \& Zhou, X. (2015). To nostalgize. In Advances in Experimental Social Psychology

(Vol. 51, pp. 189-273). https://doi.org/10.1016/bs.aesp.2014.10.001

Sherry, J. L. (2004). Flow and Media Enjoyment. Communication Theory, 14(4), 328-347. https://doi.org/10.1111/j.1468-2885.2004.tb00318.x

Spencer, C. (2017, August). Night In The Woods Treats Depression Like A Part Of Life. Retrieved January 12, 2019, from Kotaku website: https://kotaku.com/night-in-the-woods-treats-depression-like-a-part-of-lif1797400607

Stamatellos, G. (2007). Plotinus and the presocratics: A philosophical study of presocratic influences in Plotinus’ Enneads. Albany: State University of New York Press.

Steuer, J. (1992). Defining virtual reality: Dimensions determining telepresence. Journal of Communication, 42(4), 73-93. https://doi.org/10.1111/j.14602466.1992.tb00812.x

Tamborini, R. (2011). Moral intuition and media entertainment. Journal of Media Psychology, 23(1), 39-45. https://doi.org/10.1027/1864-1105/a000031

Tamborini, R., Bowman, N. D., Eden, A., Grizzard, M., \& Organ, A. (2010). Defining media enjoyment as the satisfaction of intrinsic needs. Journal of 
Communication, 60(4), 758-777. https://doi.org/10.1111/j.14602466.2010.01513.x

Telltale Games. (2012). The Walking Dead [Windows]. San Rafael, CA: Telltale Games.

Thompson, S. C., \& Janigian, A. S. (1988). Life Schemes: A Framework for Understanding the Search for Meaning. Journal of Social and Clinical Psychology, 7(2-3), 260-280. https://doi.org/10.1521/jscp.1988.7.2-3.260

Thrash, T. M., \& Elliot, A. J. (2003). Inspiration as a psychological construct. Journal of Personality and Social Psychology, 84(4), 871-889. https://doi.org/10.1037/0022-3514.84.4.871

Undead Labs (2013). State of Decay [Windows]. Seattle, WA: Microsoft Studios. Valve Corporation (2008). Left 4 Dead 2 [Windows]. Bellevue, WA: Valve Corporation.

Vorderer, P., Klimmt, C., \& Ritterfeld, U. (2004). Enjoyment: At the Heart of Media Entertainment. Communication Theory, 14(4), 388-408. https://doi.org/10.1111/j.1468-2885.2004.tb00321.x

Westerman, D. K., Bowman, N. D., \& Lachlan, K. L. (2014). Introduction to computer mediated communication: A functional approach.

Wirth, W., Hofer, M., \& Schramm, H. (2012). Beyond pleasure: Exploring the eudaimonic entertainment experience. Human Communication Research, 38(4), 406-428. https://doi.org/10.1111/j.1468-2958.2012.01434.x 
Wulf, T., Bowman, N. D., Rieger, D., Velez, J. A., \& Breuer, J. (2018). Video game nostalgia and retro gaming. Media and Communication, 6(2), 60. https://doi.org/10.17645/mac.v6i2.1317

Yager Development (2012). Spec Ops: The Line [Sony PlayStation 3]. Novato, CA: 2K Games.

Zillmann, D. (1996). Sequential dependencies in emotional experience and behavior. In R. D. Kavanaugh, B. Zimmerberg, \& S. Fein (Eds.), Emotion: interdisciplinary perspectives (pp. 243-272). Mahwah, N.J: L. Erlbaum Associates.

Zillmann, D. (2000). Basal morality in drama appreciation. In Ib Bondebjerg (Ed.), Moving images, culture, and the mind (pp. 53-63). Luton, UK: University of Luton Press. 


\section{APPENDIX A}

\section{Script Question Guide}

Below is the script and question guide that will be used for the conducting of the

focus group:

Alright, let's get started. Thank you all for coming. My name is Evan, I'm a PhD candidate here in WVU's Department of Communication Studies. I study primarily video games and other forms of entertainment, and I'm particularly interested in what you might call meaningful video game experiences, which, of course, can mean a lot of things. It almost goes without saying that video games are fun - why else would we play them? But at the same time, sometimes game experiences can be a bit more than just fun and make us feel something...maybe a bit deeper. For me personally, the example that sticks with me is the first time I played through the first Mass Effect, and I don't want to give too much away, but there's a point at which you have to make a choice between which squadmate lives and which one dies, after spending a lot of time up to that point getting to know each one of their characters... and that was the first time I experienced something like that, so it really stuck with me. It's the kind of experience that "fun” doesn't really describe, because it doesn't really make you feel "good," but it was a really powerful experience. Of course, probably a lot of ways people can have experiences that are meaningful in games that are different than this, and that there's a lot that game scholars like me don't know about these kinds of experiences, so that's where you come in.

If you've never been in a focus group, basically how it works is that I'll pose a general question to the group and whoever wants to answer can answer. I want to keep it pretty conversational and free flowing because I'm really most interested in what you have to say about what games can mean to you. I will warn you, some of these questions may seem a bit...weird? But, part of why we're doing this is to sort of inform what scientists say video games can do with input from actual gamers about what real meaningful video game experiences are like. So, the more you can tell me, the better - everything is helpful, and nothing is stupid! First, to get us started, why don't we go around and introduce ourselves, and tell the group 1) a name you want to be called, and 2) the best video game you've played recently and why you liked it.

\section{Participants go around and answer question}

Great, awesome. So now what I want to do is start by thinking about a video game experience you found to be particularly meaningful. Meaningfulness can happen in relation to lots of different aspects of the game experience, and it could have to do with the game itself, the people you played with, the story, the gameplay, or you fill in the blank. The goal here is in part to get insight into what kinds of 
experiences can be meaningful in video games. What is this experience? And, what does meaningful mean to you?

\section{Participants answer question}

One of the things that's so cool about video games is that unlike most other media, they are interactive. This means that there are experiences you can have with games that just don't exist on other platforms. You can control what happens on the screen, or at least you can influence what happens on screen. You're not a passive observer, you're actively making things happen. When I mention interactivity, that's what I'm talking about.

The researcher will move on to the structured questions for henosis.

\section{Henosis}

One way that people can have meaningful experiences is when video games surprise us in a way that makes us think or feel a bit differently about life, the world, or something important. It's tricky to talk about, because we might not really think consciously that much about it, but even then, we can still feel like we've experienced something meaningful and important as a result of something unexpected in a game.

If no one has yet mentioned an applicable example:

Can you think of anything experience's you've had that are meaningful because of something unexpected that happened?

Alternate approach if somebody has already mentioned an applicable experience: $<$ Participant name $>$, your experience seems like it kinda fits into this idea. What role would you say the unexpectedness of the event played in how meaningful it was?

Opening up:

Has anyone else had a similar experience to this?

\section{Global \& Appraised Schema Probes}

Probe set 1 - Appraised meaning: Tell me more about this event - how did it make you feel?

- Did the event signal anything to you?

- How did you interpret the event?

- What did the event mean to you?

- Can you talk about how you interpreted that event in light of... 
Probe 2 - Global Schema - asked to each person that volunteers an experience:

Let me ask a different question: what about that event do you think it was that made it so surprising?

Probe 2a: What would you have typically expected that didn't happen?

Based on the reasons participants give as to why the event was unexpected: Has anyone else also had experiences where something surprised you

Probe 2b: One way we can think about meaningfulness is that we experience something and it reminds us of some kind of ideal that we personally. For example, maybe something happens that reminds you of extreme aesthetic beauty, or of the best version of yourself, or the goodness of humanity - something like that. Did any of your experiences remind you of some ideal, and if so, what kind of ideal?

Probe 3: Maybe another way of thinking about it is that things can be meaningful when they are different than our expectations, because if something happens we don't expect, good or bad, we have to sort of figure out how to work the event into our worldview. One of the things we're really interested is how gamers incorporate meaningful events into their worldview - in other words, when you're faced with something that violates some really central belief you have about the world or people or life, how do you balance those two things. Do the games change your worldview, or do you change how you interpret the event to be consistent with your worldview. Does that make sense?

Here, the researcher will attempt to relate the discussed experiences into the henosis framework, using the global schemas identified earlier, and ask: When this happened, how did you deal with the fact that you experienced something in conflict with how you see the world?

Gaming/Narrative/Global Schema Teasing Probes:

We've talked a lot about expectations and worldviews, but one of the counterpoints here is that sometimes we're aware that things are "just a game" right? And then again, sometimes not. I'm the first one to admit I can get swallowed up in a game to the point where I'm tearing up watching Old Solid Snake crawl down that microwave corridor as his suit's burning off. The point is, sometimes we see games as their own little universes with their own rules, and sometimes not.

Here, the researcher will use the experiences discussed so far and ask:

When you experienced , was it surprising in the sense that you didn't expect that to happen in a story, didn't expect it to happen in a game, or in general didn't expect to see things like that happen in life?

\section{Closing}


Finally I wanted to ask, are there any ways that games can be meaningful that we didn't talk about today? Are there any other profound or even life-changing experiences ... or ones that just took your breath away ... that you'd like to share? Or is there anything about your experiences you feel like didn't get covered adequately?

Cool, alright. Well, thanks for coming out today, I really do appreciate it. We'll let you know as soon as we finish conducting all the focus groups who won the Amazon card. If you win, you'll get an email from me at the mix email you provided when you signed up for the focus group session.

And, we're done! Thanks again! 


\section{APPENDIX B}

Henosis Survey Instrument

\section{HenosisScaleDev}

\section{Start of Block: Consent}

\section{Dear Participant:}

Evan Watts and Dr. Jaime Banks in the WVU Department of Communication Studies are conducting research on people's experiences of meaningfulness in video games. You can participate in this research by describing a meaningful gaming experience you have had and then filling out an online questionnaire.

From start to finish, we expect this study to take approximately 30 minutes to complete.

In order to participate, you must be 18 years of age or older.

There are no known risks associated with participation in this study.

Although you will not receive direct benefits for your participation, your answers will be very valuable to the study.

All participants will be provided with a unique participant code and receipt so they may validate participation in the case they are eligible for research credit per departmental IRB policy. You can print out the receipt if you have access to a printer, or you can take a screen capture to print it or save it or send it digitally. You will also be entered into a drawing for a \$100 Amazon Gift Card at the end of the survey.

Your participation is completely voluntary, and you may stop the questionnaire at any time. Your actual performance in this study or your refusal to participate or withdrawal from this study will in no way affect your class standing, grades, job status, or status in any athletic or other activity associated with West Virginia University.

Only approved researchers will have access to the data you provide. Data will be collected anonymously, and stored on a password-protected storage cloud or a password-protected computer hard drive. 
You may access this questionnaire from any computer with Internet access. This study has received IRB acknowledgement (protocol \#1903515807).

If you have any questions, feel free to contact Evan Watts (co-investigator) at erw0008@mix.wvu.edu (or by calling 304-293-3905), or Dr. Jaime Banks (Principal Investigator) at jabanks@mail.wvu.edu.

If you agree to participate in this research, please indicate so below. Thank you in advance for your help!

Sincerely,

Evan Watts

Ph.D. Student

Co-Investigator

erw00008@mix.wvu.edu

Dr. Jaime Banks

Assistant Professor

Principal Investigator

jabanks@mail.wvu.edu

I have read the information above and...

I agree to participate in this research

I do not agree to participate in this research and would like to exit the survey

Skip To: End of Survey If I have read the information above and... = I do not agree to participate in this research and would like to exit the survey

\section{End of Block: Consent}

\section{Start of Block: Intro}

Thank you for taking the time to participate in this survey! Today we are going to ask you some questions about your experiences you've had with video games. We're particularly interested in what you might call "meaningful" video game experiences, which, of course, can mean a lot of different things to different 
people.

Scientifically speaking, there is a lot we don't know about the kinds of experiences gamers find to be meaningful. That's where you come in! Your experiences can help us gain a much better understanding of what meaningfulness in video games can look like.

We STRONGLY suggest you take this survey on a desktop or laptop computer, or with some other device that has a keyboard because you'll be asked to type out a few things in addition to clicking buttons.

Click the arrow to continue.

\section{End of Block: Intro}

\section{Start of Block: PrimeMeaningful}

Part 1: Describing a Meaningful Game Experience

To begin:

Think about a specific time that you played a video game that you would personally describe as being particularly meaningful. First, what game were you playing?

Page Break 
Next, take a moment to recall that meaningful game experience in as much detail as you can.

Think about what it was it like, who was there, and why it was meaningful to you. The "next" arrow will appear shortly.

\section{Page Break}

Now, please describe that meaningful gaming experience, in as much detail as possible.

Why was this experience meaningful? Please explain in as much detail as possible. 
How long ago did this experience happen?

(Note: it's fine if you don't remember exactly how long ago - just give your best estimate.)

Page Break

Part 2: Questions About Your Meaningful Experience

Great! Thanks for your time in sharing that meaningful gaming experience. For the next part of the survey, we are going to present you with a whole bunch of statements for you to consider and give your thoughts on. This will take a bit of time to complete and some questions may seem repetitive or even a little confusing, but your honest and careful answers are extremely important to the study. We literally cannot do this without you! So please take your time, read the questions carefully, and give your honest and immediate reactions. The more information we have, the more helpful and the more we can build a better understanding of game experiences and how they impact gamers.

\section{End of Block: PrimeMeaningful}

\section{Start of Block: Henosis Items}

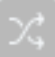

About your meaningful experience

Think again about that meaningful gaming experience you just described.

With that experience in mind, please indicate how much you agree or disagree that each of the following statements describes that experience.

Rate each statement on a scale of 1-7, with 1 being strongly disagree and 7 being strongly agree.

There are a lot of items here, but they are all important, so please take your time. 
During that meaningful game experience ...

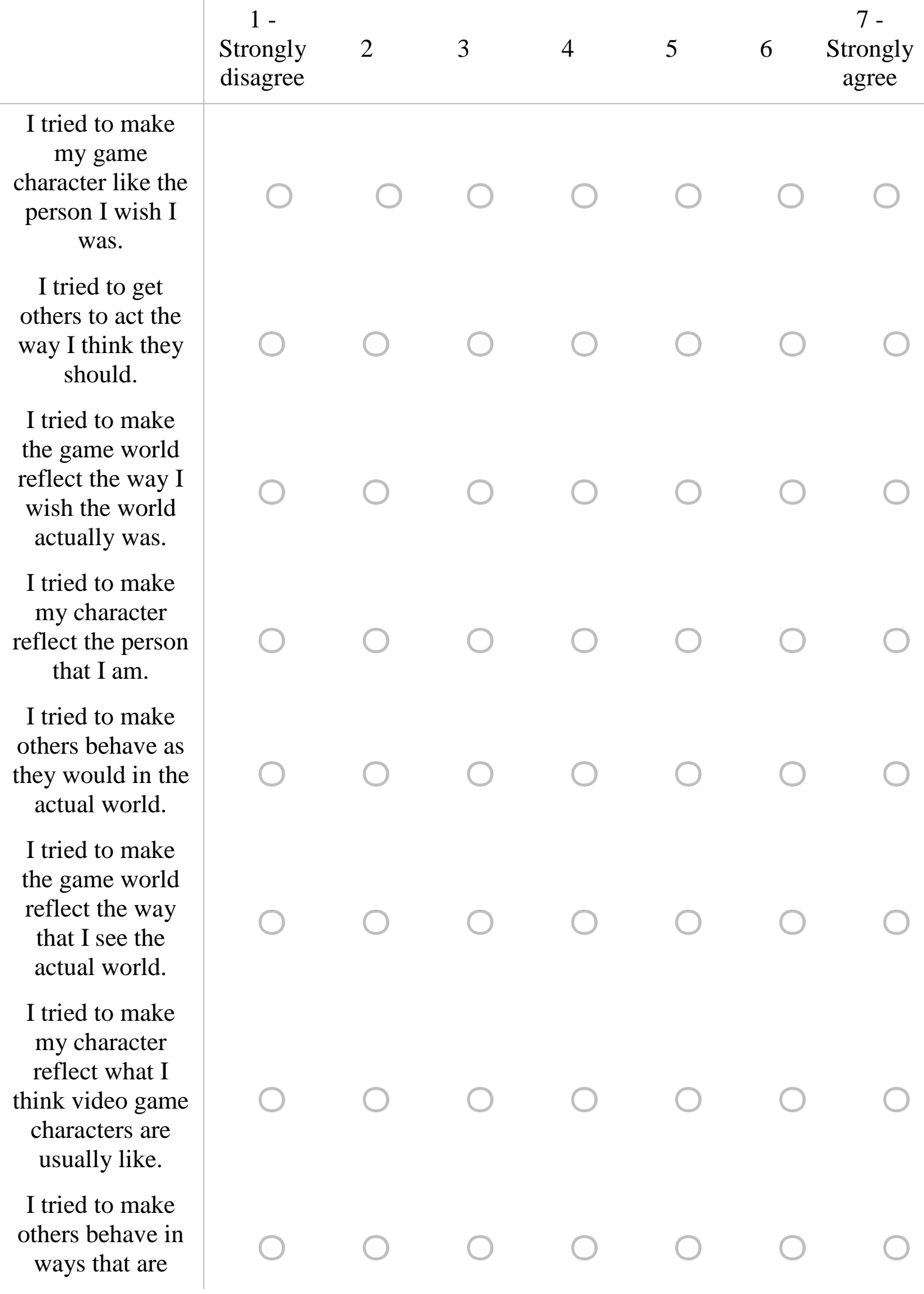




\begin{abstract}
appropriate for a video game.

I tried to make the world reflect what I think a video game world is usually like.

I began to like the character I played in this game more than those I've played in other games.
\end{abstract}

I prefer how others acted in this game compared to other games I've played.

Compared to other games, the game world was like how I wish the actual world would be.

The character I played was more like my actual self than characters in other games I've played.

Others behaved more realistically compared to other games I've played.

The game world was more like the actual world than 


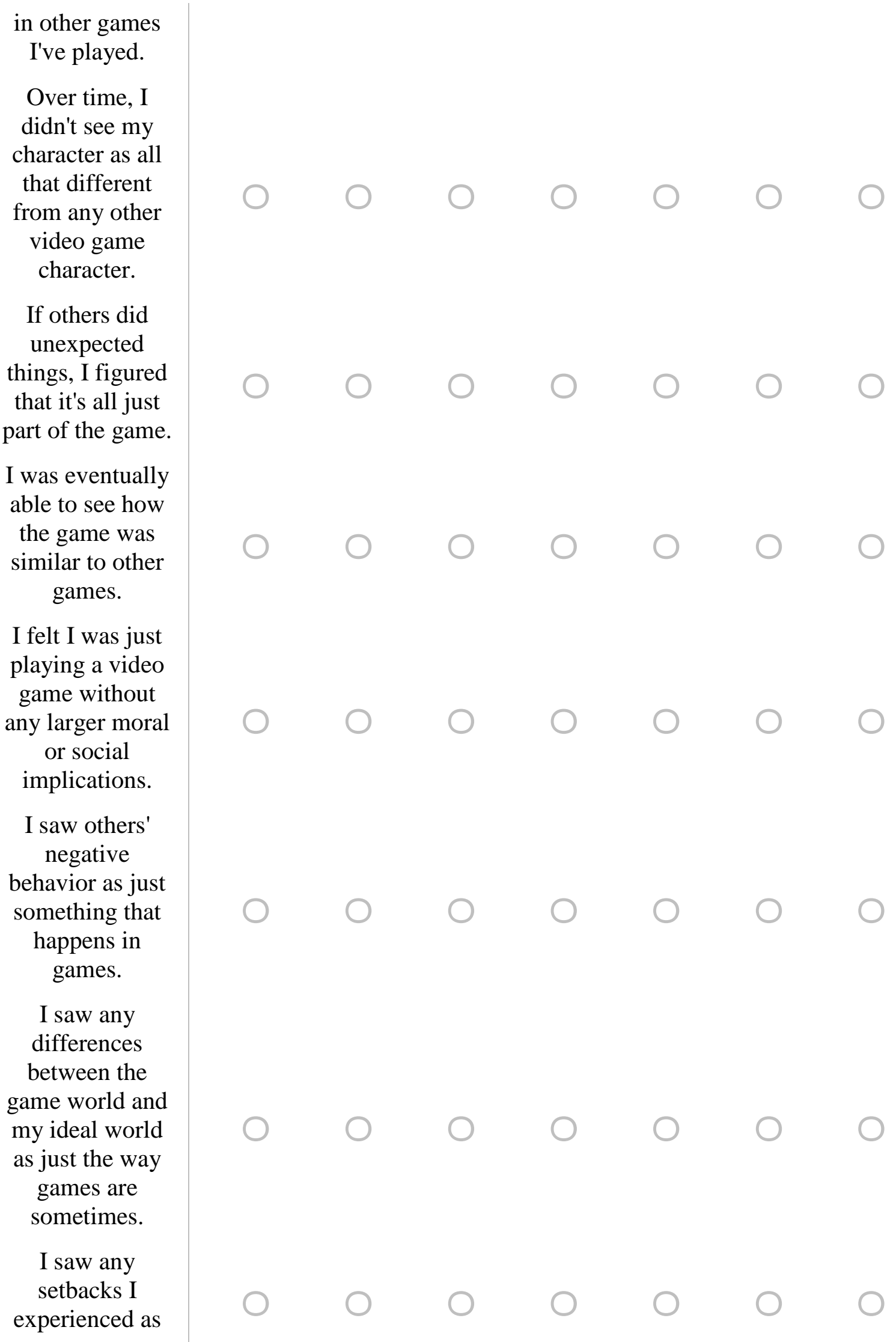




opportunities to
improve.
Even when
others behaved in
ways I didn't
like, I knew they
had good reason.
The things I
didn't like about
the game world
were outweighed
by the things I
did like about the
game world.
I found it true to
reality when the
game would
prevent me from
doing something
I thought should
be done.
their actions
made sense.
I found it
realistic when
others acted
differently than I
thought they
should.
what I know
I found it
realistic when the
game world
wasn't a perfect
world.
I got to act like
myself in some
ways to make up
for not being able
in other ways.
thed on
thers until
tout


The game was realistic in some ways to make up for being unrealistic in other ways

I got used to the differences between the character I played in this game compared to who I am in real life.

Differences in how others act in the game compared to how people act in real life are just because games and real life are different.

It made sense that the game world was different from the actual world.

My character began to feel closer to how I wish I was than how I actually am.

Others acted more like I wish people would act than how I expect people to act.

Unexpected things in the 


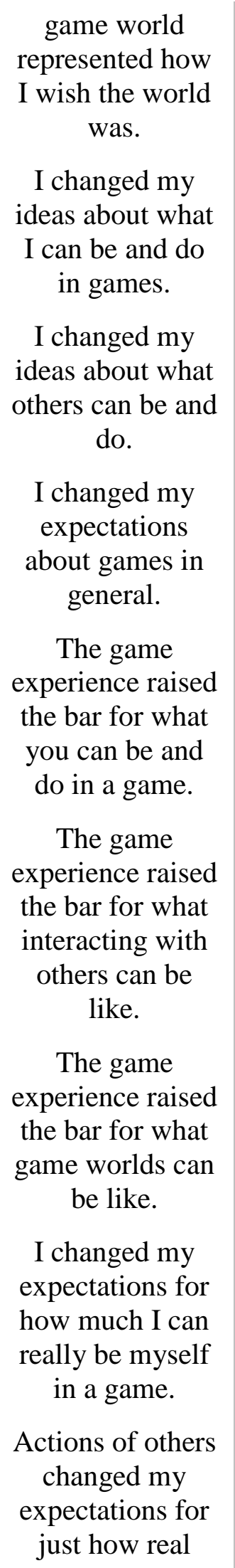


interactions in
games can feel.

The game world changed my

expectations for how much a game can feel like the actual world

The way I see myself in everyday life had an impact on how I saw myself in the game.

The way I see others in my everyday life had an impact on how I saw others in the game.

The way I see the actual world had an impact on how I see the game world.

I changed how I see myself to be more like the person I've always wanted to be.

I gained a better outlook on humanity.

I began to feel like the world is a good place. I saw myself changing to be more like the 


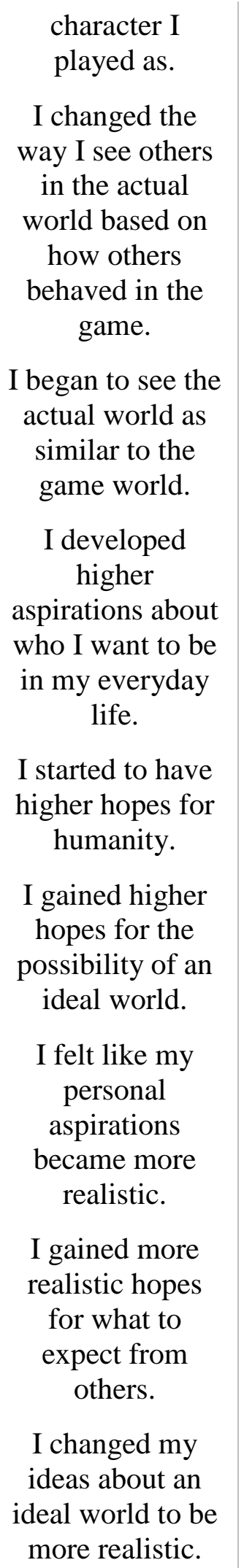




I changed my
ideas of who I
want to be based
on the character I
played as in the
game.
I changed my
ideas about what
the best of
humanity looks
like based on
how I saw others
behave in the
game.
I changed my
ideas about what
an ideal world
would be like
based on the
world in the
game.

\section{End of Block: Henosis Items}

\section{Start of Block: Validation}

\section{Other Questions About Your Experience}

Phew! You've made it through Part 2. Great job!

Next, we just have a few more questions for you about your meaningful gaming experience. The format is the same - thinking about that meaningful game experience you described earlier, just tell us whether you agree or disagree with each one statement.

Click the arrow to continue. 


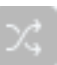

Appreciation

First, we just want to ask you a few general questions about your experiences of meaningfulness and enjoyment. Thinking about the meaningful game experience you described earlier, please tell us how much you disagree or agree that....

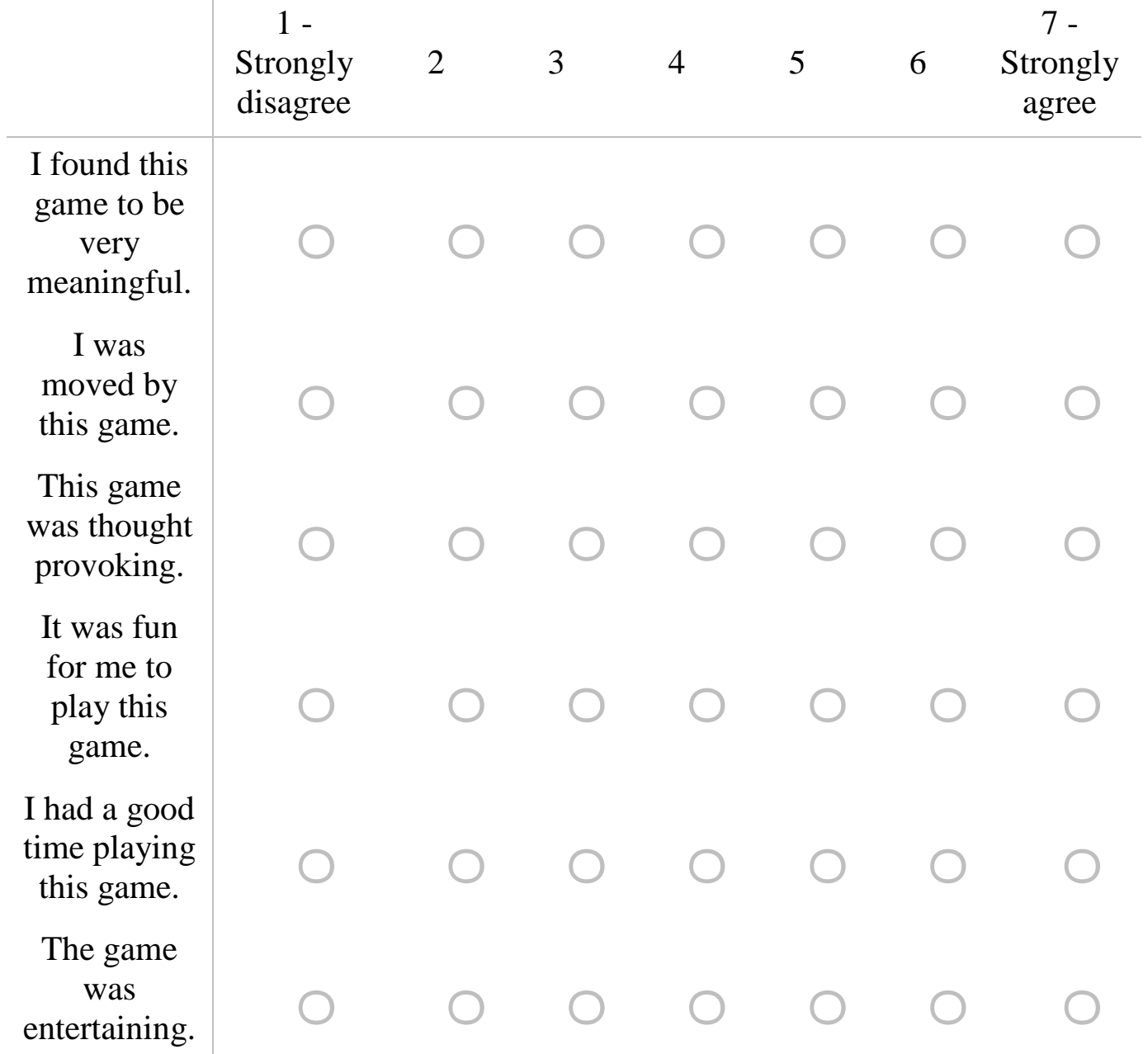

Page Break 


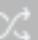

Other emotions

Now, we'd like to ask you about how much you experienced some additional emotions during the meaningful game experience you described. Please rate how much you felt these emotions during the meaningful game experience:

\begin{tabular}{c|ccccccc} 
& $\begin{array}{c}1-\text { Not } \\
\text { at all }\end{array}$ & 2 & 3 & 4 & 5 & 6 & $\begin{array}{c}7-\text { Very } \\
\text { much }\end{array}$ \\
Compassion & 0 & 0 & 0 & 0 & 0 & 0 & 0 \\
Inspired & 0 & 0 & 0 & 0 & 0 & 0 & 0 \\
Awe & 0 & 0 & 0 & 0 & 0 & 0 & 0 \\
Admiration & 0 & 0 & 0 & 0 & 0 & 0 & 0
\end{tabular}

Page Break

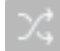

Inspiration

Next, we'd like to ask you about inspiration. Thinking about your meaningful game experience, please tell us how much you felt the following:

\begin{tabular}{c|ccccccc}
$\begin{array}{c}1- \\
\text { Not at } \\
\text { all }\end{array}$ & 2 & 3 & 4 & 5 & 6 & $\begin{array}{c}7- \\
\text { Very } \\
\text { strongly }\end{array}$ \\
\hline $\begin{array}{c}\text { I experienced } \\
\text { inspiration. }\end{array}$ & 0 & 0 & 0 & 0 & 0 & 0 & 0 \\
$\begin{array}{c}\text { Something I } \\
\text { encountered or } \\
\text { experienced } \\
\text { inspired me. }\end{array}$ & & & 0 & 0 & 0 & 0 & 0
\end{tabular}


I was inspired

to do

something.

I felt inspired

Page Break

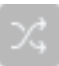

Other ways to describe your experience

Next, we'd like to ask you some questions about what you got out of the game experience you've been describing.

Reflecting on that same meaningful game experience, please rate your agreement with the following statements:

\begin{tabular}{c|ccccccc}
$\begin{array}{c}1- \\
\text { Strongly } \\
\text { disagree }\end{array}$ & 2 & 3 & 4 & 5 & 6 & $\begin{array}{c}7 \text { - } \\
\text { Strongly } \\
\text { agree }\end{array}$ \\
$\begin{array}{c}\text { I felt competent } \\
\text { at the game }\end{array}$ \\
$\begin{array}{c}\text { I felt very } \\
\text { capable and } \\
\text { effective when } \\
\text { playing. }\end{array}$
\end{tabular}


The game let me do interesting things.

I experienced a lot of freedom in the game.

I found the relationships I formed through this game fulfilling.

I found the relationships I formed through this game important.

I don't feel close to others in the game.

.




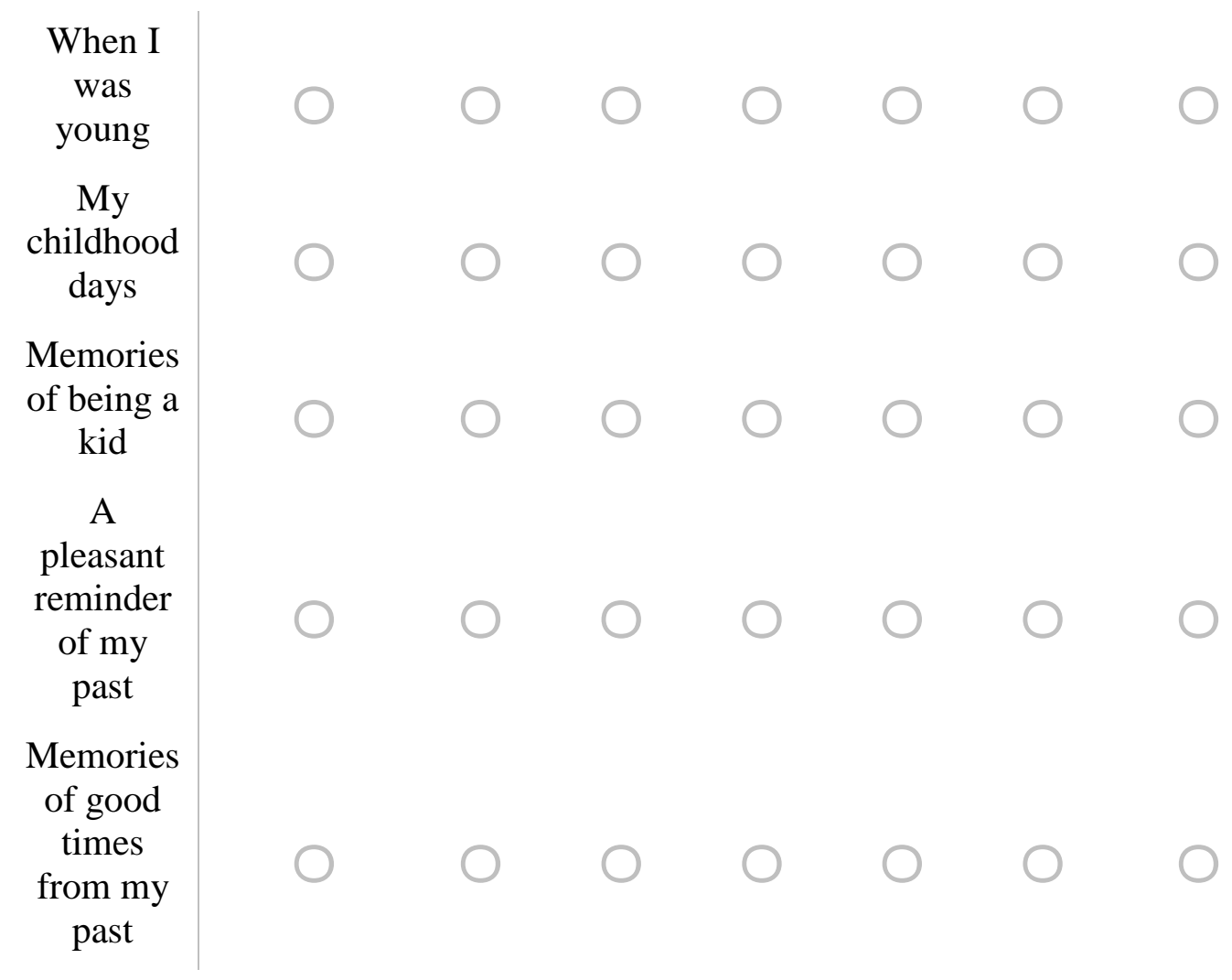

\section{End of Block: Validation}

\section{Start of Block: Game EXP}

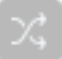

Part 4: Questions About You

Below, you will see a few questions about your experience playing specific games and game types. Answer each statement using the responses provided.

\begin{tabular}{|c|c|c|c|c|c|c|c|}
\hline & $\begin{array}{c}1 \text { - } \\
\text { No } \\
\text { experience }\end{array}$ & 2 & 3 & 4 & 5 & 6 & $\begin{array}{c}7 \text { - } \\
\text { Expert }\end{array}$ \\
\hline $\begin{array}{c}\text { How } \\
\text { experienced } \\
\text { are you } \\
\text { playing } \\
\text { video } \\
\text { games? }\end{array}$ & & & & & & & \\
\hline
\end{tabular}




How
experienced
are you
playing
console
games?
How
experienced
are you
playing
mobile
phone
games?
How
experienced
are you
playing PC
games?

\section{End of Block: Game EXP}

\section{Start of Block: Demographics}

\section{Demographics}

Finally, the questions below give us an idea of the many different types of people who might have participated in our study. This data is confidential, but your answers will be used so that we can describe (broadly) the different people that took our study. Please take a moment to answer them. You may leave blank any question you'd rather not answer.

What is your age?

What is your gender?

What is your ethnicity?

What is your nationality? 
Are you a current college student?
Yes
No

\section{End of Block: Demographics}

\section{Start of Block: contactstudent}

Drawing Entry

Thanks very much, and good news! You're all done! Your answers will be recorded. To be entered into the drawing for the Amazon gift card, please enter your email address here (this information will be used solely to notify the gift card winner and will be immediately purged after a winner is chosen).

If you are taking this survey for course credit, click the next button to receive your unique identifier.

Page Break 
Receipt

Thanks for your participation in the "Meaningful Video Game Experience Survey" study!

Your Response has been recorded. Here is your unique response code: \$ rand://int/10000000:99999999\}

IF YOU PLAN ON RECEIVING EXTRA COURSE CREDIT, IT IS YOUR RESPONSIBILITY TO SUBMIT THIS RECEIPT TO YOUR INSTRUCTOR AS EVIDENCE THAT YOU PARTICIPATED IN THIS RESEARCH.

PLEASE PRINT THIS RECEIPT NOW, OR TAKE A SCREEN CAPTURE OR PHOTO

AND SAVE IT FOR YOUR RECORDS.

End of Block: contactstudent 